NBER WORKING PAPER SERIES

\title{
ASSESSING THE INCIDENCE AND EFFICIENCY OF A PROMINENT PLACE
} BASED POLICY

\author{
Matias Busso \\ Jesse Gregory \\ Patrick M. Kline \\ Working Paper 16096 \\ http://www.nber.org/papers/w16096 \\ NATIONAL BUREAU OF ECONOMIC RESEARCH \\ 1050 Massachusetts Avenue \\ Cambridge, MA 02138 \\ June 2010
}

The authors would like to thank David Albouy, John Bound, David Card, Raj Chetty, Bryan Graham, Justin McCrary and Edson Severini for helpful comments. An early version of this paper circulated under the title "Do Local Economic Development Programs Work? Evidence from the Federal Empowerment Zone Program." Any opinions and conclusions expressed herein are those of the authors and do not necessarily represent the views of the U.S. Census Bureau or the National Bureau of Economic Research. All results have been reviewed to ensure that no confidential information is disclosed. Support for this research at the Berkeley, Michigan, and Suitland RDCs from NSF (ITR-0427889) is also gratefully acknowledged.

NBER working papers are circulated for discussion and comment purposes. They have not been peerreviewed or been subject to the review by the NBER Board of Directors that accompanies official NBER publications.

(C) 2010 by Matias Busso, Jesse Gregory, and Patrick M. Kline. All rights reserved. Short sections of text, not to exceed two paragraphs, may be quoted without explicit permission provided that full credit, including $\odot$ notice, is given to the source. 
Assessing the Incidence and Efficiency of a Prominent Place Based Policy

Matias Busso, Jesse Gregory, and Patrick M. Kline

NBER Working Paper No. 16096

June 2010

JEL No. C21,H2,O1,R58

\section{ABSTRACT}

This paper empirically assesses the incidence and efficiency of Round I of the federal urban Empowerment Zone (EZ) program using confidential microdata from the Decennial Census and the Longitudinal Business Database. To ground our welfare analysis, we develop a heterogeneous agent general equilibrium model in which the distortions generated by place-based policies depend upon a set of reduced form elasticities which our empirical work centers on estimating. Using rejected and future applicants to the EZ program as controls we find that EZ designation substantially increased employment in zone neighborhoods, particularly for zone residents. The program also generated wage increases for workers from zone neighborhoods worth approximately \$320M per year. Based upon estimates of the number of jobs created for zone residents, we find that EZ employment credits generated deadweight costs equal to (at most) seven percent of their flow cost.

Matias Busso

University of Michigan

and IZA

matiasb@umich.edu

Jesse Gregory

University of Michigan

jessgreg@umich.edu
Patrick M. Kline

Department of Economics

UC, Berkeley

508-1 Evans Hall \#3880

Berkeley, CA 94720

and NBER

pkline@econ.berkeley.edu 
A growing class of "place based" policies explicitly target transfers towards particular geographic areas rather than groups of individuals ${ }^{1}$ Economists have traditionally expressed little support for such programs, fearing that they will generate large distortions in economic behavior ${ }^{2}$ Indeed, standard models of spatial equilibrium suggest mobile workers and firms will arbitrage the benefits associated with local policies by relocating across the boundaries of targeted areas. Local land prices ought then to rise and offset any welfare gains that might otherwise accrue to prior residents.

This paper critically examines this conjecture by conducting an empirical welfare analysis of Round I of the federal urban Empowerment Zone (EZ) program - one of the largest place based policies in the United States. In doing so, we contribute to a growing empirical literature on the effects of local economic policies including state level "enterprise zones" and spatially biased tax policies (Holmes, 1998; Albouy, 2009) in the U.S., and industrial and regional policies in Europe (Wren and Taylor, 1999; Criscuolo et al, 2007; Bronzini and de Blasio, 2006). Our work extends these literatures by conducting the first general equilibrium evaluation of a large scale highly localized place based policy founded on an explicit microeconomic model of commuting and labor supply with heterogeneous agents.

We develop a general equilibrium model with landlords, firms, and mobile workers who make labor supply and commuting decisions. The incidence and efficiency of local subsidies are shown to depend critically upon the distribution of agents' preferences over residential and commuting options. If most agents are inframarginal in their commuting and residential decisions, deadweight loss will be small and local workers will reap the benefits of place based interventions. If, on the other hand, agents have nearly identical preferences, as in the classic models of Rosen (1979) and Roback (1982), deadweight loss will be substantial and

\footnotetext{
${ }^{1}$ See Bartik (2002) and Glaeser and Gottleib (2008) for reviews. Nichols and Zeckhauser (1982) provide a useful general discussion of the welfare economics of targeted transfers.

${ }^{2}$ Kain and Persky (1969) provide an early critique of proposals for "gilding the ghetto". Glaeser and Gottleib (2008) exemplify the conventional view, stating that "the rationale for spending federal dollars to try to encourage less advantaged people to stay in economically weak places is itself extremely weak."

${ }^{3}$ See Papke (1993, 1994), Boarnet and Bogart (1996), Bondonio (2003), Bondonio and Engberg (2000), Elvery (2003), and Engberg and Greenbaum (1999). Peters and Fisher (2002) provide extensive reviews. More recently Neumark and Kolko (2010) provide an updated review and an interesting contribution based upon spatially disaggregate data.
} 
government expenditures will be capitalized into land rents. We show that our model allows for simple approximations to the incidence and deadweight loss of EZs via a set of reduced form elasticities quantifying the program's impact on the wages of local zone workers and commuters, the rental rate of zone housing, and the number of zone jobs for local residents and commuters.

Our empirical work centers on estimating these impacts using confidential geocoded microdata from the Decennial Census and the Longitudinal Business Database (LBD). These data provide us with two independent sources of information on local employment and allow us to adjust for changes over time in the composition of firms and workers. Crucial to our analysis, the Journey to Work component of the Census allows us to separate the impacts of EZ designation on workers by place of residence and place of work.

To identify the causal impacts of EZ designation we construct a set of control zones based upon proprietary data obtained from the Department of Housing and Urban Development on the census tract composition of rejected and later round Empowerment Zones. Since these tracts were nominated for designation by their local governments, they are likely to share unobserved traits and trends in common with first round EZs which also underwent a local nomination phase. We present an extensive body of evidence indicating that our control tracts provide a suitable proxy for the counterfactual behavior of EZs over the 1990s. To account for the clustered nature of our data, and the fact that only six EZs were awarded over our sample period, we rely on a wild bootstrap testing procedure studied by Cameron, Gelbach, and Miller (2008) to conduct inference.

We find, in both the LBD and Census, that neighborhoods receiving EZ designation experienced substantial $(13 \%-19 \%)$ increases in total employment relative to observationally equivalent tracts in rejected and future zones. The hourly wages paid to zone residents working inside the zone also rose significantly (by approximately 8\%). Yet despite these improvements in the zone labor market, we find little evidence of an influx of residents to zone neighborhoods. Population, rental rates, and vacancy rates all appear stable over the dura- 
tion of the study suggesting that most workers consider zone neighborhoods poor substitutes for areas outside of the zone.

We conclude with a quantitative assessment of the program's incidence and a calculation of deadweight costs. We find that EZ designation generated wage increases for workers from zone neighborhoods worth approximately $\$ 320 M$ per year. Our point estimates also suggest the earnings of nonresident commuters increased by $\$ 580 M$ per year though this figure is not statistically significant.

Based upon two independent estimates of the number of zone jobs created for zone residents, we find that the tax credits associated with designation yielded relatively small deadweight costs equal to (at most) seven percent of the flow cost of the subsidy. The wage increases experienced by non-resident zone workers indicate that the zone block grants may have raised local productivity levels. Our estimates suggest the benefits of those local investments likely exceeded the dollar cost of the grants by a substantial margin though the imprecision of our results make this conclusion tentative.

The remainder of the paper is structured as follows: Section I provides background on the EZ program, Section II develops a general equilibrium model of EZs, and Section III introduces our empirical strategy, Section IV describes the data used, Section V outlines our main results, Section VI tests for violations of the assumptions underlying our research design, Section VII conducts a welfare analysis and Section VIII concludes.

\section{The Empowerment Zone Program}

The federal Empowerment Zone program is a series of spatially targeted tax incentives and block grants designed to encourage economic, physical, and social investment in the neediest urban and rural areas in the United States. In 1993 Congress authorized the Department of Housing and Urban Development (HUD) to award Empowerment Zones to local communities via a competitive application process. Local governments were invited to submit 
proposals for an EZ defined in terms of 1990 census tracts subject to certain restrictions on the characteristics of each proposed tract.4

HUD awarded EZs to six urban communities: Atlanta, Baltimore, Chicago, Detroit, New York City, and Philadelphia/Camden. Two additional cities, Los Angeles and Cleveland, received "supplemental" EZ (SEZ) designation while forty-nine rejected cities were awarded smaller enterprise communities (ECs) as consolation prizes $5^{5}$ Table 1 shows summary statistics of EZ neighborhoods by city. The average Round I EZ spanned 10 square miles, contained 113,340 people, and had a 1990 poverty rate of $48 \%$. Most zones are contiguous groupings of census tracts, although some EZs, such as the one in Chicago pictured in Figure 1, cover multiple disjoint groupings of tracts.

EZ designation brought with it a host of fiscal and procedural benefits, the most important of which are the following:

1. Employment Tax Credits - Starting in 1994, firms operating in the six original EZs became eligible for a credit of up to 20 percent of the first $\$ 15,000$ in wages earned in that year by each employee who lived and worked in the community. Tax credits for each such employee were available to a business for as long as ten years, with the maximum annual credit per employee declining over time. This was a substantial subsidy given that, in 1990 , the average EZ worker only earned approximately $\$ 16,000$ in wage and salary income.

2. Title XX Social Services Block Grant (SSBG) Funds -Each EZ became eligible for $\$ 100$ million in SSBG funds. These funds could be used for such purposes as: business assistance, infrastructure investment, training programs, youth services, promotion of home ownership, and emergency housing assistance.

Evidence from the General Accounting Office (1999) and Hebert et al. (2001) suggests that participation in the tax credit program was incomplete and most common among large

\footnotetext{
${ }^{4}$ All zone tracts were required to have poverty rates above twenty percent. Moreover, ninety percent of zone tracts were required to have poverty rates of at least twenty-five percent and fifty percent were required to have poverty rates of at least thirty-five percent. Tract unemployment rates were required to exceed $6.3 \%$. The maximum population allowed within a zone was 200,000 or the greater of 50,000 or ten percent of the population of the most populous city within the nominated area.

${ }^{5}$ ECs were not entitled to tax credits but were allocated $\$ 3$ million in SSBG funds and made eligible for tax-exempt bond financing. SEZs were awarded block grants similar to those received by EZs but did not become eligible for the EZ tax credit until 1999.

${ }^{6}$ See IRS (2004) for more details. Other benefits appear not to have been heavily utilized. See Hebert et al. (2001), General Accounting Office (2004), and Government Accountability Office (2006).
} 
firms who were more likely to have positive taxable income. Roughly $\$ 200$ million in employment credits was claimed over the period 1994 to 2000, with the amount claimed each year trending up steadily over time. IRS data show that, in the year 2000, close to five hundred corporations, and over five thousand individuals, claimed EZ Employment Credits worth a total of approximately $\$ 55$ million. ${ }^{7}$

Table 2 summarizes information compiled from HUD's internal performance monitoring system on the amount of money allocated to various program activities by source. By 2000, the first round EZs had spent roughly $\$ 400$ million dollars in SSBG funds. However, large quantities of outside capital accompanied the grant spending. The six EZs reported allocating roughly $\$ 3$ billion to local projects by 2000 , with more than seven dollars of outside money accompanying every dollar of SSBG funds 8 Audits by HUD's Office of Inspector Genera $I^{9}$ and the Government Accountability Office (2006) have called the accuracy of these data into question, suggesting that they should be interpreted as loose upper bounds on the amount of money raised, particularly since it is difficult to ascertain how any outside funds would have been spent in the absence of the program.

In sum, the six Round I EZs constitute a 60 square mile area containing less than 700,000 residents. Federal expenditures on EZ wage credits and block grants amounted to roughly $\$ 850$ per resident over the first six years of the program (1994-2000). And HUD's internal records suggest that as much as $\$ 3,000$ per resident of outside investment may also have been leveraged over this period though we suspect this figure to be a substantial overestimate.

\footnotetext{
${ }^{7}$ These figures come from General Accounting Office (2004).

${ }^{8}$ The most commonly reported use of funds was enhancing access to capital. One-stop capital shops were a component of the plans of most EZs, training local entrepreneurs to develop business plans and apply for loans either from local organizations or commercial banks. The second most common use of funds was business development which involved technical and financial assistance. Some EZs developed business incubators for this purpose or invested in the physical revitalization of commercial corridors. See Hebert et al. (2001) and Appendix IV of Government Accountability Office (2006) for detailed descriptions of the projects implemented in particular zones.

${ }^{9}$ See Chouteau (1999) and Wolfe (2003).
} 


\section{Model}

We turn now to the development of a general equilibrium model allowing a welfare analysis of the EZ program. The framework adopted is a generalization of the classic equilibrium models of Rosen (1979) and Roback (1982) extended to allow for heterogeneity, labor supply decisions, commuting, elastic housing supply, and imperfect compliance in the EZ wage credit program. The decisions of workers are modeled in a discrete choice framework as in Bayer, Ferreira, and McMillan (2007) with an emphasis on the distinction between place of residence and place of work as in, for example, Baum-Snow (2007). After developing the model, we show that a set of reduced form elasticities of the sort discussed by Chetty (2009) can be used to approximate the EZ program's deadweight loss.

Assume a continuum of agents of measure one and a finite collection $\mathcal{N}=\left\{\mathcal{N}_{0}, \mathcal{N}_{1}\right\}$ of neighborhoods in which they may live or work consisting of neighborhoods inside $\left(\mathcal{N}_{1}\right)$ or outside $\left(\mathcal{N}_{0}\right)$ of an Empowerment Zone. Neighborhoods have fixed bundles of amenities consumed by local residents and used by local firms in production. Commuting between neighborhoods is costly. To deal with imperfect compliance with the EZ tax credit we introduce two sectors of the economy: a first sector of covered firms likely to participate in the EZ wage credit program and a second sector of firms likely to be ineligible for (or unaware of) the program. It is useful to think of sector one as consisting of large establishments and sector two as small family run businesses.

Agents choose a neighborhood to live in, whether to work, and (if so) a neighborhood and sector in which to work. Each agent inelastically demands a single unit of housing which they rent at market rates. Write the utility of individual $i$ living in community $j \in \mathcal{N}$ and working in community $k \in\{\emptyset, \mathcal{N}\}$ and sector $s \in\{1,2\}$ as:

$$
\begin{aligned}
u_{i j k s} & =w_{j k s}-r_{j}-\kappa_{j k}+A_{j}+\varepsilon_{i j k s} \\
& =v_{j k s}+\varepsilon_{i j k s}
\end{aligned}
$$

where $w_{j k s}$ is the wage a worker from neighborhood $j$ receives when working in sector $s$ 
of neighborhood $k, r_{j}$ is the local rent level, $\kappa_{j k}$ is the cost associated with commuting to work in location $k$ given residence in $j, A_{j}$ is the mean consumption value of local amenities, and $v_{j k s}$ is the mean utility (across individuals) of each choice. The wage for nonworkers $\left(w_{\emptyset}\right)$ is the dollar value of leisure which we normalize to zero without loss of generality. We likewise normalize $\kappa_{j \emptyset}=0$. The individual and choice specific error terms $\varepsilon_{i j k s}$ represent heterogeneity in the valuation of local amenities, the value of leisure, tastes for work in the two sectors, and commuting costs ${ }^{10}$ The $\varepsilon_{i j k s}$ are independently and identically distributed across individuals and assumed to possess a continuous multivariate distribution independent of $v_{j k s}$.

Heterogeneity is substantively important as it allows some workers to be inframarginal with respect to their residential and work location choices; thereby creating the potential for economic rents. Traditional models of spatial equilibrium are predicated upon the absence of such rents 11 A Rosen-Roback type model for example would start by specifying that $u_{i j k s}=\bar{u}$. Such indifference implies that the incidence of a local subsidy cannot fall on pre-existing residents since the supply elasticity of workers to particular locations will be infinite. Heterogeneity weakens this knife edge result and yields the possibility of finite supply elasticities to the various residence/work alternatives.

Define a set of indicator variables $\left\{D_{i j k s}\right\}$ equal to one if and only if $\max _{j^{\prime} k^{\prime} s^{\prime}}\left\{u_{i j^{\prime} k^{\prime} s^{\prime}}\right\}=u_{i j k s}$ for worker $i$, where $j^{\prime} \in N, k^{\prime} \in\{\emptyset, N\}$, and $s^{\prime} \in\{1,2\}$. Then the measure of agents in each residential/work location is $N_{j k s}=P\left(D_{i j k s}=1 \mid\left\{v_{j^{\prime} k^{\prime} s^{\prime}}\right\}\right)$. Denote the average utility of agents as $V=E_{\varepsilon}\left[\max _{j^{\prime} k^{\prime} s^{\prime}}\left\{u_{i j^{\prime} k^{\prime} s^{\prime}}\right\}\right]$ where the expectation operator $E_{\varepsilon}$ is defined over the heterogeneity terms $\varepsilon_{i j^{\prime} k^{\prime} s^{\prime}}$. It can be shown that the choice probabilities $N_{j k s}$ and the

\footnotetext{
${ }^{10}$ It is useful to allow for the possibility that some zone residents face a higher cost of commuting to work inside the zone than outside the zone as might happen if some residents live on the border of the zone or are located near public transportation more integrated with one neighborhood than another. This will allow some zone workers to prefer working outside the zone even if wages are equalized across all neighborhoods.

${ }^{11}$ See for example the traditional urban economics models covered in Glaeser (2008).

${ }^{12}$ Proof:

$\frac{d V}{d v_{j k s}}=E_{\varepsilon}\left[\frac{d}{d v_{j k s}} \max _{j^{\prime} k^{\prime} s^{\prime}}\left\{u_{i j^{\prime} k^{\prime} s^{\prime}}\right\}\right]=E_{\varepsilon}\left[I\left[\max _{j^{\prime} k^{\prime} s^{\prime}}\left\{u_{i j^{\prime} k^{\prime} s^{\prime}}\right\}=u_{i j k s}\right]\right]=P\left(D_{i j k s}=1 \mid\left\{v_{j^{\prime} k^{\prime} s^{\prime}}\right\}\right)=N_{j k s} . \mathrm{We}$ are grateful to David Card for help in simplifying an earlier version of this proof.
} 
average valuation $V$ obey the following relationship,

$$
\frac{d}{d v_{j k s}} V=N_{j k s}
$$

which amounts to a generalization of Roy's Identity for a representative agent with indirect utility function $V$. This relationship will prove useful in our analysis of social welfare.

We turn now to the demand side of the model. Goods are produced in each neighborhood $k$ and sector $s$ with a constant returns to scale technology $F\left(K_{k s}, B_{k} L_{k s}\right)=B_{k} L_{k s} f\left(\chi_{k s}\right)$ where the arguments $K_{k s}$ and $L_{k s}$ refer to total capital and labor inputs respectively, $\chi_{k s}=$ $\frac{K_{k s}}{B_{k} L_{k s}}$ is the capital to effective labor ratio, and $B_{k}$ is the local productivity level which may depend upon infrastructure investments, natural features of the physical environment (e.g. access to a body of water, proximity to downtown), and crime levels ${ }^{13}$ Productivity differences across neighborhoods yield unequal derived demands for inputs across space. Because the supply elasticity of workers to any given location is finite in the presence of taste heterogeneity and commuting costs, these unequal factor demands result in unequal wages across neighborhoods.

Workers from different neighborhoods are assumed to be perfect (and homogeneous) substitutes in production so that $L_{k s}=\sum_{j \in \mathcal{N}} L_{j k s}$ where $L_{j k s}$ is the labor input of workers from neighborhood $j$ to firms in neighborhood $k$ and sector $s \sqrt[14]{14}$ The EZ tax credit program induces a cost difference for zone firms between workers residing inside of the zone (whose wages are subsidized at rate $\tau$ ) and zone commuters who are unsubsidized. Hence at any given wage, zone employers strictly prefer zone residents, which means that at an interior equilibrium zone firms must pay different wages to residents and commuters.

We assume capital is supplied at fixed rental rate $\rho$ to all neighborhoods and sectors and that output is sold on an international market at price one 15 Define the indicator variable

\footnotetext{
${ }^{13}$ See Kline (2010a) for an analysis of this sort of model when $B_{k}$ exhibits agglomeration effects.

${ }^{14}$ In Supplemental Appendix A we derive an extended version of the model which incorporates productivity differences among workers and show that it yields similar conclusions.

${ }^{15}$ It is straightforward to extend the model to the case where output is sold locally and prices are endogenous. Since we have no data on local product prices we omit this feature from our analysis.
} 
$\delta_{j k s}=I\left[j \in \mathcal{N}_{1}, k \in \mathcal{N}_{1}, s=1\right]$ which equals one for jobs subject to the wage subsidy and zero otherwise. Firms equate the marginal product of each factor to its corresponding aftertax cost so that:

$$
\begin{aligned}
B_{k}\left[f\left(\chi_{k s}\right)-\chi_{k s} f^{\prime}\left(\chi_{k s}\right)\right] & =w_{j k s}\left(1-\tau \delta_{j k s}\right) \\
f^{\prime}\left(\chi_{k s}\right) & =\rho
\end{aligned}
$$

The second of these conditions may be inverted to yield $\chi_{k, s}=\chi=h(\rho)$ where $h^{\prime}() \leq$.0 . We may then rewrite the condition for wages as:

$$
w_{j k s}=\frac{B_{k} R(\rho)}{1-\tau \delta_{j k s}}
$$

where $R(\rho)=f(h(\rho))-h(\rho) \rho$ is the marginal product of a "raw" unit of labor. The fact that zone and nonzone workers are perfect substitutes implies that the tax subsidy for zone workers will be completely transferred into their wages. Zone jobs in the higher paying sector are not rationed because workers have idiosyncratic tastes for working in different sectors.

Finally, we allow for upward sloping housing supply curves in each neighborhood as in Moretti (2010a,b) and Notowidigdo (2010). Each neighborhood has a continuum of risk neutral land owners distributed on the unit interval. Each land owner may develop a unit of housing on her plot of land in neighborhood $j$ at a cost which is continuously distributed across owners according to the $\mathrm{CDF} G_{j}($.$) with strictly positive support. These costs might$ include the time cost of rehabilitating a boarded up vacant unit or the pecuniary cost of creating a new structure on an open lot.

If a unit of housing is built, the owner rents the unit out and receives payoff $r_{j}$ minus the cost of constructing the unit, otherwise she receives nothing. Let $H_{j}$ represent the number of units rented out in community $j$. Optimization implies that the marginal landowner in each neighborhood breaks even on house construction so that:

$$
G_{j}^{-1}\left(H_{j}\right)=r_{j}
$$


To close the model we assume the housing market clears which requires:

$$
H_{j}=\sum_{k} \sum_{s} N_{j k s}
$$

The model's predictions for the response of zone neighborhoods to EZ designation are now easily derived. The EZ program involved two treatments - a wage tax credit $(\tau)$ and a block grant which we model as affecting local productivity $\left(B_{k}\right)$ and amenity $\left(A_{j}\right)$ levels. From (2) we see that the EZ wage subsidies should raise the wages of local zone workers and hence their employment at EZ firms in the covered sector. Because the tax credits have no effect on wages in the uncovered sector, employment may fall at such firms as workers switch their employment to the more lucrative covered sector. Likewise, because the wage subsidies yield no increase in the wages of nonresident commuters their employment may also be expected to fall slightly as some workers decide to move to the neighborhood to take advantage of the higher wages for residents.

Any productive effect of the block grants however, may counteract these negative employment effects. Note that (2) implies:

$$
\frac{d \ln w_{j k s}}{d \ln B_{k}}=1
$$

Thus productivity changes proportionally boost the wages of all workers in a neighborhood regardless of their place of residence. This may be expected to yield a large employment response among nonresident zone commuters who likely view most jobs within a sector with the same commuting distance as close substitutes. It may also counteract any negative employment effects at smaller firms not covered by the tax credit.

Finally, depending on the distribution of workers tastes for living in zone neighborhoods and features of the housing supply locus, the rental rate of housing in zone neighborhoods may increase as agents seek to move to the zone in order to take advantage of higher local wage levels and any possible increases in local amenity value. If workers have relatively ho- 
mogeneous residential preferences and the housing stock is fixed we should see large increases in rental rates, while if housing is easily supplied we should see an increase in population and little change in rental rates. If, however, few workers are on the margin of moving to distressed neighborhoods we should see little response in either population or rental rates.

We turn now to an analysis of the model's welfare implications. Total social welfare in this economy is the sum of total worker utility and the utility of landlords which may now be written compactly as follows:

$$
W=V+\sum_{j}\left[r_{j} H_{j}-\int_{0}^{H_{j}} G_{j}^{-1}(x) d x\right]
$$

the first term giving the average (which is also the total) utility of workers and the second the total profits of landowners.

Consider first the block grant which we model as affecting local productivity and amenity levels. The marginal social benefit of an improvement in the local productivity level of community $m$ may be written:

$$
\begin{aligned}
\left.\frac{d}{d B_{m}} W\right|_{\tau=0} & =\sum_{j} \sum_{k} \sum_{s} N_{j k s}\left[\frac{d w_{j k s}}{d B_{m}}-\frac{d r_{j}}{d B_{m}}\right] \\
& +\sum_{j} \frac{d r_{j}}{d B_{m}} H_{j}
\end{aligned}
$$

where we have made repeated use of the relationship given in (1). The first line gives the effect of the productivity change on workers and the second line the effect on housing producers ${ }^{16}$ A remarkable feature of this welfare calculation is that it does not include any terms of the form $\frac{d N_{j k s}}{d B_{m}}$. This is a result of optimization which makes the marginal agent indifferent between alternatives despite the fact that the micro-level decision is discrete. Thus, to first order, the welfare implications of zone grants are the same as the implications of changing prices on an immobile population.

\footnotetext{
${ }^{16}$ Note that in a Rosen-Roback model $\frac{d}{d \ln w_{j k s}} d=\frac{d \ln r_{j}}{d \ln B_{k}}$ so that any increases in local wages would be perfectly offset by increases in the local cost of living. By assumption such a model requires $d V=0$.
} 
In an economy without behavioral responses price changes simply generate transfers of wealth between market participants, which, in our framework, have no aggregate welfare implications. Substituting the market clearing conditions (3) and (4) into (6) and simplifying yields:

$$
\begin{aligned}
\left.\frac{d}{d B_{m}} W\right|_{\tau=0} & =\sum_{j} \sum_{k} \sum_{s} N_{j k s} \frac{d w_{j k s}}{d B_{m}} \\
& =R(\rho) N_{. m}
\end{aligned}
$$

where $N_{. m}=\sum_{j} \sum_{s} N_{j m s}$ is the total number of jobs in neighborhood $m$ and the second line follows from (2). Note that this is simply the total increase in output the economy would experience due to an increase in the local productivity level if the behavior of firms, workers, and landlords were unchanged.

Now consider an increase in amenities. By similar reasoning it can be shown that:

$$
\left.\frac{d}{d A_{m}} W\right|_{\tau=0}=N_{m}
$$

where $N_{m}$. $=\sum_{k} \sum_{s} N_{m k s}$ is the total number of residents of neighborhood $m$. Again, the intuition is that, to first order, improving amenities in neighborhood $m$ is equivalent to making an in-kind transfer to an immobile population.

Finally, consider the wage tax credit. A derivation equivalent to that in (6) and (7) yields:

$$
\frac{d}{d \tau} W=\sum_{j \in \mathcal{N}_{1}} \sum_{k \in \mathcal{N}_{1}} N_{j k 1} w_{j k 1} \frac{d \ln w_{j k 1}}{d \tau}
$$

Thus, in contrast to the case of block grants, the total welfare effects of the wage subsidy depend to first order on price changes. This is because of the ad valorem nature of the subsidy which makes the size of the transfer from the federal government to zone employers contingent upon the base wage. So even if no firms or workers move, an increase in the wage will increase the total transfer to the local economy. 
The marginal cost of an increase in the ad valorem wage subsidy is:

$$
\begin{aligned}
\frac{d}{d \tau} \sum_{j \in \mathcal{N}_{1}} \sum_{k \in \mathcal{N}_{1}} N_{j k 1} w_{j k 1} \tau & =\sum_{j \in \mathcal{N}_{1}} \sum_{k \in \mathcal{N}_{1}} N_{j k 1} w_{j k 1}\left(1+\tau \frac{d \ln N_{j k 1}}{d \tau}+\tau \frac{d \ln w_{j k 1}}{d \tau}\right) \\
& =\sum_{j \in \mathcal{N}_{1}} \sum_{k \in \mathcal{N}_{1}} N_{j k 1} w_{j k 1}\left(\frac{d \ln w_{j k 1}}{d \tau}+\tau \frac{d \ln N_{j k 1}}{d \tau}\right)
\end{aligned}
$$

where in the second line we have made use of the fact that (2) implies $\frac{d \ln w_{j k 1}}{d \tau}=\frac{1}{1-\tau \delta_{j k 1}}$. The extra term in this expression relative to 9 constitutes the marginal deadweight loss of the wage subsidies; it reflects the fact that marginal entrants have first order effects on program cost even if they value the resulting net wage increases little.

The total deadweight loss of the tax subsidy may be written:

$$
\begin{aligned}
D W L_{\tau} & =\sum_{j \in \mathcal{N}_{1}} \sum_{k \in \mathcal{N}_{1}} N_{j k 1} w_{j k 1} \int_{0}^{d \tau} t \frac{d \ln N_{j k 1}}{d t} d t \\
& \approx \frac{1}{2} \psi d \tau^{2} \sum_{j \in \mathcal{N}_{1}} \sum_{k \in \mathcal{N}_{1}} N_{j k 1} w_{j k 1}
\end{aligned}
$$

where in the second line we have assumed a constant semi-elasticity of local employment $\psi=\frac{d \ln N_{j k 1}}{d \tau}$. The efficiency cost of the employment credit is proportional to $\psi$ and the local wage bill in the zone and is increasing in the square of the tax change. This formula corresponds to the standard Harberger (1964) formula for approximating deadweight loss with the number of jobs in the zone as the "good" being subsidized. It is also analogous to results found in local public finance models of between-city equilibrium (e.g. Albouy, 2009) where the local employment elasticity serves as a key input to calculations of the deadweight loss induced by local taxes. A key difference with such papers is that the present elasticity depends critically upon taste heterogeneity which generates different conclusions regarding program incidence.

Note that in the absence of taste heterogeneity among workers $\psi$ will be large and the employment credits will be "wasted" on workers indifferent about the prospect of switching between neighborhoods, sectors, and labor force states. If, however, few nonzone residents 
are on the margin of moving to an EZ (as might be the case if EZs are perceived by most to be undesirable locations in which to live) and few EZ residents are on the margin of working (as might be the case if public assistance receipt provides disincentives to work among a large fraction of the local population) then $\psi$ will be small and the deadweight loss of the program will be small.

The block grant investments may yield additional deadweight losses if their total cost $C$ exceeds the value of the resulting amenity and productivity increases. Suppose every dollar of block grants proportionally raises zone neighborhood amenity levels by a factor of $\lambda_{a}$ and zone neighborhood productivity levels by $\lambda_{b}$. Then we may approximate the deadweight loss associated with the block grants by assuming marginal welfare effects are constant as follows:

$$
\begin{aligned}
D W L_{G} & \approx C\left[1-\left.\lambda_{a} \sum_{j \in \mathcal{N}_{1}} \frac{d W}{d \ln A_{j}}\right|_{\tau=0}-\left.\lambda_{b} \sum_{k \in \mathcal{N}_{1}} \frac{d W}{d \ln B_{k}}\right|_{\tau=0}\right] \\
& =C\left[1-\lambda_{a} \sum_{j \in \mathcal{N}_{1}} A_{j} N_{j}-\lambda_{b} \sum_{j} \sum_{k \in \mathcal{N}_{1}} \sum_{s} N_{j k s} w_{j k s}\right]
\end{aligned}
$$

where the second line follows from (7) and (8). If the block grants are wasted on unproductive investments, as is likely if the funds are mismanaged or mistargeted relative to the needs of local firms, the program's deadweight costs could be substantial. If, however, local public goods are underprovided in zone neighborhoods the social return on these local investments may dramatically exceed their cost.

\section{Empirical Strategy}

Our theoretical discussion highlights the point that the incidence and efficiency of EZ designation are both empirical questions incapable of being answered on prior grounds. The incidence of the program hinges critically upon the manner in which factor prices change. Wage increases in the zone will benefit workers with a preference for working in the zone while residents who prefer to take leisure will be unaffected. Rent increases will benefit zone 
landlords but reduce the disposable income of zone residents. Residents outside the zone may also reap some benefit from EZ designation if the productivity of zone jobs rises or rental rates for housing fall in response to any population losses. But the total economy wide gain associated with the program will be small relative to its cost if workers are highly responsive to the wage subsidies or if the block grants are wasted on unproductive investments.

Our empirical tasks, then, are threefold. First, we must identify the impact of EZ designation on local price levels in order to assess the program's incidence. Second, to compute an estimate of deadweight loss due to the program's tax credits, we need to determine $\psi$ which corresponds to the effect of the wage subsidies on the number of zone jobs for zone residents. Third, we need to isolate the cost effectiveness of the block grants which will require determining the impact of EZ designation on the wages of nonresident zone workers, who according to (5) should experience wage increases in proportion to any productivity increases $d B_{k}$. With knowledge of $d \ln B_{k}$ and information on the cost $C$ of the EZ investments we may in turn identify $\lambda_{b}$. Note that without more assumptions the model does not allow point identification of $\lambda_{a}$ from reduced form impacts alone. However, provided housing supply is not perfectly elastic, if the impact on rents of designation is nearly zero we can be assured that $\lambda_{a}$ is very small as well. We return to this issue again in Section VII.

Our research design for accomplishing these tasks will be to compare the experience over the 1990s of census tracts in Round I EZs to tracts in rejected and later round zones with similar characteristics ${ }^{17}$ This approach has a number of advantages. First, tracts in rejected zones, like those in winning zones, were nominated by their local governments for inclusion in an EZ proposal. If the nomination process was similar in winning and losing cities this ought to yield a set of control tracts with both observable and unobservable characteristics similar to EZs. Second, our control zones consist of contiguous clusters of poor census tracts just like real EZs. If spillovers exist across census tracts or if poor tracts surrounded by other poor tracts have important unmeasured characteristics then such agglomerated controls may be

\footnotetext{
${ }^{17}$ Use of rejected applicants as controls as a means of mitigating selection biases has a long history in the literature on econometric evaluation of employment and training programs. See the monograph by Bell et al. (1995) for a review.
} 
necessary for identifying causal effects. Finally, the majority of rejected and future zones are located in different cities than treated zones which reduces the sensitivity of our estimates to geographic spillover effects.

Though the use of rejected tracts as controls has many advantages, one may still be concerned that the cities that won first round EZs are fundamentally different from losing cities. A cursory inspection of Table 1 indicates that two of the three largest US cities won EZs, while the remaining winners are large manufacturing intensive cities. If large cities experienced fundamentally different conditions over the 1990s than small cities, the comparison of observationally equivalent census tracts in winning and losing zones will be biased.

To further explore this possibility we conduct a number of robustness tests aimed at assessing the credibility of our differences-in-differences research design. First, we construct a set of "placebo zones" in treated cities with characteristics similar to real zones. If our research design is confounded by city wide shocks we should find nonzero effects on these placebo zones as well. Second, we examine how the outcomes of EZ tracts change in the city-wide distribution of tract level outcomes relative to controls. This approach, which is a nonparametric variant of the traditional differences-in-differences-in-differences (DDD) research design, is robust to arbitrary rank preserving city specific shocks.

\section{Econometric Methods}

In our comparison of EZ neighborhoods to tracts in rejected and future zones we will rely on simple generalizations of standard differences-in-differences estimators. To motivate this approach we develop here a statistical model of census tract behavior and EZ assignment based upon the theoretical model of Section II.

Let $\Delta Y_{t z c}$ be the change in some outcome (e.g. log population) over the 1990s in census tract $t$ of proposed zone $z$ in city $c$. Taking census tracts as the relevant definition of neighborhoods, our theoretical model suggests that such changes are the result of the introduction 
of zone specific labor subsidies $\tau_{z}$ and shifts over time in the local amenity $\left(A_{t z c}\right)$ and productivity $\left(B_{t z c}\right)$ levels of all tracts in the city. To reduce the state space, we assume that tract level outcomes depend only on city-wide averages $A_{c}$ and $B_{c}$ of these quantities and local distance weighted averages $A_{n(t)}$ and $B_{n(t)}$ among tracts within a radius-based neighborhood $n(t)$ of census tract $t$.

We work with the following linear approximation to the model's reduced form:

$$
\Delta Y_{t z c} \approx a_{t}^{1} \Delta A_{n(t)}+a_{t}^{2} \Delta B_{n(t)}+a_{t}^{3} \Delta A_{c}+a_{t}^{4} \Delta B_{c}+a_{t}^{5} \Delta \tau_{z}
$$

where the random coefficients $a_{t}^{1}$ through $a_{t}^{5}$ represent the potentially heterogeneous tractlevel responses to these exogenous factors. Let $T_{z}$ be an indicator for whether zone $z$ is designated as an EZ. To model the impact of designation we assume that $\Delta A_{n(t)}=\Delta A_{n(t)}^{0}+$ $\phi_{t}^{a} T_{z}, \Delta B_{n(t)}=\Delta B_{n(t)}^{0}+\phi_{t}^{b} T_{z}$ and $\Delta \tau_{z}=\Delta \tau_{E Z} T_{z}$ where $\Delta A_{n(t)}^{0}$ and $\Delta B_{n(t)}^{0}$ are the changes in local amenity and productivity levels a tract would experience in the absence of treatment, $\phi_{t}^{a}$ and $\phi_{t}^{b}$ are the incremental amenity and productivity impacts of EZ designation, and $\Delta \tau_{E Z}$ is the EZ employment tax credit.

Let $P_{c}$ be a vector of mean city-level characteristics and $X_{t}$ a vector of tract level proxies for trends in local productivity and amenities. Define $X_{n(t)}$ as a distance weighted average of those tract level covariates within a given radius-based neighborhood $n(t)$ of tract $t$. We write the projection of the factors governing untreated behavior onto the observed proxy variables as:

$$
\begin{gathered}
a_{t}^{1} \Delta A_{n(t)}^{0}+a_{t}^{2} \Delta B_{n(t)}^{0}+a_{t}^{3} \Delta A_{c}+a_{t}^{4} \Delta B_{c}=X_{n(t)}^{\prime} \alpha^{x}+P_{c}^{\prime} \alpha^{p}+\xi_{c}+e_{t z c} \\
E\left[\xi_{c}+e_{t z c} \mid X_{n(t)}, P_{c}\right]=0
\end{gathered}
$$

where the proxy errors $\xi_{c}$ and $e_{t z c}$ are unobserved city-wide and tract specific shocks to productivity and amenities that would have occurred in the absence of treatment. Using 
this notation we may now write:

$$
\Delta Y_{t z c}=\beta_{t z c} T_{z}+X_{n(t)}^{\prime} \alpha^{x}+P_{c}^{\prime} \alpha^{p}+\xi_{c}+e_{t z c}
$$

where the random coefficient $\beta_{t z c}=a_{t}^{1} \phi_{t}^{a}+a_{t}^{2} \phi_{t}^{b}+a_{t}^{5} \Delta \tau_{E Z}$ represents the potentially heterogeneous reduced form effect of EZ designation mediated through changes in local taxes, amenities, and productivity levels. This heterogeneity may arise either from neglected nonlinearities in the reduced form (as captured by randomness in the $a_{t}$ coefficients) or spatially uneven EZ investments across zone neighborhoods (as captured by randomness in the $\phi_{t}^{a}$ and $\left.\phi_{t}^{b}\right)$.

EZs are assumed to have been assigned based upon the mean characteristics $X_{z}$ of the zone and features $P_{c}$ of the city as follows: ${ }^{18}$

$$
T_{z}=I\left[X_{z}^{\prime} \gamma^{x}+P_{c}^{\prime} \gamma^{p}+v_{z c}>0\right]
$$

where the error $v_{z c}$ is distributed independently of $\left(X_{n(t)}, X_{z}, P_{c}, \xi_{c}, e_{t z c}\right)$. This is a strong assumption which we will later test with a number of robustness exercises.

The assumptions made so far imply: 19

$$
E\left[\xi_{c}+e_{t z c} \mid T_{z}, X_{n(t)}, P_{c}\right]=0
$$

which, given the usual regularity conditions, is sufficient to ensure that the parameters $\left(\alpha^{x}, \alpha^{p}\right)$ are identified via a tract-level regression of $\Delta Y_{t z c}$ on $X_{n(t)}$ and $P_{c}$ in the sample of untreated tracts.

\footnotetext{
${ }^{18}$ The assumption that it is the mean characteristics of the zone that influence designation is not as restrictive as might be thought since $X_{t}$ may include indicator functions (e.g. a dummy for tract poverty less than $20 \%$ ) and polynomial terms.

${ }^{19}$ Our assumption that $v_{z c}$ is distributed independently of $\left(X_{n(t)}, X_{z}, P_{c}, \xi_{c}, e_{t z c}\right)$ implies $P\left(T_{z}=1 \mid X_{n(t)}, P_{c}, \xi_{c}, e_{t z c}\right)=P\left(T_{z}=1 \mid X_{n(t)}, P_{c}\right)$. A straightforward application of Bayes' rule to the expression $E\left[\xi_{c}+e_{t z c} \mid T_{z}, X_{n(t)}, P_{c}\right]$ reveals that the above result and independence of $\left(\xi_{c}, e_{t z c}\right)$ from $\left(X_{n(t)}, P_{c}\right)$ imply (14).
} 
The average treatment effect on the treated (ATT) may be written:

$$
\theta \equiv E\left[\beta_{t z c} \mid T_{z}=1\right]
$$

We consider two estimators of this quantity, each of which rely on different assumptions about the nature of treatment effect heterogeneity. Under the first approach we assume $\beta_{t z c}$ to be independent of $\left(X_{n(t)}, X_{z}, P_{c}, v_{z c}\right)$ in which case $E\left[\beta_{t z c} \mid T_{z}=1\right]=E\left[\beta_{t z c}\right]$ and we may write $\beta_{t z c}=\theta+\zeta_{t z c}$ where $E\left[\zeta_{t z c} \mid T_{z}, X_{n(t)}, P_{c}\right]=0$. It is straightforward to verify in this case that, subject to the usual regularity conditions, OLS estimation of $(12)$ on the pooled sample of tracts identifies $\theta$.

In a second approach we allow $E\left[\beta_{t z c} \mid T_{z}, X_{n(t)}, P_{c}\right]$ to be an arbitrary real valued function. We construct an estimator of the ATT by observing that (14) implies:

$$
\theta=E\left[\Delta Y_{t z c}-X_{n(t)}^{\prime} \alpha^{x}-P_{c}^{\prime} \alpha^{p} \mid T_{z}=1\right]
$$

This suggests that $\theta$ may be estimated by a two-step procedure where in a first step $\alpha^{x}$ and $\alpha^{p}$ are estimated via an OLS regression of $\Delta Y_{t z c}$ on $X_{n(t)}$ and $P_{c}$ in the sample of untreated tracts and in a second step the predicted values from this regression are used to form counterfactual mean estimates $X_{n(t)}^{\prime} \widehat{\alpha}^{x}+P_{c}^{\prime} \widehat{\alpha}^{p}$ for each treated tract. An estimate of $\theta$ may then be computed as:

$$
\widehat{\theta}=\frac{1}{N_{1}} \sum_{t} T_{t}\left(\Delta Y_{t z c}-X_{n(t)}^{\prime} \widehat{\alpha}^{x}-P_{c}^{\prime} \widehat{\alpha}^{p}\right)
$$

where $T_{t}$ is a tract level indicator for whether tract $t$ is in a treated zone and $N_{1}=\sum_{t} T_{t}$ is the number of treated tracts. This expression is simply the mean prediction error among treated tracts of a regression model estimated on controls.

In practice, we implement this parametric reweighting (PW) procedure in a single step via an interacted regression described in Appendix I. Kline (2010b) shows that this estimator, which is a variant of the classic Blinder-Oaxaca approach to measuring wage gaps, is equiv- 
alent to a propensity score reweighting estimator with weights derived from a log-logistic propensity score model. We use these parametric weights in the next section to assess the extent to which our regression model is able to balance the distribution of covariates across treatment and control samples over time.

The presence of a random effect $\xi_{c}$ in 12 suggests the need to account for within city spatial correlation in the errors when conducting inference. Because we have only six treated zones, standard cluster-robust variance estimation methods relying upon first order asymptotics may yield poor control over the probability of making type I errors. To deal with this problem we use a clustered wild bootstrap-t procedure explored in Cameron, Gelbach, and Miller (2008) which has been found to yield dramatic improvements in the performance of cluster-robust methods in small samples. We conduct a Monte Carlo study, presented in Supplemental Appendix B, demonstrating that this procedure effectively controls the size of Wald tests for both the OLS and PW estimators in a variety of data generating processes mimicking the design of our data.

\section{Data}

Our analysis relies upon three decades worth of confidential household and establishment level microdata from the Decennial Census, the Standard Statistical Establishment List (SSEL), and the Longitudinal Business Database (LBD) which we have geocoded to the level of the 1990 Census tract. Appendix II provides information on sample selection, construction of the geocodes, and variable definitions.

In order to construct a suitable control group for EZs, we obtained 73 of the 78 first round EZ applications submitted to HUD by nominating jurisdictions via a Freedom of Information Act request. These applications contain the tract composition of rejected zones which we merged with publicly available data on the tract composition of future zones to create a composite set of controls for use in our analysis. Appendix Table A1 details the composition of the cities in our evaluation sample, whether they applied for a Round I EZ, 
and the treatments (if any) they received.

Table 3 shows average characteristics of EZ and control tracts. Our analysis focuses on the six original EZs which received both tax credits and block grants and restricts the sample of controls to zones containing at least 10 census tracts in cities with population greater than $100,000{ }^{20}$ We also drop all control tracts with 1990 poverty and unemployment rates below the minimum thresholds specified in the EZ eligibility criteria ${ }^{21}$ This yields a baseline estimation sample of 234 EZ tracts in six cities and 1,429 controls distributed across sixty nine cities.

While the residents of rejected and future zones are poor and have high rates of unemployment we see from columns one and two of Table 3 that they are not quite as poor or detached from the labor force as residents of EZ areas. It is also clear that working residents of EZ neighborhoods are, on average, less likely to work in the zone than residents of rejected and future zones. This is primarily due to the fact that EZs tend to be in larger cities which simply have more census tracts to which an individual may commute in a short amount of time.

To find a more comparable subset of controls we estimate a logistic propensity score model at the tract level explaining EZ designation as a function of the 1980 and 1990 values of a number of different tract and city characteristics measured in the Census along with a number of tract-level variables measured in the 1987 and 1992 waves of the LBD. Coefficients on the variables used in the propensity score model are given in Appendix Table A2. Because some of our controls are lagged values of outcomes we wish to investigate via regression based methods, we construct our tract level covariates $X_{n(t)}$ (which are kernel weighted spatial averages) omitting the actual tract level outcome $X_{t}$ in order reduce the threat of division bias (Borjas, 1980) in our later results. ${ }^{22}$

\footnotetext{
${ }^{20}$ Census tracts in the two SEZs are dropped from our baseline analysis because they were not eligible for wage tax credits during our sample period. We also drop the Washington, DC Enterprise Zone (EnZ) from our sample because it received a wage tax credit but not block grants and hence cannot be properly characterized as an EZ or a control.

${ }^{21}$ Zone tracts were required to have poverty rates in excess of $20 \%$ and unemployment rates in excess of $6.3 \%$ as measured in the 1990 Census.

${ }^{22}$ See Appendix II for more on the construction of the $X_{n(i)}$.
} 
Figure 2 plots the distribution of estimated propensity scores above 0.05 among treated and control units. Though it is not visible on the histogram, approximately $20 \%$ of the control tracts have estimated propensity scores below the minimum value found among the EZ tracts. To deal with this failure of overlap in the two distributions we drop tracts with propensity scores less than the minimum value found among the treated units and those with propensity scores greater than 0.9 as recommended in Crump et al. (2009). This shrinks our estimation sample to $232 \mathrm{EZ}$ tracts and 1,088 controls distributed across sixty four cities. The bottom panel of Figure 2 shows the results of reestimating the same propensity score model on this trimmed sample of tracts.

The third column of Table 3 shows that trimming the sample does not substantially change the average characteristics of the EZ tracts. However, we see from the fourth column of Table 3 that the mean characteristics of the control group do change in a manner making the two groups substantially more comparable. The fifth column of Table 3 uses the regression based weights, described in Kline (2010b) and in Appendix I, to reweight the controls in this trimmed sample to mimic the covariate distribution of the treated observations using the same covariates as the earlier logit. After reweighting, the first two moments of tract characteristics exhibit dramatically improved balance despite the fact that the majority of these variables were not included in the weighting procedure. ${ }^{23}$

Figure 3 shows the mean behavior of the EZ and control tracts before and after reweighting across the three decades in our sample. After trimming is applied to the pooled set of controls their history over the past two decades mirrors that of actual Empowerment Zones remarkably well. One can actually see most of our results from these graphs themselves. A number of key labor market outcomes (total employment, log wages of zone workers, and log wages of zone resident workers) seem to have improved in EZ neighborhoods relative to reweighted controls over the 1990s indicating a substantial boost to local labor demand. Also noticeable however is the absence of a discernable impact on population or housing rents. We discuss this finding in more detail in the next section.

\footnotetext{
${ }^{23}$ See also Appendix Tables A3.a and A3.b where we document balance on other covariates (including pre-treatment trends) and on other moments of the marginal distribution of covariates.
} 


\section{Results}

We turn now to our differences-in-differences estimates of the impact of EZ designation. We confine our attention to the trimmed sample of tracts where simple linear adjustments are most likely to be valid. To deal with the hierarchical nature of our data we report wild bootstrapped standard errors clustered at the city level and percentile-t tests of the null of no-effect as suggested by Cameron, Gelbach, and Miller (2008) ${ }^{24}$ Because the empirical bootstrap distributions of our test statistics may be asymmetric and/or leptokurtotic our bootstrap standard errors and p-values occasionally move in opposite directions across specifications.

Table 4 presents estimates of the impact of EZ designation on economic activity in EZ neighborhoods as measured in the LBD. Column 1 reports simple differences-in-differences estimates which yield large (10\%) positive effects on the number of jobs and small insignificant effects on the number of establishments and average earnings per worker. Column 2 shows that after adjusting the differences-in-differences estimates for covariate imbalance via OLS the estimated impact on jobs increases to $13 \%$ and becomes more precise. Column 3 gives the results of our regression based reweighting estimator which yields even larger jobs impacts. The tendency for covariate adjustment to increase the point estimates suggests that EZs were awarded to economically declining neighborhoods.

The second panel of Table 4 computes impacts on firms located in the zone in 1992. This attenuates the estimated job impacts suggesting that some of the overall employment impact is due to firm births. The negative impacts on the number of establishments in this restricted sample indicate that designation may have also increased firm death rates. ${ }^{25}$ The bottom two panels of the table break impacts down by 1992 establishment size. Though the estimates are quite noisy, we find that employment increased only at establishments that were already large in the 1992 economic census. These findings are consistent with the

\footnotetext{
${ }^{24}$ See Supplemental Appendix B for details.

${ }^{25}$ The net impacts in the first panel suggest the effect on births is larger than the corresponding effect on deaths.
} 
survey evidence in Hebert et al. (2001) that large firms were more likely to take advantage of the tax credits and suggest an important role for this feature of the program.

Table 5 provides estimates of the number of jobs created based upon the Journey to Work component of the Decennial Census. The point estimates are extremely stable across specifications with an estimated increase of 18\%-19\%. These figures are in line with, though slightly larger than, the corresponding LBD based estimates in Table 4. In Supplemental Appendix C we show that employment increased more in zone industries with a larger 1990 employment share of local workers, providing additional evidence that the tax credits were likely an important source of the jobs impacts.

By crossing Census questions on place of work with place of residence we can in principle determine who occupied any jobs that were created. The second panel of Table 5 reports the results of this exercise. Though all specifications find that the largest employment increases in the zone occurred among zone residents, the magnitude and precision of the results vary with the specification used. Employment of non-resident commuters seems to have increased by nearly the same proportion as local residents suggesting the wage credits are unlikely to be the only source of increased labor demand in the zones.

Table 6 provides estimates of the impact of EZ designation on the log hourly wages of individuals broken down by place of residence and place of work. To remove the influence of changes in neighborhood composition over time we also report results where the wages have been regression adjusted for individual characteristics at the micro-level via a procedure described in Appendix II. We label the impact on the difference between adjusted and unadjusted wages a third "composition" effect, providing the change in wages that would be expected due solely to changes in the composition of the workforce.

Though all of our point estimates suggest modest wage increases for zone residents, we lack the power to reject the null hypothesis of no effect except in our OLS specification. Adjusting for individual characteristics has little effect other than to slightly increase precision. No detectable wage effects are present for zone workers as a whole. However because only 
roughly $10 \%$ of zone workers are zone residents ${ }^{26}$ it is important to further disaggregate these estimates.

The bottom panel of Table 6 provides wage impacts broken down jointly by place of residence and place of work. Here we find large wage increases among zone residents who work in the zone of more than $12 \%$. These effects are in part due to changes in composition which appear to have increased the predicted wage of local workers by roughly $5 \%$. But even after accounting for composition the wages of local workers increased by approximately $8 \%$. We also find in some specifications that the wages of resident commuters increased which may reflect spillovers in the demand for labor across zone boundaries. Non-resident commuters exhibit small and insignificant wage increases suggesting that the elasticity of supply of commuter labor to the zone is very large.

Table 7 examines the impact of EZ designation on the housing market and population. As in Table 6, we use the Census microdata to construct adjusted estimates that hold tract dwelling characteristics constant over time 27 Owner occupied housing values exhibit dramatic increases of approximately a third across all specifications and samples. Rental rates on the other hand exhibit no perceptible increase. Adjusting for building characteristics has little effect on the estimates.

This large discrepancy between rental rates and housing values is troublesome. We suspect it reflects the fact that owner occupied housing values are self-reported in the Census. If slum housing markets are relatively illiquid, residents may not know whether (or by how much) designation has changed the value of their residence. An alternative explanation is that they are pricing in expected future increases in the attractiveness of the neighborhood which have yet to materialize and may or may not be overly optimistic.

The remaining results of Table 7 call the interpretation of the housing value estimates further into question. Neither total tract population nor the number of zone households seem to have been affected by zone designation. We also fail to find an appreciable effect on

\footnotetext{
${ }^{26}$ See Table 10.

${ }^{27}$ See Appendix II for details on our adjustment procedure.
} 
the fraction of housing units that are vacant. Finally, if rents or other local prices increased substantially one would expect outmigration rates to rise as lower skilled groups are priced out of the neighborhood. Yet Table 7 finds no evidence of an impact on the fraction of households living in the same house as five years ago.

Overall, these findings suggest that EZ designation created jobs in zone neighborhoods, that both zone and nonzone residents obtained employment in these neighborhoods that would not have otherwise been available, and that earnings increased substantially for zone residents. We find no evidence of important increases in the local cost of living or population. These results suggest that while commuting patterns are relatively sensitive to changes in incentives, the residential choices of workers are quite rigid, presumably because zone neighborhoods are poor substitutes for less distressed areas. The evidence also suggests an important role for both the wage credit and block grant features of the EZ program which appear to have disproportionately raised employment at large firms, raised wages among local workers, and still raised the employment of nonresident commuters by nearly as much as local residents.

\section{Robustness}

If unmeasured factors correlated with the future performance of neighborhoods influenced the process by which zones were awarded our estimates will be biased. To address such concerns, we now perform two tests of the assumptions underlying our research design.

Our first test is to create a series of "placebo" zones in treated cities and compare their performance over the 1990s to that of future and rejected tracts using our differences-indifferences estimators. A finding of nonzero treatment effects in this sample would suggest that our analysis is confounded by city specific shocks. In order to construct the placebo zones we estimated a pooled propensity score model for all tracts in treated cities (see

Appendix IV for details) and then performed nearest neighbor propensity score matching without replacement in each city, choosing exactly one control tract for each treated EZ 
tract. This yields a set of placebo zones of the same size and with approximately the same census characteristics as each real EZ.

The placebo tracts tend to be geographically clustered in much the same way as actual EZs, reflecting the underlying spatial correlation of many of the covariates used in the analysis. One potentially troublesome feature of the placebo zones however is that they tend to be located near actual EZ tracts. If EZ designation did in fact have an impact, the effects may have spilled over into adjacent communities. For this reason we impose the restriction that placebo tracts be at least one mile from the nearest EZ tract.

Table 8 shows the results of applying our differences-in-differences estimators to a trimmed sample of placebo tracts where the trimming has been conducted on an estimated propensity score of the same form as that used in Section $\mathrm{V}$ of the paper. After reweighting, none of the outcomes register statistically significant differences across placebo and control zones, save for the fraction in the same house as five years ago which exhibits a modest positive effect. However, no systematic pattern is apparent from the placebo point estimates as a whole.

As a second check on our research design we convert the outcome variables to scaled within city ranks ${ }^{28}$ If our results are merely picking up city specific shocks then the rank of an average EZ tract in its city wide distribution of poverty rates, for example, should not change over the 1990s relative to the rank of a similar rejected tract in its city-wide distribution. We scale our ranks by the number of tracts in each city so that the transformed outcomes can be thought of as percentiles which are comparable across cities of different absolute size ${ }^{29}$

Columns 4 through 6 of Table 8 show the results of applying the three differences-indifferences estimators to the transformed outcomes in the trimmed sample. The point estimates represent the average impact of EZ designation on the percentile rank of EZ neigh-

\footnotetext{
${ }^{28}$ In a previous version of this paper we experimented with a reweighted difference-in-differences-indifferences (DDD) estimator that sought to find within city controls for both actual and rejected EZ tracts. This estimator performed quite poorly severely failing a number of robustness tests. This poor performance was caused by difficulties in finding suitable control tracts in rejected cities. We believe the following percentile rank approach to be a much more transparent and robust approach to making within city comparisons.

${ }^{29}$ In other words, for any outcome $Y_{t z c}$ in tract $t$ of zone $z$ in city $c$, we form a new outcome $\widetilde{Y}_{t z c}=$ $\operatorname{rank}_{c}\left(Y_{t z c}\right) / N_{c}$ where $\operatorname{rank}_{c}$ is the track rank (the lowest value receives rank 1, the highest rank $N_{c}$ ) of $Y_{t z c}$ in the city wide distribution of the variable in that year and $N_{c}$ is the number of tracts in the relevant city.
} 
borhoods. For example, Column 5 indicates that EZ designation led EZ neighborhoods to rise, on average, 2 percentiles in the within city distribution of jobs per worker. The results are in agreement with the findings of Tables 4-7 which we take as evidence that our prior results are unlikely to have been generated by spurious correlation with city wide trends.

Finally, Table 9 provides impact estimates in three alternative estimation samples. The first sample relies entirely upon rejected round I applicants for controls and hence discards later round zones. The second sample drops New York city which may have been subject to different shocks during the sample period. The third sample adds the two SEZs (Cleveland and Los Angeles) to the sample. Much the same pattern of results is present in each sample though the statistical significance of the estimates varies in ways that reflect the differences in sample size.

\section{Welfare Analysis}

Our empirical analysis suggests that EZ designation generated important changes in local price levels and behavior. The model developed in Section II provides a framework for assessing the welfare consequences of these changes. We begin by considering the incidence of EZ designation on program stakeholders. Derivations analogous to those in (6) reveal that the total impact of the program on workers may be written:

$$
\begin{aligned}
d V & =\sum_{j} \sum_{k} \sum_{s} N_{j k s}\left[w_{j k s} d \ln w_{j k s}-r_{j} d \ln r_{j}+A_{j} d \ln A_{j}\right] \\
& \approx d \ln w^{\text {local }} \sum_{j \in \mathcal{N}_{1}} \sum_{k \in \mathcal{N}_{1}} \sum_{s} N_{j k s} w_{j k s}+d \ln w^{\text {commute }} \sum_{j \in \mathcal{N}_{0}} \sum_{k \in \mathcal{N}_{1}} \sum_{s} N_{j k s} w_{j k s} \\
& +d \ln A^{E Z} \sum_{j \in \mathcal{N}_{1}} N_{j .} A_{j}-d \ln r^{N E Z} \sum_{j \in \mathcal{N}_{0}} N_{j .} r_{j}-d \ln r^{E Z} \sum_{j \in \mathcal{N}_{1}} N_{j} r_{j}
\end{aligned}
$$

where $d \ln w^{\text {local }}$ is the average impact on the wages of zone resident workers, $d \ln w^{\text {commute }}$ is the corresponding impact on non-resident commuters, $d \ln A^{E Z}$ is the average increase in zone amenities, $d \ln r^{N E Z}$ is the average impact on rental rates of housing outside of the zone, and $d \ln r^{E Z}$ is the average impact on rental rates of housing inside the zone. 
Hence, to first order, the program's benefits may be measured as: a) the total earnings increase for zone resident workers, b) the earnings increase for non-resident commuters, c) the value of any improvements in local amenities, and d) the value of any rent reductions that occur outside the zone due to population decreases. These benefits to workers are offset by any increases in the cost of living in the zone which may be measured in terms of the total zone rental cost. Our estimates suggest little effect on population or rents inside the zone so we assume for simplicity that zone amenities and rents outside the zone were both unaffected by designation $\left(d \ln A^{E Z}=d \ln r^{N E Z} \approx 0\right)$. Note that these assumptions provide a lower bound estimate of the benefits of EZ designation.

Table 10 provides calculations converting our treatment effect estimates from Section $\mathrm{V}$ into effects on totals corresponding to the terms in (16). Approximately 52, 000 zone residents worked in EZs in 2000 with a payroll of roughly $\$ 1 B$. Our estimate of the program's impact on the wages of local residents is roughly eight percent which translates into an $\$ 80 M$ increase in annual earnings for zone residents who work in the zone ${ }^{30}$ This figure is near the $\$ 55 M$ in wage credits disbursed in 2000. Note, however, that it is possible for the wages of zone residents to rise by more than the total amount of credits if the block grants were productive. Though imprecise, our point estimates of the impact of the program on the wages of nonresident zone workers (and the corresponding impacts on employment of nonresident commuters) suggest that such effects may have been present. Averaging our PW and OLS estimates yields a $2.9 \%$ increase in the wages of nonresident EZ workers in response to designation. There were roughly 538, 000 such workers in 2000 with total annual earnings of $\$ 20 B$, hence these wage increases yielded roughly $\$ 580 M$ in additional annual earnings for zone commuters. We also found an impact on the wages of the roughly 194, 000 zone residents who in 2000 lived in the zone but worked elsewhere. An average increase of $5.7 \%$ in this group's hourly wages yields roughly $\$ 240 M$ in additional annual earnings.

Potentially offsetting these increases in the wage are small estimated increases in housing rents. Averaging our OLS and PW results yields an estimated 1.9\% increase in adjusted rents.

\footnotetext{
${ }^{30}$ Our results are in log points. We compute impacts relative to 2000 levels for expositional ease. Similar results obtain if we take 1990 levels as the base.
} 
Approximately 243,000 EZ households rented their dwellings in 2000 with total annual rental payments of $\$ 1.2 B$. Our estimated rent increases are equivalent to an aggregate transfer from renting residents to landlords of $\$ 23 M$ per year. An additional 70,000 EZ residents own their homes which were in aggregate worth $\$ 7.9 B$ in 2000 . Both estimation strategies suggest an increase in housing values of approximately one third, which amounts to $\$ 2.7 B$ in additional wealth.

Our scepticism of the housing value results and the imprecision of many of the point estimates leads us to also consider two alternative scenarios. In the first, the housing value impacts are cut by two thirds and the rent estimates are tripled. In the second the wage impact on nonresident commuters is also set to zero. This last scenario is the least favorable to the EZ program with landlords capturing $\$ 68 M$ of the $\$ 80 M$ in increased earnings for local workers. Yet even a housing wealth effect one third the size of our point estimates suggests a windfall of $\$ 909 M$ to local homeowners. Moreover, from (7) and (9), we see that the total benefit of the program (ignoring any amenity improvements) is well approximated by the total increase in zone earnings which we estimate at $\$ 320 M$ per year. Spread over six years this is remarkably close to our estimates of the program's cost.

We turn now to an analysis of the program's deadweight loss. Our estimates from Table 5 indicate that EZs generated a roughly $15 \%$ increase in the number of zone jobs for zone residents. Unfortunately, this estimate is quite noisy. We cannot for example reject the null hypothesis that the program yielded a ten percent increase in the number of zone jobs for zone residents. Moreover our large estimated impact on employment of nonresident commuters suggests some of this effect may be the result of the block grants rather than tax credits. It is useful then to supplement our estimates with auxiliary sources of information.

Recall that $\$ 55 M$ in wage credits was disbursed to EZ firms in 2000. The maximum allowable credit per worker is $\$ 3,000$, so let us suppose that $\$ 2,500$ was claimed on the average worker. This yields 22,000 workers on whom the credit was claimed - roughly forty percent of the local workforce. A 1999 General Accounting Office survey found that among firms making use of the wage tax credit, a third indicated that the credits were "very 
important" or "extremely important" for the hiring decision 31 Suppose then that one third of the credits claimed resulted in jobs that would not otherwise have occurred. This yields an impact of 7,333 jobs - approximately a fourteen percent increase which is nearly the same as our estimates from Table 5.

Using this estimate we can compute the jobs semi-elasticity as $\psi=\frac{.14}{.2}=0.7{ }^{32}$ Plugging this number into 10 yields an estimated deadweight loss associated with the employment tax credit of $\frac{1}{2} \times .7 \times 0.2 \times \$ 55 M=\$ 3.85 M$ or roughly seven percent of the flow cost of the subsidy ${ }^{33}$ We consider this figure a substantial overestimate since the zone wage credit should offset pre-existing payroll taxes and hence, to some extent, actually reduce the amount of distortion in hiring decisions.

As noted in Section II, the block grants accompanying EZ designation may yield either a deadweight loss or a net welfare gain depending upon how effectively they were spent. We have already assumed that EZs had no effect on amenity levels so we set $\lambda_{a}=0$ in (11). Roughly $C=\$ 400 M$ worth of federal block grants was invested in zone neighborhoods over the sample period. Averaging across models, we found a three percent increase in the wages of nonresident commuters which in the context of our model implies $d \ln B_{E Z}=0.031$. Though these estimates are statistically insignificant they are economically quite important.

The zone workforce $\left(\sum_{k \in \mathcal{N}_{1}} N_{. k}\right)$ consisted of approximately 600, 000 workers in 2000 with approximately $\$ 21 B$ in annual earnings. This means that the block grants yielded $0.031 \times$ $\$ 21 B=\$ 660 M$ in additional earnings per year. Assuming a social discount rate of ten percent yields an annuitized value for this earnings stream of $\$ 6.6 B$ which dwarfs the $\$ 400 M$ cost of the block grants. In the notation of the model this implies $\lambda_{b}=\frac{\$ 6.6 B}{\$ 400 M}=16.5$ so that every dollar invested yields a discounted societal gain of $\$ 16.5$. Allowing the effects of the block grant to gradually depreciate over time does little to mitigate this conclusion. One

\footnotetext{
${ }^{31}$ See Table III.1 of General Accounting Office (1999).

${ }^{32}$ This figure is substantially smaller than the intra-metropolitan job elasticity estimates surveyed by Bartik (1991). A potential explanation for this discrepancy is that these tax credits are tied to residence in distressed neighborhoods which the bulk of workers find relatively undesirable.

${ }^{33}$ We have made use here of the fact that $\tau \sum_{j \in \mathcal{N}_{1}} \sum_{k \in \mathcal{N}_{1}} N_{j k 1} w_{j k 1}$ is the size of the aggregate subsidy when firms are able to claim a credit of $20 \%$ on the wage bill of every covered worker.
} 
could also include the outside funds that seem to have been crowded into the program in the cost, raising the figure spent to as much as $\$ 3 B{ }^{34}$ We still reach the conclusion that the block grant benefits exceed the costs by a factor of two $\left(\lambda_{b}=2.2\right)$.

It is clear, however, that our estimates of the local productivity increase are quite noisy. It is interesting then to compute the productivity increase that would be necessary for the block grant investments to break even. If one works with a program cost of $\$ 400 M$ and a discount rate of ten percent, the breakeven productivity increase would be approximately $0.2 \%$ - a number we cannot reject but which is less than one tenth of our preferred point estimates. With a program cost of $\$ 2 B$ the breakeven increase would be roughly $1 \%$. Hence, we interpret the weight of the evidence as suggesting that the local investments generated by the block grants yielded benefits larger than the program's cost though we lack the statistical power to be confident in this conclusion.

\section{Conclusion}

Our comparison of EZ neighborhoods to rejected and future tracts revealed important impacts of EZ designation on local price levels and behavior. Designation resulted in large increases in zone employment which were accompanied by increases in the wages of zone residents, particularly those living and working in the zone. These changes in the zone labor market appear not to have been accompanied by dramatic changes in the housing market. Population and housing rents remained roughly constant. Though we find large increases in the price of owner occupied housing we suspect the magnitude of these results may be more a reflection of the manner in which housing value data is collected in the Census than a sign of dramatic windfalls to zone landlords.

The conclusion of our welfare analysis has been twofold. First, the EZ program successfully transferred income to a small spatially concentrated labor force with relatively little

\footnotetext{
${ }^{34}$ This is an upper bound both because it is unlikely that $\$ 3 B$ was actually spent (see Section I) and because alternative uses of the money crowded in are unlikely to have yielded dollar for dollar improvements in social welfare.
} 
deadweight loss. Whether it makes sense, on equity grounds, to target transfers to workers who prefer to live and work in poor places is beyond the scope of this paper. We caution however that larger interventions may well raise local price levels in which case the gains of local workers will be offset by losses among the many zone residents not in the labor force, many of whom may be living on fixed incomes.

Second, we found that a proper reckoning of the social return to the EZ program hinges critically on the efficacy of the local block grants. Our point estimates indicate the block grants paid for themselves many times over by raising local productivity, as might be expected if public goods were, for some reason, initially underprovided in these communities. Unfortunately, the imprecision of our estimates makes this conclusion quite tentative. 


\section{References}

1. Albouy, David. 2009. "The Unequal Geographic Burden of Federal Taxation." Journal of Political Economy 117(4):635-667.

2. Bartik, Timothy J. 1991. Who Benefits From State and Local Economic Development Policies? Kalamazoo, MI: W.E. Upjohn Institute for Employment Research.

3. Bartik, Timothy J. 2002. "Evaluating the Impacts of Local Economic Development Policies on Local Economic Outcomes: What Has Been Done and What is Doable?" Upjohn Institute Staff Working Paper \#03-89.

4. Baum-Snow, Nathaniel. 2007. "Suburbanization and Transportation in the Monocentric Model." Journal of Urban Economics 62(3): 405-423.

5. Bayer, Patrick, Fernando Ferreira, and Robert McMillan. 2007. "A Unified Framework for Measuring Preferences for Schools and Neighborhoods." Journal of Political Economy 115(4): 588-638.

6. Bell, Stephen, Larry Orr, John Blomquist, and Glenn Cain. 1995. Program Applicants as a Comparison Group in Evaluating Training Programs: Theory and a Test. Kalamazoo, MI: W.E. Upjohn Institute for Employment Research.

7. Boarnet, Marlon G. and William T. Bogart. 1996. "Enterprise Zones and Employment: Evidence from New Jersey." Journal of Urban Economics 40(2):198-215.

8. Bondonio, Daniele. 2003. "Do Tax Incentives Affect Local Economic Growth? What Mean Impacts Miss in the Analysis of Enterprise Zone Policies." Center for Economic Studies Working Paper 03-17.

9. Bondonio, Daniele and John Engberg. 2000. "Enterprise Zones and Local Employment: Evidence from the States' Programs." Regional Science \& Urban Economics, $30(5): 519-549$.

10. Borjas, George. 1980. "The Relationship Between Wages and Weekly Hours of Work: The Role of Division Bias." Journal of Human Resources 15(3):409-423.

11. Brashares, Edith. 2000. "Empowerment Zone Tax Incentive Use: What the 1996 Data Indicate." Statistics of Income Bulletin, 2000(3):236-252.

12. Bronzini, Raffaello and Guido de Blasio. 2006. "Evaluating the Impact of Investment Incentives: The Case of Italy's Law 488/1992." Journal of Urban Economics 60(2): 327-349.

13. Cameron, Colin, Jonah Gelbach, and Doug Miller. 2008. "Bootstrap Based Improvement for Inference with Clustered Errors." Review of Economics and Statistics 90(3): 414-427.

14. Chetty, Raj. 2009. "Sufficient Statistics for Welfare Analysis: A Bridge Between Structural and Reduced-Form Methods." Annual Review of Economics 1:451-488. 
15. Chouteau, Dale L. 1999. "HUD's Oversight of the Empowerment Zone Program, Office of Community Planning and Development, Multi-Location Review." Department of Housing and Urban Development, Office of Inspector General. Audit Case \# 99-CH156-0001.

16. Crump, Richard, Joseph Hotz, Guido Imbens, and Oscar Mitnik. 2009. "Dealing with Limited Overlap in Estimation of Average Treatment Effects." Biometrika 96(1): 187-199.

17. Criscoulo, Chiara, Ralf Martin, Henry Overman, and John Van Reenan. 1999. "The Effect of Industrial Policy on Corporate Performance: Evidence from Panel Data." Unpublished.

18. Davidson, Russell and James Mackinnon. 2010. "Wild bootstrap tests for IV regression." Journal of Business and Economic Statistics 28: 128-144.

19. Davis, Steven, John Haltiwanger, and Scott Schuh. 1996. Job Creation and Job Destruction. MIT Press.

20. Elvery, Joel. 2003. "The Impact of Enterprise Zones on Residents' Employment: An Evaluation of the Enterprise Zone Programs of California and Florida." Unpublished manuscript.

21. Engberg, John and Robert Greenbaum. 1999. "State Enterprise Zones and Local Housing Markets." Journal of Housing Research 10(2):163-187.

22. General Accounting Office. 1999. "Businesses' Use of Empowerment Zone Tax Incentives." Report \# RCED-99-253.

23. General Accounting Office. 2004. "Community Development: Federal Revitalization Programs Are Being Implemented, but Data on the Use of Tax Programs Are Limited." Report \# 04-306.

24. Government Accountability Office. 2006. "Empowerment Zone and Enterprise Community Program: Improvements Occurred in Communities, But The Effect of The Program Is Unclear." Report \# 06-727.

25. Glaeser, Edward. 2008. Cities, Agglomeration, and Spatial Equilibrium. Oxford: Oxford University Press.

26. Glaeser, Edward and Joshua Gottleib. 2008. "The Economics of Place-Making Policies." Brookings Papers on Economic Activity 2: 155-239.

27. Harberger, Arnold. 1964. "The Measurement of Waste." American Economic Review $54(3): 58-76$.

28. Hebert, S., A. Vidal, G. Mills, F. James, and D. Gruenstein. 2001. "Interim Assessment of the Empowerment Zones and Enterprise Communities (EZ/EC) Program: A Progress Report." Office of Policy Development and Research, available online at: www.huduser.org/ Publications/pdf/ezec_report.pdf 
29. Holmes, Thomas. 1998. "The Effects of State Policy on the Location of Industry: Evidence from State Borders." Journal of Political Economy 106(4): 667-705.

30. Internal Revenue Service. 2004. "Tax Incentives for Distressed Communities." Publication 954 Cat. No. 20086A.

31. Kain, John and Joseph Persky. 1969. "Alternatives to the Gilded Ghetto." Public Interest 14:74-83.

32. Kline, Patrick. 2010a. "Place Based Policies, Heterogeneity, and Agglomeration." American Economic Review, 100(2): 383-387.

33. Kline, Patrick. 2010b. "Blinder-Oaxaca as a Reweighting Estimator." Unpublished.

34. Kline, Patrick and Andres Santos. 2010. "A Score Based Approach to the Wild Bootstrap." Unpublished.

35. Moretti. 2010a. "Real Wage Inequality."Unpublished.

36. Moretti. 2010b. "Local Labor Markets." Handbook of Labor Economics Vol. IV In press.

37. Neumark, David and Jed Kolko. 2010. "Do Enterprise Zones Create Jobs? Evidence from California's Enterprise Zone Program." Journal of Urban Economics In press.

38. Nichols, Albert and Richard Zeckhauser. 1982. "Targeting Transfers Through Restrictions on Recipients." American Economic Review 72(2):372-377.

39. Notowidigdo, Matthew. 2010. "The Incidence of Local Labor Demand Shocks." Unpublished.

40. Papke, Leslie. 1993. "What Do We Know About Enterprise Zones?" NBER Working Paper \#4251.

41. Papke, Leslie. 1994. "Tax Policy and Urban Development: Evidence from the Indiana Enterprise Zone Program." Journal of Public Economics 54(1):37-49.

42. Peters, Alan H. and Peter S. Fisher. 2002. State Enterprise Zone Programs: Have They Worked? Kalamazoo, MI: W.E. Upjohn Institute for Employment Research.

43. Roback, Jennifer. 1982. "Wages, Rents, and the Quality of Life." Journal of Political Economy 90(6): 1257-1278.

44. Rosen, Sherwin. 1979. "Wage-Based Indexes of Urban Quality of Life." in Current Issues in Urban Economics eds. Miezkowsi and Strazheim pp.74-104.

45. Wolfe, Heath. 2003. "HUD's Oversight of Empowerment Zone Program: Office of Community Planning and Development Multi-Location Review." Department of Housing and Urban Development, Office of Inspector General. Audit Case \# 2003-CH-0001.

46. Wren, Colin and Jim Taylor. 1999. "Industrial Restructuring and Regional Policy." Oxford Economic Papers 51:487-516. 
TABLE 1: 1990 CHARACTERISTICS OF FIRST ROUND EMPOWERMENT ZONES (EZ)

\begin{tabular}{lcccccc}
\hline \hline City & $\begin{array}{c}\text { Total } \\
\text { Population }\end{array}$ & $\begin{array}{c}\text { Population } \\
\text { Rank }\end{array}$ & $\begin{array}{c}\text { Population in } \\
\text { EZ }\end{array}$ & $\begin{array}{c}\text { Poverty } \\
\text { Rate in EZ }\end{array}$ & $\begin{array}{c}\text { Unemp. Rate in } \\
\text { EZ }\end{array}$ & $\begin{array}{c}\text { EZ Area } \\
\text { (sq. miles) }\end{array}$ \\
\hline Atlanta & 395,337 & 37 & 43,792 & 58 & 20 & 8.1 \\
Baltimore & 736,014 & 13 & 72,725 & 42 & 16 & 7.1 \\
Chicago & $2,783,484$ & 3 & 200,182 & 49 & 28 & 14.3 \\
Detroit & $1,027,974$ & 7 & 106,273 & 47 & 28 & 19.5 \\
New York & $7,320,621$ & 1 & 204,625 & 42 & 18 & 6.3 \\
Philadelphia & $1,594,339$ & 5 & 52,440 & 50 & 23 & 4.3 \\
\hline \hline
\end{tabular}

Source: 1990 Decennial Census and HUD

TABLE 2: TOTAL SPENDING

\begin{tabular}{lccc}
\hline \hline & SSBG & Outside Money & Total \\
\hline Total (in million \$): & 386 & 2,848 & 3,234 \\
\hline $\begin{array}{l}\text { Expenditure by category } \\
\text { (in million dollars): }\end{array}$ & & & \\
Access to Capital & 83 & 1,483 & 1,566 \\
Business Assistance & 56 & 482 & 538 \\
Workforce Development & 48 & 49 & 97 \\
Social Improvement & 76 & 163 & 240 \\
Public Safety & 18 & 255 & 272 \\
Physical Development & 14 & 82 & 97 \\
Housing & 71 & 326 & 397 \\
Capacity Improvement & 20 & 7 & 27 \\
\hline Average annual expenditure (in \$): & & & \\
Access to Capital per firm & & & 20,881 \\
Business Assistance per firm & & & 7,172 \\
Workforce Development per unemployed & & 261 \\
Social Improvement per housing unit & & 591,295 \\
Public Safety per person & & & \\
Physical Development per poor person & & \\
Housing per housing unit & & & \\
Capacity Improvement per EZ & & & \\
\hline \hline Source: HUD PERMS data Brashar & & \\
\hline
\end{tabular}

Source: HUD PERMS data, Brashares (2000), and Decennial Census 
TABLE 3: SAMPLE CHARACTERISTICS (1990)

\begin{tabular}{|c|c|c|c|c|c|}
\hline & \multicolumn{2}{|c|}{ Untrimmed } & \multicolumn{3}{|c|}{ Trimmed } \\
\hline & \multirow{3}{*}{$\begin{array}{c}\text { EZ's } \\
{[1]}\end{array}$} & \multirow{3}{*}{$\begin{array}{c}\text { Rejected/ } \\
\text { Future Zones } \\
\text { [2] }\end{array}$} & \multirow{3}{*}{$\begin{array}{c}\text { EZ's } \\
{[3]}\end{array}$} & \multirow{3}{*}{$\begin{array}{c}\text { Rejected/ } \\
\text { Future Zones } \\
{[4]}\end{array}$} & \multirow{3}{*}{$\begin{array}{c}\text { Rejected/ } \\
\text { Future Zones } \\
\text { Reweighted } \\
{[5]}\end{array}$} \\
\hline & & & & & \\
\hline & & & & & \\
\hline \multicolumn{6}{|l|}{ Mean (census tracts) } \\
\hline Log(Jobs) -- LBD & 5.742 & 6.265 & 5.751 & 6.188 & 5.952 \\
\hline Log(Establishments) --LBD & 3.058 & 3.479 & 3.062 & 3.399 & 3.157 \\
\hline Log(Earnings Per Worker) --LBD & 9.791 & 9.774 & 9.788 & 9.770 & 9.749 \\
\hline Log(Jobs) -- JTW & 6.577 & 6.966 & 6.578 & 6.911 & 6.793 \\
\hline Log(Hourly Wage) -- JTW & 2.037 & 1.943 & 2.036 & 1.948 & 1.965 \\
\hline Employment Rate & 0.366 & 0.438 & 0.365 & 0.429 & 0.379 \\
\hline Unemployment Rate & 0.241 & 0.182 & 0.241 & 0.190 & 0.216 \\
\hline Poverty Rate & 0.480 & 0.424 & 0.481 & 0.431 & 0.461 \\
\hline Log(Population) & 7.773 & 7.887 & 7.771 & 7.891 & 7.860 \\
\hline Prop. Black & 0.739 & 0.610 & 0.739 & 0.649 & 0.747 \\
\hline Prop. Latino & 0.180 & 0.163 & 0.179 & 0.176 & 0.176 \\
\hline Prop. College & 0.067 & 0.077 & 0.067 & 0.072 & 0.059 \\
\hline Prop. High school dropouts & 0.316 & 0.275 & 0.317 & 0.284 & 0.311 \\
\hline Prop pop. age $65+$ & 0.126 & 0.119 & 0.126 & 0.118 & 0.126 \\
\hline Prop. pop. age $<18$ & 0.306 & 0.310 & 0.306 & 0.312 & 0.310 \\
\hline Prop. of HHs with public assistance & 0.370 & 0.277 & 0.371 & 0.289 & 0.329 \\
\hline Prop. female-headed $\mathrm{HH}$ & 0.567 & 0.516 & 0.567 & 0.527 & 0.572 \\
\hline Prop. Workers Travel less $20 \mathrm{~min}$ & 0.123 & 0.208 & 0.123 & 0.197 & 0.164 \\
\hline $\log ($ Rent $)$ & 5.350 & 5.370 & 5.349 & 5.371 & 5.319 \\
\hline Log(House Value $)$ & 10.490 & 10.566 & 10.490 & 10.560 & 10.351 \\
\hline Prop. Vacant Houses & 0.166 & 0.143 & 0.167 & 0.141 & 0.145 \\
\hline Prop. In same house & 0.573 & 0.509 & 0.572 & 0.523 & 0.560 \\
\hline Log (Zone Jobs Held by Zone Residents) & 4.715 & 5.271 & 4.720 & 5.279 & 5.255 \\
\hline Log (Zone Jobs Held by Non-Residents) & 6.382 & 6.703 & 6.382 & 6.629 & 6.466 \\
\hline Log (Non-Zone Jobs Held by Zone Residents) & 6.068 & 6.176 & 6.063 & 6.143 & 5.938 \\
\hline Log (Hourly Wage of Zone Residents Working in Zone) & 1.983 & 1.962 & 1.982 & 1.974 & 2.021 \\
\hline Log (Hourly Wage of Zone Workers) & 2.330 & 2.255 & 2.330 & 2.268 & 2.305 \\
\hline \multicolumn{6}{|l|}{ Means (city) } \\
\hline Total crime / population* 100 & 0.099 & 0.105 & 0.099 & 0.103 & 0.099 \\
\hline Avg. across tracts $\%$ black & 0.480 & 0.349 & 0.480 & 0.385 & 0.480 \\
\hline Prop. of workers in Manufacture & 0.157 & 0.156 & 0.158 & 0.158 & 0.158 \\
\hline Prop. of workers in city government & 0.065 & 0.046 & 0.065 & 0.050 & 0.065 \\
\hline Log(Population) & 14.508 & 13.031 & 14.509 & 13.113 & 13.205 \\
\hline Observations (number of census tracts) & 234 & 1429 & 232 & 1088 & 1088 \\
\hline
\end{tabular}

Note: Covariates marked JTW are based on the Journey-to-Work component of the Decennial Census. Covariates marked as LBD come from the Longitudinal Business Database. All other tract level covariates come from the Census. City covariates are from the City Databook. Columns [1] and [2] report statistics for the complete (i.e. untrimmed) sample. Columns [3]-[5] report statistics for a sample that has been trimmed based on the estimated propensity score (see Section IV for details.) Columns [1] and [3] show statistics for census tracts inside EZs; columns [2] and [4] for control tracts in rejected or future treated areas (see Table A1 for details); column [5] shows statistics for control areas that have been parametrically reweighted (see Section III for details.) 


\section{TABLE 4: WAGE AND JOBS IMPACTS (Longitudinal Business Database -LBD-)}

\begin{tabular}{|c|c|c|c|}
\hline Sample & & & \\
\hline Model & Naïve & OLS & PW \\
\hline All firms & {$[1]$} & [2] & [3] \\
\hline \multirow[t]{2}{*}{ Log (Jobs) } & 0.102 & 0.131 & 0.147 \\
\hline & {$[0.067]^{*}$} & {$[0.057]^{*}$} & {$[0.045]^{*}$} \\
\hline \multirow[t]{2}{*}{ Log (Establishments) } & 0.019 & 0.030 & 0.029 \\
\hline & {$[0.029]$} & {$[0.024]$} & {$[0.018]$} \\
\hline \multirow[t]{2}{*}{ Log (Average Earnings per Worker) } & 0.038 & 0.030 & 0.008 \\
\hline & {$[0.028]$} & {$[0.033]$} & {$[0.014]$} \\
\hline \multicolumn{4}{|l|}{ All firms present in 1992} \\
\hline \multirow[t]{2}{*}{ Log (Jobs) } & 0.021 & 0.055 & 0.079 \\
\hline & {$[0.049]$} & {$[0.055]$} & [0.029] \\
\hline \multirow[t]{2}{*}{ Log (Establishments) } & -0.057 & -0.033 & -0.040 \\
\hline & {$[0.032]$} & {$[0.029]$} & [0.019] \\
\hline \multirow[t]{2}{*}{ Log (Average Earnings per Worker) } & 0.041 & 0.039 & 0.032 \\
\hline & [0.031] & {$[0.030]$} & [0.018] \\
\hline \multicolumn{4}{|l|}{$<5$ Employees } \\
\hline \multirow[t]{2}{*}{ Log (Jobs) } & -0.140 & -0.068 & -0.048 \\
\hline & {$[0.114]$} & {$[0.103]$} & {$[0.056]$} \\
\hline \multirow[t]{2}{*}{ Log (Establishments) } & -0.084 & -0.054 & -0.056 \\
\hline & {$[0.072]$} & {$[0.060]$} & {$[0.034]$} \\
\hline \multirow[t]{2}{*}{ Log (Average Earnings per Worker) } & 0.034 & 0.057 & 0.043 \\
\hline & {$[0.030]$} & [0.044] & {$[0.027]$} \\
\hline \multicolumn{4}{|l|}{$\geq 5$ Employees } \\
\hline \multirow[t]{2}{*}{ Log (Jobs) } & 0.058 & 0.086 & 0.110 \\
\hline & {$[0.072]$} & {$[0.069]$} & {$[0.041]$} \\
\hline \multirow[t]{2}{*}{ Log (Establishments) } & 0.002 & 0.008 & 0.012 \\
\hline & {$[0.020]$} & {$[0.022]$} & {$[0.011]$} \\
\hline \multirow[t]{2}{*}{ Log (Average Earnings per Worker) } & 0.022 & 0.014 & 0.008 \\
\hline & {$[0.028]$} & {$[0.025]$} & [0.016] \\
\hline
\end{tabular}

Note: Each entry gives the 1992-2000 differences-in-differences (DD) estimate of EZ designation on the outcome presented in each row. All figures computed from trimmed estimation sample (see Section IV.) Column [1] reports DD estimate without controls; [2] reports the OLS DD estimate controlling for lagged city and tract level characteristics; [3] reports parametric reweighting DD estimates. See Appendix II.G for list of covariates. Standard errors are shown in square brackets and are clustered by city (64 clusters.) Stars reflect significance level obtained by a clustered wild bootstrap-t procedure described in the appendix. Legend: * significant at 10\% level; ** significant at $5 \%$ level; *** significant at $1 \%$ level. See the Appendix and Section III for details. 
TABLE 5: EMPLOYMENT IMPACTS (Census, Journey-to-Work -JTW-)

\begin{tabular}{lccc}
\hline \hline Sample & \multicolumn{3}{c}{} \\
\cline { 2 - 4 } Model & Naïve & OLS & PW \\
\cline { 2 - 5 } & {$[1]$} & {$[2]$} & {$[3]$} \\
Log (Jobs) & 0.188 & 0.19 & 0.177 \\
& {$[0.100]$} & {$[0.078]^{* *}$} & {$[0.070]^{* *}$} \\
By place of residence and place of work & & & \\
\hline Log (Zone Jobs Held by Zone Residents) & 0.175 & 0.149 & 0.159 \\
& {$[0.111]$} & {$[0.077]^{*}$} & {$[0.064]$} \\
Log (Zone Jobs Held by Non-Residents) & 0.158 & 0.143 & 0.127 \\
& {$[0.083]^{*}$} & {$[0.060]^{*}$} & {$[0.056]^{* *}$} \\
Log (Non-Zone Jobs Held by Zone Residents) & 0.059 & 0.069 & 0.059 \\
& {$[0.074]$} & {$[0.070]$} & {$[0.055]$} \\
\hline \hline
\end{tabular}

Note: Each entry gives the 1990-2000 differences-in-differences (DD) estimate of EZ designation on the outcome presented in each row. All figures computed from trimmed estimation sample (see Section IV.) Column [1] reports DD estimate without controls; [2] reports the OLS DD estimate controlling for lagged city and tract level characteristics; [3] reports parametric reweighting DD estimates. See Appendix II.G for list of covariates. Standard errors are shown in square brackets and are clustered by city (64 clusters.) Stars reflect significance level obtained by a clustered wild bootstrapt procedure described in the appendix. Legend: * significant at 10\% level; ** significant at $5 \%$ level; *** significant at 1\% level. See the Appendix and Section III for details. 
TABLE 6: WAGE IMPACTS

(Census, Journey-to-Work -JTW-)

\begin{tabular}{|c|c|c|c|c|c|c|c|c|c|}
\hline$\frac{\text { Sample }}{\text { Model }}$ & \multicolumn{3}{|c|}{ Unadjusted } & \multicolumn{3}{|c|}{ Composition-adjusted } & \multicolumn{3}{|c|}{ Composition Effect } \\
\hline Model & $\begin{array}{c}\text { Naïve } \\
{[1]}\end{array}$ & $\begin{array}{c}\text { OLS } \\
{[2]} \\
\end{array}$ & $\begin{array}{r}\mathrm{PW} \\
{[3]} \\
\end{array}$ & $\begin{array}{c}\text { Naïve } \\
{[4]}\end{array}$ & $\begin{array}{c}\text { OLS } \\
{[5]} \\
\end{array}$ & $\begin{array}{r}\mathrm{PW} \\
{[6]} \\
\end{array}$ & $\begin{array}{c}\text { Naïve } \\
{[7]}\end{array}$ & $\begin{array}{c}\text { OLS } \\
{[8]}\end{array}$ & $\begin{array}{c}\text { PW } \\
{[9]} \\
\end{array}$ \\
\hline Log (Hourly Wage of Zone Residents) & $\begin{array}{r}0.034 \\
{[0.036]}\end{array}$ & $\begin{array}{c}0.046 \\
{[0.024]^{*}}\end{array}$ & $\begin{array}{r}0.036 \\
{[0.017]}\end{array}$ & $\begin{array}{r}0.031 \\
{[0.035]}\end{array}$ & $\begin{array}{c}0.049 \\
{[0.024]^{*}}\end{array}$ & $\begin{array}{r}0.040 \\
{[0.017]}\end{array}$ & $\begin{array}{r}0.003 \\
{[0.006]}\end{array}$ & $\begin{array}{c}-0.002 \\
{[0.005]}\end{array}$ & $\begin{array}{r}-0.004 \\
{[0.004]}\end{array}$ \\
\hline Log (Hourly Wage of Zone Workers) & $\begin{array}{c}-0.002 \\
{[0.021]}\end{array}$ & $\begin{array}{r}0.022 \\
{[0.024]}\end{array}$ & $\begin{array}{r}0.023 \\
{[0.015]}\end{array}$ & $\begin{array}{r}0.009 \\
{[0.021]}\end{array}$ & $\begin{array}{r}0.029 \\
{[0.021]}\end{array}$ & $\begin{array}{r}0.031 \\
{[0.013]}\end{array}$ & $\begin{array}{c}-0.012 \\
{[0.008]}\end{array}$ & $\begin{array}{c}-0.007 \\
{[0.008]}\end{array}$ & $\begin{array}{r}-0.009 \\
{[0.003]}\end{array}$ \\
\hline By place of residence and place of work & & & & & & & & & \\
\hline Log (Hourly Wage of Zone Residents Working in Zone) & $\begin{array}{c}0.092 \\
{[0.051]^{*}}\end{array}$ & $\begin{array}{c}0.138 \\
{[0.068]^{* *}}\end{array}$ & $\begin{array}{c}0.121 \\
{[0.047]^{* *}}\end{array}$ & $\begin{array}{r}0.053 \\
{[0.034]}\end{array}$ & $\begin{array}{c}0.084 \\
{[0.039]^{* * *}}\end{array}$ & $\begin{array}{c}0.078 \\
{[0.033]^{*}}\end{array}$ & $\begin{array}{r}0.039 \\
{[0.026]}\end{array}$ & $\begin{array}{c}0.054 \\
{[0.033]^{* *}}\end{array}$ & $\begin{array}{r}0.043 \\
{[0.019]^{*}}\end{array}$ \\
\hline Log (Hourly Wage of Non-Residents Working in Zone) & $\begin{array}{r}-0.011 \\
{[0.022]}\end{array}$ & $\begin{array}{r}0.008 \\
{[0.024]}\end{array}$ & $\begin{array}{r}0.017 \\
{[0.014]}\end{array}$ & $\begin{array}{r}0.008 \\
{[0.018]}\end{array}$ & $\begin{array}{r}0.025 \\
{[0.021]}\end{array}$ & $\begin{array}{r}0.033 \\
{[0.013]}\end{array}$ & $\begin{array}{c}-0.019 \\
{[0.010]^{*}}\end{array}$ & $\begin{array}{c}-0.017 \\
{[0.009]}\end{array}$ & $\begin{array}{r}-0.016 \\
{[0.005]}\end{array}$ \\
\hline Log (Hourly Wage of Zone Residents Working Outside Zone) & $\begin{array}{r}0.028 \\
{[0.031]}\end{array}$ & $\begin{array}{c}0.068 \\
{[0.033]^{* *}}\end{array}$ & $\begin{array}{c}0.067 \\
{[0.017]^{*}}\end{array}$ & $\begin{array}{r}0.015 \\
{[0.030]}\end{array}$ & $\begin{array}{c}0.058 \\
{[0.029]^{*}}\end{array}$ & $\begin{array}{r}0.056 \\
{[0.016]}\end{array}$ & $\begin{array}{c}0.013 \\
{[0.007]^{*}}\end{array}$ & $\begin{array}{r}0.010 \\
{[0.007]}\end{array}$ & $\begin{array}{r}0.011 \\
{[0.004]}\end{array}$ \\
\hline
\end{tabular}

Note: Each entry gives the 1990-2000 differences-in-differences (DD) estimate of EZ designation on the outcome presented in each row. All figures computed from trimmed estimation sample (see Section IV.) Columns [4]-[6] adjust the outcomes for demographic changes at the micro-level (see Appendix III.) Columns [7]-[9] report the results due to changes in demographic composition. Columns labeled "Naive" report a DD estimate without controls. Columns labeled "OLS" report the OLS DD estimate controlling for lagged city and tract level characteristics. Columns labeled "PW" report parametric reweighting DD estimates. See Appendix II.G for list of covariates. Standard errors are shown in square brackets and are clustered by city (64 clusters.) Stars reflect significance level obtained by a clustered wild bootstrap-t procedure described in the appendix. Legend: * significant at $10 \%$ level; ** significant at $5 \%$ level; *** significant at $1 \%$ level. See the Appendix and Section III for details. 


\section{TABLE 7: IMPACT ON HOUSING MARKET AND POPULATION}

\begin{tabular}{|c|c|c|c|}
\hline Model & $\begin{array}{c}\text { Naïve } \\
{[1]} \\
\end{array}$ & $\begin{array}{c}\text { OLS } \\
{[2]} \\
\end{array}$ & $\begin{array}{r}\text { PW } \\
{[3]} \\
\end{array}$ \\
\hline Housing market impacts & & & \\
\hline Log (Rent) -unadjusted & $\begin{array}{r}0.028 \\
{[0.036]}\end{array}$ & $\begin{array}{r}0.030 \\
{[0.025]}\end{array}$ & $\begin{array}{r}0.031 \\
{[0.022]}\end{array}$ \\
\hline Log (Rent) -adjusted & $\begin{array}{r}0.020 \\
{[0.031]}\end{array}$ & $\begin{array}{r}0.017 \\
{[0.022]}\end{array}$ & $\begin{array}{r}0.021 \\
{[0.021]}\end{array}$ \\
\hline Log (Rent) -comp. & $\begin{array}{r}0.009 \\
{[0.012]}\end{array}$ & $\begin{array}{r}0.012 \\
{[0.010]}\end{array}$ & $\begin{array}{r}0.010 \\
{[0.007]}\end{array}$ \\
\hline Log (House Value) -unadjusted & $\begin{array}{c}0.368 \\
{[0.217]^{*}}\end{array}$ & $\begin{array}{c}0.347 \\
{[0.163]^{* *}}\end{array}$ & $\begin{array}{r}0.350 \\
{[0.136]}\end{array}$ \\
\hline Log (House Value) -adjusted & $\begin{array}{c}0.361 \\
{[0.215]^{*}}\end{array}$ & $\begin{array}{c}0.344 \\
{[0.165]^{* *}}\end{array}$ & $\begin{array}{c}0.345 \\
{[0.136]^{*}}\end{array}$ \\
\hline Log (House Value) -comp. & $\begin{array}{r}0.007 \\
{[0.008]} \\
\end{array}$ & $\begin{array}{r}0.003 \\
{[0.006]} \\
\end{array}$ & $\begin{array}{r}0.004 \\
{[0.004]} \\
\end{array}$ \\
\hline Population/Mobility impacts & & & \\
\hline$\overline{\log \text { (Households) }}$ & $\begin{array}{c}-0.009 \\
{[0.072]}\end{array}$ & $\begin{array}{r}-0.004 \\
{[0.033]}\end{array}$ & $\begin{array}{c}0.009 \\
{[0.030]}\end{array}$ \\
\hline Log (Population) & $\begin{array}{c}0.006 \\
{[0.056]}\end{array}$ & $\begin{array}{c}0.027 \\
{[0.031]}\end{array}$ & $\begin{array}{c}0.038 \\
{[0.028]}\end{array}$ \\
\hline$\%$ Same House as Five Yrs Ago & $\begin{array}{c}-0.001 \\
{[0.009]}\end{array}$ & $\begin{array}{r}-0.001 \\
{[0.010]}\end{array}$ & $\begin{array}{c}0.000 \\
{[0.006]}\end{array}$ \\
\hline$\%$ Vacant Houses & $\begin{array}{r}0.008 \\
{[0.012]}\end{array}$ & $\begin{array}{c}-0.005 \\
{[0.009]}\end{array}$ & $\begin{array}{r}-0.001 \\
{[0.006]}\end{array}$ \\
\hline
\end{tabular}

Note: Each entry gives the 1990-2000 differences-in-differences (DD) estimate of EZ designation on the outcome presented in each row. All figures computed from trimmed estimation sample (see Section IV.) Column [1] reports a DD estimate without controls; [2] reports the OLS DD estimate controlling for lagged city and tract level characteristics. [3] reports parametric reweighting DD estimates. "Adjusted" outcomes controls for demographic changes at the micro-level (see Appendix III.) "Comp." outcomes refer to impact on the outcome due to changes in demographic composition. See Appendix II.G for list of covariates. Standard errors are shown in square brackets and are clustered by city (64 clusters.) Stars reflect significance level obtained by a clustered wild bootstrap- $\mathrm{t}$ procedure described in the appendix. Legend: * significant at $10 \%$ level; ** significant at $5 \%$ level; *** significant at $1 \%$ level. See the Appendix and Section III for details. 
TABLE 8: ROBUSTNESS CHECKS

\begin{tabular}{|c|c|c|c|c|c|c|}
\hline Experiment & & Placebo & & & Percentile & \\
\hline Model & $\begin{array}{c}\text { Naïve } \\
{[1]}\end{array}$ & $\begin{array}{c}\text { OLS } \\
{[2]}\end{array}$ & $\begin{array}{r}\mathrm{PW} \\
{[3]}\end{array}$ & $\begin{array}{c}\text { Naïve } \\
{[4]}\end{array}$ & $\begin{array}{c}\text { OLS } \\
{[5]}\end{array}$ & $\begin{array}{c}\mathrm{PW} \\
{[6]}\end{array}$ \\
\hline Log (Jobs) -LBD & $\begin{array}{l}-0.036 \\
{[0.068]}\end{array}$ & $\begin{array}{l}-0.116 \\
{[0.096]}\end{array}$ & $\begin{array}{l}-0.122 \\
{[0.058]}\end{array}$ & $\begin{array}{c}0.022 \\
{[0.012]^{*}}\end{array}$ & $\begin{array}{c}0.020 \\
{[0.008]^{* *}}\end{array}$ & $\begin{array}{c}0.019 \\
{[0.008]^{* *}}\end{array}$ \\
\hline Log (Jobs) -JTW & $\begin{array}{c}0.184 \\
{[0.124]}\end{array}$ & $\begin{array}{c}0.145 \\
{[0.104]}\end{array}$ & $\begin{array}{c}0.134 \\
{[0.079]}\end{array}$ & $\begin{array}{c}0.036 \\
{[0.018]^{*}}\end{array}$ & $\begin{array}{c}0.039 \\
{[0.018]^{* *}}\end{array}$ & $\begin{array}{c}0.037 \\
{[0.012]^{* * *}}\end{array}$ \\
\hline Log (Average Earnings per Worker) & $\begin{array}{c}-0.014 \\
{[0.019]}\end{array}$ & $\begin{array}{l}-0.009 \\
{[0.016]}\end{array}$ & $\begin{array}{c}0.003 \\
{[0.008]}\end{array}$ & $\begin{array}{r}0.048 \\
{[0.028]}\end{array}$ & $\begin{array}{r}0.033 \\
{[0.028]}\end{array}$ & $\begin{array}{r}0.019 \\
{[0.014]}\end{array}$ \\
\hline Log (Hourly Wage of Zone Residents) & $\begin{array}{c}0.004 \\
{[0.020]}\end{array}$ & $\begin{array}{c}0.009 \\
{[0.012]}\end{array}$ & $\begin{array}{c}0.011 \\
{[0.018]}\end{array}$ & $\begin{array}{r}0.038 \\
{[0.022]}\end{array}$ & $\begin{array}{r}0.018 \\
{[0.018]}\end{array}$ & $\begin{array}{r}0.010 \\
{[0.011]}\end{array}$ \\
\hline Log (Establishments) & $\begin{array}{l}-0.010 \\
{[0.029]}\end{array}$ & $\begin{array}{c}0.000 \\
{[0.035]}\end{array}$ & $\begin{array}{l}-0.002 \\
{[0.025]}\end{array}$ & $\begin{array}{r}0.007 \\
{[0.007]}\end{array}$ & $\begin{array}{r}0.000 \\
{[0.005]}\end{array}$ & $\begin{array}{c}-0.002 \\
{[0.004]}\end{array}$ \\
\hline Log (Rent) -unadjusted & $\begin{array}{r}0.014 \\
{[0.041]}\end{array}$ & $\begin{array}{c}-0.009 \\
{[0.024]}\end{array}$ & $\begin{array}{c}-0.020 \\
{[0.013]}\end{array}$ & $\begin{array}{c}0.024 \\
{[0.013]^{*}}\end{array}$ & $\begin{array}{r}0.012 \\
{[0.009]}\end{array}$ & $\begin{array}{r}0.013 \\
{[0.008]}\end{array}$ \\
\hline Log (House Value) -unadjusted & $\begin{array}{r}0.152 \\
{[0.104]}\end{array}$ & $\begin{array}{r}0.023 \\
{[0.045]}\end{array}$ & $\begin{array}{r}0.026 \\
{[0.050]}\end{array}$ & $\begin{array}{c}0.099 \\
{[0.072]^{*}}\end{array}$ & $\begin{array}{c}0.102 \\
{[0.055]^{* *}}\end{array}$ & $\begin{array}{r}0.102 \\
{[0.045]}\end{array}$ \\
\hline Log (Households) & $\begin{array}{r}0.005 \\
{[0.066]}\end{array}$ & $\begin{array}{r}-0.034 \\
{[0.045]}\end{array}$ & $\begin{array}{r}-0.036 \\
{[0.033]}\end{array}$ & $\begin{array}{c}-0.009 \\
{[0.071]}\end{array}$ & $\begin{array}{l}-0.004 \\
{[0.033]}\end{array}$ & $\begin{array}{c}0.009 \\
{[0.029]}\end{array}$ \\
\hline Log (Population) & $\begin{array}{r}0.002 \\
{[0.070]}\end{array}$ & $\begin{array}{r}-0.026 \\
{[0.045]}\end{array}$ & $\begin{array}{r}-0.030 \\
{[0.030]}\end{array}$ & $\begin{array}{l}-0.005 \\
{[0.013]}\end{array}$ & $\begin{array}{l}-0.007 \\
{[0.007]}\end{array}$ & $\begin{array}{l}-0.005 \\
{[0.006]}\end{array}$ \\
\hline$\%$ Same House as Five Yrs Ago & $\begin{array}{c}0.021 \\
{[0.013]^{*}}\end{array}$ & $\begin{array}{c}0.030 \\
{[0.015]^{* *}}\end{array}$ & $\begin{array}{c}0.033 \\
{[0.012]^{* *}}\end{array}$ & $\begin{array}{c}0.030 \\
{[0.022]}\end{array}$ & $\begin{array}{c}0.021 \\
{[0.027]}\end{array}$ & $\begin{array}{c}0.029 \\
{[0.014]}\end{array}$ \\
\hline$\%$ Vacant Houses & $\begin{array}{r}0.011 \\
{[0.014]}\end{array}$ & $\begin{array}{r}0.018 \\
{[0.016]}\end{array}$ & $\begin{array}{r}0.016 \\
{[0.010]}\end{array}$ & $\begin{array}{c}-0.033 \\
{[0.029]}\end{array}$ & $\begin{array}{r}-0.057 \\
{[0.029]^{*}}\end{array}$ & $\begin{array}{r}-0.046 \\
{[0.020]}\end{array}$ \\
\hline
\end{tabular}

Note: Outcomes marked JTW are based on the Journey-to-Work component of the Decennial Census. Outcomes marked as LBD come from the Longitudinal Business Database and are analyzed over the period 1992-2000, all other outcomes come from the Census and are analyzed over the period 1990-2000. All figures computed from trimmed estimation sample (see Section IV.) Columns [1]-[3] give differences-in-differences (DD) estimates on a sample of untreated placebo tracts chosen by nearest neighbor matching. Columns [4]-[6] give DD impacts on percentile ranks of outcomes (see Section VI) in trimmed sample. Columns labeled "Naive" report a DD estimate without controls. Columns labeled "OLS" report the OLS DD estimate controlling for lagged city and tract level characteristics. Columns labeled "PW" report parametric reweighting DD estimates. See Appendix II.G for list of covariates. Standard errors are shown in square brackets and are clustered by city (64 clusters). Stars reflect significance level obtained by a clustered wild bootstrap-t procedure

described in the appendix. Legend: * significant at $10 \%$ level; ** significant at $5 \%$ level; *** significant at $1 \%$ level. See the Appendix and Section III for details. 
TABLE 9: ROBUSTNESS CHECKS (SAMPLES)

\begin{tabular}{|c|c|c|c|c|c|c|c|c|c|}
\hline \multirow{2}{*}{$\frac{\text { Sample }}{\text { Model }}$} & \multicolumn{3}{|c|}{ Rejected } & \multicolumn{3}{|c|}{ No New York } & \multicolumn{3}{|c|}{ with SEZs } \\
\hline & Naïve & OLS & PW & Naïve & OLS & PW & Naïve & OLS & PW \\
\hline & [1] & [2] & [3] & [4] & [5] & [6] & [7] & [8] & [9] \\
\hline \multirow[t]{2}{*}{ Log (Jobs) -LBD } & 0.117 & 0.124 & 0.093 & 0.052 & 0.080 & 0.065 & 0.122 & 0.138 & 0.153 \\
\hline & {$[0.070]^{*}$} & {$[0.068]^{*}$} & {$[0.030]$} & {$[0.042]$} & {$[0.042]^{*}$} & {$[0.030]$} & {$[0.056]^{*}$} & {$[0.047]^{* *}$} & {$[0.040]^{* *}$} \\
\hline \multirow[t]{2}{*}{ Log (Jobs) -JTW } & 0.227 & 0.240 & 0.191 & 0.211 & 0.202 & 0.213 & 0.190 & 0.193 & 0.175 \\
\hline & {$[0.119]^{*}$} & {$[0.110]$} & {$[0.070]^{* *}$} & {$[0.119]$} & {$[0.079]^{* *}$} & {$[0.078]^{*}$} & {$[0.082]^{*}$} & {$[0.070]^{* * *}$} & {$[0.054]^{* *}$} \\
\hline \multirow[t]{2}{*}{ Log (Zone Jobs Held by Zone Residents) } & 0.206 & 0.172 & 0.199 & 0.143 & 0.112 & 0.147 & 0.138 & 0.120 & 0.132 \\
\hline & {$[0.115]^{*}$} & {$[0.084]$} & {$[0.053]^{* *}$} & {$[0.120]$} & {$[0.087]$} & {$[0.067]$} & {$[0.094]$} & {$[0.068]$} & {$[0.055]$} \\
\hline \multirow[t]{2}{*}{ Log (Zone Jobs Held by Non-Residents) } & 0.208 & 0.209 & 0.158 & 0.167 & 0.150 & 0.148 & 0.172 & 0.170 & 0.146 \\
\hline & {$[0.106]^{*}$} & {$[0.107]$} & {$[0.060]^{*}$} & {$[0.089]$} & {$[0.062]^{*}$} & {$[0.060]^{* *}$} & {$[0.067]^{*}$} & {$[0.061]^{* * *}$} & {$[0.047]^{* *}$} \\
\hline \multirow[t]{2}{*}{ Log (Non-Zone Jobs Held by Zone Residents) } & 0.093 & 0.147 & 0.156 & 0.053 & 0.047 & 0.048 & 0.073 & 0.094 & 0.094 \\
\hline & {$[0.073]$} & {$[0.068]^{* *}$} & {$[0.052]^{* *}$} & {$[0.094]$} & {$[0.069]$} & {$[0.055]$} & {$[0.062]$} & {$[0.061]$} & {$[0.045]$} \\
\hline \multirow[t]{2}{*}{ Log (Average Earnings per Worker) } & 0.028 & 0.029 & 0.017 & 0.037 & 0.042 & 0.031 & 0.011 & 0.022 & 0.003 \\
\hline & {$[0.019]$} & {$[0.022]$} & {$[0.007]$} & {$[0.038]$} & {$[0.038]$} & {$[0.019]$} & {$[0.026]$} & {$[0.026]$} & {$[0.013]$} \\
\hline \multirow[t]{2}{*}{ Log (Hourly Wage of Zone Workers) } & -0.002 & 0.014 & 0.028 & 0.002 & 0.018 & 0.019 & -0.011 & 0.022 & 0.026 \\
\hline & {$[0.032]$} & {$[0.019]$} & {$[0.016]$} & {$[0.028]$} & {$[0.027]$} & {$[0.019]$} & {$[0.018]$} & {$[0.018]$} & {$[0.011]$} \\
\hline \multirow[t]{2}{*}{ Log (Hourly Wage of Zone Residents) -unadjusted } & 0.057 & 0.086 & 0.062 & 0.051 & 0.060 & 0.058 & 0.014 & 0.039 & 0.030 \\
\hline & {$[0.046]$} & {$[0.038]^{*}$} & {$[0.026]$} & {$[0.035]$} & {$[0.028]^{* *}$} & {$[0.023]$} & {$[0.030]$} & {$[0.021]^{*}$} & {$[0.017]$} \\
\hline \multirow[t]{2}{*}{ Log (Hourly Wage of Zone Residents) -adjusted } & 0.048 & 0.071 & 0.049 & 0.049 & 0.057 & 0.053 & 0.017 & 0.041 & 0.033 \\
\hline & {$[0.039]$} & {$[0.035]^{*}$} & {$[0.021]$} & {$[0.036]$} & {$[0.029]^{*}$} & {$[0.021]$} & {$[0.028]$} & {$[0.022]^{*}$} & {$[0.017]$} \\
\hline \multirow[t]{2}{*}{ Log (Hourly Wage of Zone Residents) -comp. } & 0.008 & 0.015 & 0.013 & 0.002 & 0.003 & 0.006 & -0.003 & -0.002 & -0.003 \\
\hline & {$[0.007]$} & {$[0.006]^{* *}$} & {$[0.004]^{*}$} & {$[0.006]$} & {$[0.005]$} & {$[0.004]$} & {$[0.006]$} & {$[0.004]$} & {$[0.003]$} \\
\hline \multirow[t]{2}{*}{ Log (Hourly Wage of Zone Residents Working in Zone) } & 0.054 & 0.157 & 0.145 & 0.090 & 0.146 & 0.136 & 0.071 & 0.118 & 0.115 \\
\hline & {$[0.035]^{*}$} & {$[0.068]^{* *}$} & {$[0.046]^{* *}$} & {$[0.053]$} & {$[0.074]^{* * *}$} & {$[0.053]^{* *}$} & {$[0.041]^{*}$} & {$[0.046]^{* * *}$} & {$[0.038]^{* * *}$} \\
\hline \multirow[t]{2}{*}{ Log (Hourly Wage of Non-Residents Working in Zone) } & -0.010 & -0.011 & 0.012 & -0.008 & -0.001 & 0.007 & -0.019 & 0.009 & 0.019 \\
\hline & {$[0.030]$} & {$[0.020]$} & {$[0.014]$} & {$[0.028]$} & {$[0.026]$} & {$[0.018]$} & {$[0.018]$} & {$[0.021]$} & {$[0.011]$} \\
\hline \multirow[t]{2}{*}{ Log (Hourly Wage of Zone Residents Working Outside Zone) } & 0.058 & 0.080 & 0.069 & 0.046 & 0.071 & 0.074 & 0.012 & 0.059 & 0.058 \\
\hline & {$[0.043]$} & {$[0.030]^{* *}$} & {$[0.020]^{* *}$} & {$[0.032]$} & {$[0.036]^{*}$} & {$[0.022]$} & {$[0.026]$} & {$[0.026]^{* *}$} & {$[0.015]^{*}$} \\
\hline \multirow[t]{2}{*}{ Log (Establishments) } & 0.025 & 0.029 & -0.006 & -0.001 & 0.015 & 0.014 & 0.050 & 0.052 & 0.043 \\
\hline & {$[0.028]$} & {$[0.036]$} & {$[0.024]$} & {$[0.026]$} & {$[0.024]$} & {$[0.017]$} & {$[0.032]^{*}$} & {$[0.027]^{*}$} & {$[0.018]$} \\
\hline \multirow[t]{2}{*}{ Log (Rent) -unadjusted } & 0.029 & 0.041 & 0.058 & 0.021 & 0.011 & 0.014 & 0.005 & 0.024 & 0.032 \\
\hline & {$[0.031]$} & {$[0.026]$} & {$[0.014]^{* *}$} & {$[0.041]$} & {$[0.024]$} & {$[0.020]$} & {$[0.040]$} & {$[0.023]$} & {$[0.022]$} \\
\hline Log (Rent) -adjusted & 0.023 & 0.031 & 0.050 & 0.007 & -0.003 & 0.000 & 0.001 & 0.017 & 0.027 \\
\hline & {$[0.026]$} & {$[0.029]$} & {$[0.015]^{*}$} & {$[0.036]$} & {$[0.019]$} & {$[0.019]$} & {$[0.036]$} & {$[0.022]$} & {$[0.021]$} \\
\hline Log (Rent) -comp. & 0.006 & 0.010 & 0.009 & 0.014 & 0.014 & 0.014 & 0.004 & 0.007 & 0.006 \\
\hline & {$[0.013]$} & {$[0.006]$} & {$[0.004]$} & {$[0.014]$} & {$[0.011]$} & {$[0.008]$} & {$[0.010]$} & {$[0.008]$} & {$[0.006]$} \\
\hline Log (House Value) -unadjusted & 0.413 & 0.475 & 0.445 & 0.380 & 0.316 & 0.324 & 0.344 & 0.341 & 0.354 \\
\hline & {$[0.287]$} & {$[0.185]^{* *}$} & {$[0.153]^{* *}$} & {$[0.238]$} & {$[0.180]^{*}$} & {$[0.155]$} & {$[0.171]^{*}$} & {$[0.128]^{* * *}$} & {$[0.104]^{* *}$} \\
\hline Log (House Value) -adjusted & 0.411 & 0.473 & 0.439 & 0.372 & 0.306 & 0.311 & 0.338 & 0.343 & 0.353 \\
\hline & {$[0.289]$} & {$[0.187]^{* *}$} & {$[0.151]^{* *}$} & {$[0.232]$} & {$[0.179]^{*}$} & {$[0.151]$} & {$[0.166]^{*}$} & {$[0.133]^{* * *}$} & {$[0.108]^{* *}$} \\
\hline Log (House Value) -comp. & 0.002 & 0.003 & 0.006 & 0.008 & 0.010 & 0.013 & 0.006 & -0.002 & 0.000 \\
\hline & {$[0.009]$} & {$[0.011]$} & {$[0.006]$} & {$[0.008]$} & {$[0.006]$} & {$[0.005]^{*}$} & {$[0.009]$} & {$[0.006]$} & {$[0.005]$} \\
\hline Log (Households) & 0.072 & 0.045 & 0.074 & -0.065 & -0.042 & -0.053 & 0.026 & 0.017 & 0.025 \\
\hline & {$[0.070]$} & {$[0.030]$} & {$[0.022]$} & {$[0.053]$} & {$[0.031]$} & {$[0.024]$} & {$[0.060]$} & {$[0.029]$} & {$[0.026]$} \\
\hline Log (Population) & 0.057 & 0.041 & 0.052 & -0.027 & -0.005 & -0.011 & 0.027 & 0.033 & 0.042 \\
\hline & {$[0.063]$} & {$[0.033]$} & {$[0.015]$} & {$[0.024]$} & {$[0.029]$} & {$[0.017]$} & {$[0.048]$} & {$[0.027]$} & {$[0.023]$} \\
\hline$\%$ Same House as Five Yrs Ago & -0.006 & 0.014 & 0.016 & -0.001 & 0.004 & 0.004 & -0.003 & -0.001 & 0.000 \\
\hline & {$[0.011]$} & {$[0.008]$} & {$[0.006]$} & {$[0.012]$} & {$[0.011]$} & {$[0.007]$} & {$[0.010]$} & {$[0.008]$} & {$[0.005]$} \\
\hline$\%$ Vacant Houses & 0.004 & -0.004 & 0.005 & 0.000 & -0.012 & -0.009 & 0.016 & 0.003 & 0.007 \\
\hline & [0.011] & {$[0.010]$} & [0.007] & [0.015] & {$[0.013]$} & [0.010] & [0.012] & [0.008] & {$[0.007]$} \\
\hline
\end{tabular}

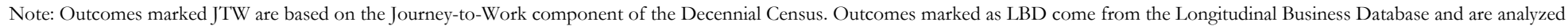

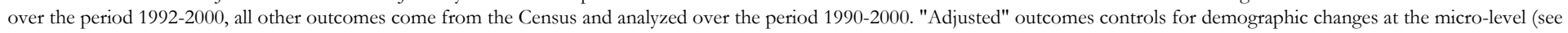

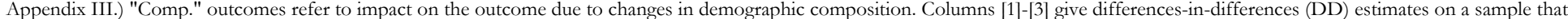

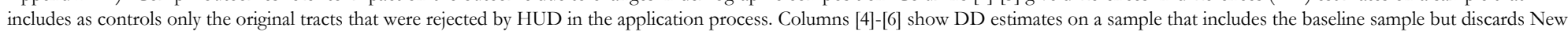

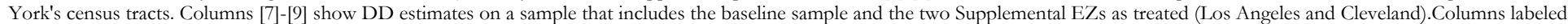

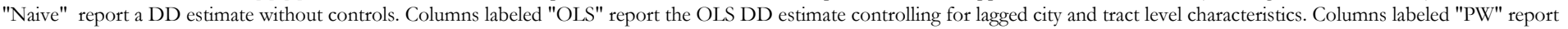

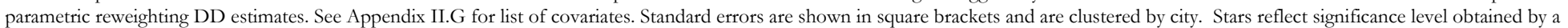

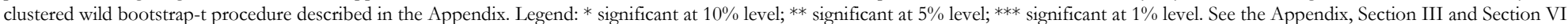
for details. 
TABLE 10: WELFARE ANALYSIS

\begin{tabular}{|c|c|c|c|c|c|c|c|c|}
\hline & \multicolumn{2}{|c|}{ Baseline Numbers } & \multicolumn{2}{|c|}{ Scenario 1} & \multicolumn{2}{|c|}{ Scenario 2} & \multicolumn{2}{|c|}{ Scenario 3} \\
\hline & & $\begin{array}{c}\text { Total payroll/ } \\
\text { rents/housing } \\
\text { value } \\
\text { (in billion } \$ \text { ) }\end{array}$ & $\begin{array}{l}\text { Average } \\
\text { impact of the } \\
\text { program }\end{array}$ & $\begin{array}{l}\text { Increase in annual } \\
\text { payroll / rents / } \\
\text { housing value } \\
\text { (in million \$) }\end{array}$ & $\begin{array}{l}\text { Average } \\
\text { impact of the } \\
\text { program }\end{array}$ & $\begin{array}{l}\text { Increase in annual } \\
\text { payroll / rents/ } \\
\text { housing value } \\
\text { (in million \$) }\end{array}$ & $\begin{array}{l}\text { Average } \\
\text { impact of the } \\
\text { program }\end{array}$ & $\begin{array}{l}\text { Increase in annual } \\
\text { payroll / rents / } \\
\text { housing value } \\
\text { (in million \$) }\end{array}$ \\
\hline Zone Residents Working in Zone & 52,000 & 1 & $8.1 \%$ & 81 & $8.1 \%$ & 81 & $8.1 \%$ & 81 \\
\hline Zone Residents Working Outside Zone & 194,000 & 4.2 & $5.7 \%$ & 239 & $5.7 \%$ & 239 & $5.7 \%$ & 239 \\
\hline Non-Residents Working in Zone & 538,000 & 20 & $2.9 \%$ & 580 & $2.9 \%$ & 580 & $0.0 \%$ & 0 \\
\hline Zone Workers & 590,000 & 21 & $3.1 \%$ & 661 & $3.1 \%$ & 661 & $0.4 \%$ & 81 \\
\hline Zone Residents who Work & 246,000 & 5.2 & $6.2 \%$ & 320 & $6.2 \%$ & 320 & $6.2 \%$ & 320 \\
\hline House Renters in the Zone & 243,000 & 1.2 & $1.9 \%$ & 23 & $5.7 \%$ & 68 & $5.7 \%$ & 68 \\
\hline House Owners in the Zone & 70,000 & 7.9 & $34.5 \%$ & 2726 & $11.5 \%$ & 909 & $11.5 \%$ & 909 \\
\hline
\end{tabular}

Note: See Section VII for details. 
TABLE A1: TREATMENT BY CITY

\begin{tabular}{|c|c|c|c|c|c|c|c|c|c|c|c|c|c|}
\hline City & Sample & $\mathrm{EZ}-1$ & $\begin{array}{l}\text { Appli- } \\
\text { cation }\end{array}$ & $\begin{array}{c}\text { Round } \\
\text { I }\end{array}$ & $\begin{array}{c}\text { Round } \\
\text { II }\end{array}$ & $\begin{array}{c}\text { Round } \\
\text { III }\end{array}$ & City & Sample & $\mathrm{EZ}-1$ & $\begin{array}{l}\text { Appli- } \\
\text { cation }\end{array}$ & $\begin{array}{c}\text { Round } \\
\text { I }\end{array}$ & $\begin{array}{c}\text { Round } \\
\text { II }\end{array}$ & $\begin{array}{c}\text { Round } \\
\text { III }\end{array}$ \\
\hline Akron (Summit) & $\mathrm{x}$ & & $\mathrm{x}$ & EC-1 & & & Louisville & $\mathrm{x}$ & & $\mathrm{x}$ & EC-1 & & \\
\hline Albany (Dougherty) & & & $\mathrm{x}$ & EC-1 & & & Lowell & $\mathrm{x}$ & & & & & $\mathrm{RC}$ \\
\hline Albuquerque (Bernalillo) & $\mathrm{x}$ & & $\mathrm{x}$ & $\mathrm{EC}-1$ & & & Manchester (Hillsborough) & $\mathrm{x}$ & & $\mathrm{x}$ & EC-1 & & \\
\hline Anniston & & & $\mathrm{x}$ & & & & Memphis & $\mathrm{x}$ & & $\mathrm{x}$ & & & $\mathrm{RC}$ \\
\hline Atlanta & $\mathrm{x}$ & $\mathrm{x}$ & $\mathrm{x}$ & & & $\mathrm{RC}$ & Miami & $\mathrm{x}$ & & $\mathrm{x}$ & $\mathrm{EC}-1$ & $\mathrm{EZ}-2$ & \\
\hline Austin & $\mathrm{x}$ & & $\mathrm{x}$ & & & & Milwaukee & $\mathrm{x}$ & & $\mathrm{x}$ & & & $\mathrm{RC}$ \\
\hline Baltimore & $\mathrm{x}$ & $\mathrm{x}$ & $\mathrm{x}$ & & & & Minneapolis & $\mathrm{x}$ & & $\mathrm{x}$ & EC-1 & $\mathrm{EZ}-2$ & \\
\hline Bellmead & & & $\mathrm{x}$ & EC-1 & & & Mobile & $\mathrm{x}$ & & $\mathrm{x}$ & & & $\mathrm{RC}$ \\
\hline Benton Harbor & & & $\mathrm{x}$ & & & & Monroe & & & $\mathrm{x}$ & & & $\mathrm{RC}$ \\
\hline Boston & & & $\mathrm{x}$ & EEC-1 & EZ-2 & & Muskegon & & & $\mathrm{x}$ & EC-1 & & \\
\hline Bridgeport & $\mathrm{x}$ & & $\mathrm{x}$ & $\mathrm{EC}-1$ & & & Nashville (Davidson) & & & $\mathrm{x}$ & EC-1 & & \\
\hline Buffalo / Lackawanna & $\mathrm{x}$ & & & & & $\mathrm{RC}$ & New Haven & & & $\mathrm{x}$ & EC-1 & $\mathrm{EZ}-2$ & \\
\hline Camden & & & & & & $\mathrm{RC}$ & New Orleans & $\mathrm{x}$ & & $\mathrm{x}$ & & & $\mathrm{RC}$ \\
\hline Charleston-SC & $\mathrm{x}$ & & & & & $\mathrm{RC}$ & New York & $\mathrm{x}$ & $\mathrm{x}$ & $\mathrm{x}$ & & & \\
\hline Charleston-WV & $\mathrm{x}$ & & $\mathrm{x}$ & & & & Newark & $\mathrm{x}$ & & & & & $\mathrm{RC}$ \\
\hline Charlotte (Mecklenburg) & $\mathrm{x}$ & & $\mathrm{x}$ & EC-1 & & & Niagara Falls & & & & & & $\mathrm{RC}$ \\
\hline Chattanooga & $\mathrm{x}$ & & & & & $\mathrm{RC}$ & Norfolk & $\mathrm{x}$ & & $\mathrm{x}$ & EC-1 & $\mathrm{EZ}-2$ & \\
\hline Chester & & & $\mathrm{x}$ & & & & Oakland & $\mathrm{x}$ & & $\mathrm{x}$ & EEC-1 & & \\
\hline Chicago & $\mathrm{x}$ & $\mathrm{x}$ & $\mathrm{x}$ & & & $\mathrm{RC}$ & Ogden (Weber) & & & $\mathrm{x}$ & EC-1 & & \\
\hline Cincinnati & $\mathrm{x}$ & & & & $\mathrm{EZ}-2$ & & Oklahoma City & $\mathrm{x}$ & & $\mathrm{x}$ & EC-1 & & $\mathrm{EZ}-3$ \\
\hline Cleveland & & & $\mathrm{x}$ & SEZ-1 & & & Omaha (Douglas) & $\mathrm{x}$ & & $\mathrm{x}$ & EC-1 & & \\
\hline Columbia & $\mathrm{x}$ & & & & $\mathrm{EZ}-2$ & & Orange & & & $\mathrm{x}$ & & & \\
\hline Columbus & $\mathrm{x}$ & & & & EZ-2 & & Peoria & $\mathrm{x}$ & & $\mathrm{x}$ & & & \\
\hline Corpus Christi & $\mathrm{x}$ & & & & & $\mathrm{RC}$ & Philadelphia/Camden & $\mathrm{x}$ & $\mathrm{x}$ & $\mathrm{x}$ & & & $\mathrm{RC}$ \\
\hline Cumberland & & & & & $\mathrm{EZ}-2$ & & Phoenix & $\mathrm{x}$ & & $\mathrm{x}$ & EC-1 & & \\
\hline Dallas & $\mathrm{x}$ & & $\mathrm{x}$ & EC-1 & & & Pine Bluff & & & $\mathrm{x}$ & & & \\
\hline Denver & $\mathrm{x}$ & & $\mathrm{x}$ & EC-1 & & & Pittsburgh & $\mathrm{x}$ & & $\mathrm{x}$ & EC-1 & & \\
\hline Des Moines (Polk) & & & $\mathrm{x}$ & EC-1 & & & Port Arthur & & & $\mathrm{x}$ & & & \\
\hline Detroit & $\mathrm{x}$ & $\mathrm{x}$ & $\mathrm{x}$ & & & $\mathrm{RC}$ & Portland & $\mathrm{x}$ & & $\mathrm{x}$ & EC-1 & & \\
\hline East Chicago & $\mathrm{x}$ & & $\mathrm{x}$ & & $\mathrm{EZ}-2$ & & Portsmouth & $\mathrm{x}$ & & $\mathrm{x}$ & EC-1 & $\mathrm{EZ}-2$ & \\
\hline East St Louis & $\mathrm{x}$ & & $\mathrm{x}$ & EC-1 & $\mathrm{EZ}-2$ & & Providence & $\mathrm{x}$ & & $\mathrm{x}$ & EC-1 & & \\
\hline El Paso & $\mathrm{x}$ & & $\mathrm{x}$ & EC-1 & $\mathrm{EZ}-2$ & & Richmond & $\mathrm{x}$ & & $\mathrm{x}$ & & & \\
\hline Evans & & & $\mathrm{x}$ & & & $\mathrm{RC}$ & Rochester & $\mathrm{x}$ & & $\mathrm{x}$ & & & $\mathrm{RC}$ \\
\hline Fairbanks & & & $\mathrm{x}$ & & & & Sacramento & & & $\mathrm{x}$ & & & \\
\hline Flint & $\mathrm{x}$ & & $\mathrm{x}$ & & & $\mathrm{RC}$ & San Antonio & $\mathrm{x}$ & & $\mathrm{x}$ & EC-1 & & $\mathrm{EZ}-3$ \\
\hline Fort Lauderdale & & & $\mathrm{x}$ & & & & San Diego & $\mathrm{x}$ & & $\mathrm{x}$ & & & $\mathrm{RC}$ \\
\hline Fort Worth & & & $\mathrm{x}$ & & & & San Francisco & & & & & & $\mathrm{RC}$ \\
\hline Fresno & $\mathrm{x}$ & & $\mathrm{x}$ & & & EZ-3 & Santa Ana & & & & & EZ-2 & \\
\hline Gary & $\mathrm{x}$ & & $\mathrm{x}$ & & $\mathrm{EZ}-2$ & & Savannah & $\mathrm{x}$ & & $\mathrm{x}$ & & & \\
\hline Greeley & & & $\mathrm{x}$ & & & $\mathrm{RC}$ & Schenectady & & & & & & $\mathrm{RC}$ \\
\hline Hamilton & & & & & & $\mathrm{RC}$ & Shreveport & & & $\mathrm{x}$ & & & \\
\hline Hammond & $\mathrm{x}$ & & $\mathrm{x}$ & & $\mathrm{EZ}-2$ & & Sioux & & & $\mathrm{x}$ & & & \\
\hline Harrisburg (Dauphin) & & & $\mathrm{x}$ & EC-1 & & & Springfield (Hampden) & $\mathrm{x}$ & & $\mathrm{x}$ & $\mathrm{EC}-1$ & & \\
\hline Hartford & $\mathrm{x}$ & & $\mathrm{x}$ & & & & St. Louis & $\mathrm{x}$ & & $\mathrm{x}$ & $\mathrm{EC}-1$ & EZ-2 & \\
\hline Houston & $\mathrm{x}$ & & $\mathrm{x}$ & EEC-1 & & & St. Paul (Ramsey) & $\mathrm{x}$ & & $\mathrm{x}$ & $\mathrm{EC}-1$ & & \\
\hline Huntington & & & & & $\mathrm{EZ}-2$ & & Steubenville & & & $\mathrm{x}$ & & & \\
\hline Indianapolis (Marion) & $\mathrm{x}$ & & $\mathrm{x}$ & EC-1 & & & Sumter & $\mathrm{x}$ & & & & $\mathrm{EZ}-2$ & \\
\hline Ironton & & & & & $\mathrm{EZ}-2$ & & Syracuse & $\mathrm{x}$ & & & & & $\mathrm{EZ}-3$ \\
\hline Jackson (Hinds) & $\mathrm{x}$ & & $\mathrm{x}$ & EC-1 & & & Tacoma & & & $\mathrm{x}$ & & & $\mathrm{RC}$ \\
\hline Jacksonville & $\mathrm{x}$ & & $\mathrm{x}$ & & & EZ-3 & Tampa & & & $\mathrm{x}$ & EC-1 & & \\
\hline Kansas city-KS & $\mathrm{x}$ & & $\mathrm{x}$ & EEC-1 & & & Tucson & $\mathrm{x}$ & & $\mathrm{x}$ & & & $\mathrm{EZ}-3$ \\
\hline Kansas city-MO & $\mathrm{x}$ & & $\mathrm{x}$ & EEC-1 & & & Waco & & & $\mathrm{x}$ & EC-1 & & \\
\hline Knoxville & $\mathrm{x}$ & & $\mathrm{x}$ & & $\mathrm{EZ}-2$ & & Washington & & & $\mathrm{x}$ & $\mathrm{EC}-1$ & & EnZ \\
\hline Lake Charles & & & $\mathrm{x}$ & & & & Whitehall & & & $\mathrm{x}$ & & & \\
\hline Las Vegas (Clark) & & & $\mathrm{x}$ & EC-1 & & & Wilmington (New Castle) & & & $\mathrm{x}$ & $\mathrm{EC}-1$ & & \\
\hline Lawrence & & & & & & $\mathrm{RC}$ & Yakima & & & & & & $\mathrm{RC}$ \\
\hline Little Rock (Pulaski) & $\mathrm{x}$ & & $\mathrm{x}$ & EC-1 & & $\mathrm{EZ}-3$ & Yonkers & & & & & & $\mathrm{EZ}-3$ \\
\hline Los Angeles & $\mathrm{x}$ & & $\mathrm{x}$ & SEZ-1 & & $\mathrm{RC}$ & Youngstown & & & $\mathrm{x}$ & & & \\
\hline
\end{tabular}

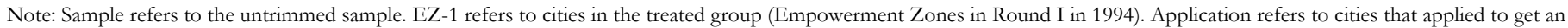

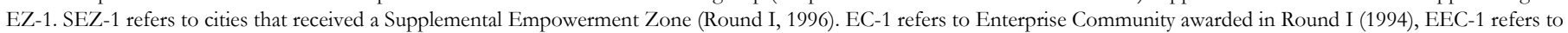

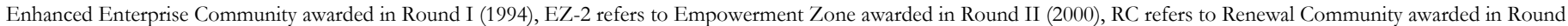
III (2002), EZ-3 refers to Empowerment Zone awarded in Round III (2002) and EnZ refers to the Enterprise Zone awarded in Round III (2002) 


\section{TABLE A.2: PROPENSITY SCORE MODEL}

\begin{tabular}{|c|c|c|}
\hline Dep Variable: Census tract level EZ dummy & Coeff. & s.e. \\
\hline \multicolumn{3}{|l|}{ City Covariates: } \\
\hline Change in log of city population $1980-1990$ & 4.206 & 5.792 \\
\hline Change in city employment rate $1980-1990$ & 23.951 & 13.457 \\
\hline Proportion of city population black (1990) & 10.314 & 3.434 \\
\hline Total city crime / population* 100 (1990) & -25.540 & 17.871 \\
\hline Proportion of city employment in manufacturing (1990) & 9.790 & 7.430 \\
\hline Proportion of city employment in city government (1990) & 18.747 & 14.286 \\
\hline \multicolumn{3}{|l|}{ Tract Covariates (non spatial moving average): } \\
\hline Indicator for Central Business District (1990) & -2.221 & 0.516 \\
\hline \multicolumn{3}{|l|}{ Tract Covariates (spatial moving average): } \\
\hline Poverty $>25 \%(1990)$ & 0.071 & 0.960 \\
\hline Poverty $>35 \%(1990)$ & 1.480 & 0.757 \\
\hline Unemployment rate (1990) & 1.149 & 3.781 \\
\hline Ratio of number of 1990 households with tenure $>10$ years to 1980 population & 0.577 & 0.300 \\
\hline Change in proportion of employed tract residents commuting $<25$ minutes $(1980-1990)$ & 7.896 & 5.430 \\
\hline Change in proportion of tract workers with college degree (1980-1990) & 4.136 & 2.236 \\
\hline Proportion Hispanic (1990) & -0.567 & 5.577 \\
\hline Proportion Hispanic (1980) & -2.115 & 3.027 \\
\hline Proportion black (1990) & 3.524 & 2.721 \\
\hline Proportion black (1980) & 11.125 & 4.739 \\
\hline Proportion of structures vacant (1990) & 11.238 & 4.347 \\
\hline Proportion of structures vacant (1980) & -15.412 & 6.711 \\
\hline Building age index (1990) & 1.058 & 0.627 \\
\hline Proportion < 18 years old $(1990)$ & 0.512 & 8.120 \\
\hline Proportion < 18 years old $(1980)$ & -22.612 & 8.120 \\
\hline Proportion of households female headed (1990) & -3.058 & 3.837 \\
\hline Proportion of households female headed (1980) & 12.352 & 3.901 \\
\hline Proportion $>=65$ years old $(1990)$ & -16.512 & 7.596 \\
\hline Proportion $>=65$ years old $(1980)$ & 0.020 & 9.349 \\
\hline Proportion of population who are high school dropouts (1990) & 9.707 & 6.090 \\
\hline Proportion of population who are high school dropouts (1980) & 7.202 & 9.580 \\
\hline Change in mean log of housing values (1980-1990) & -0.105 & 0.790 \\
\hline Change in mean log of rent (1980-1990) & -1.952 & 2.078 \\
\hline Change in log of tract population (1980-1990) & -1.383 & 1.170 \\
\hline Change in log of households (1980-1990) & 1.128 & 1.827 \\
\hline Change in mean log wage of tract residents (1980-1990) & 3.923 & 2.197 \\
\hline Change in mean log wage of tract workers (1980-1990) & -4.794 & 1.467 \\
\hline Change in log of tract employment - LBD (1987-1992) & 0.560 & 0.622 \\
\hline Change in log of average earnings per tract worker - LBD (1987-1992) & 1.767 & 1.161 \\
\hline Change in log of number of tract establishments - LBD (1987-1992) & 0.209 & 0.753 \\
\hline Intercept & -10.954 & 4.788 \\
\hline Number of tracts & 1663 & \\
\hline Number of clusters (untrimmed) & 69 & \\
\hline Pseudo- $\mathrm{R}^{2}$ & 0.4179 & \\
\hline
\end{tabular}

Note: City covariates are from the City Databook. Covariates marked as LBD come from the Longitudinal Business Database. All other covariates come from the Census. See Appendix II for details. The construction of the spatial moving averages is explained in Appendix II.G. 
TABLE A.3.A: SECOND MOMENTS IN 1990 TREATMENT AND CONTROLS

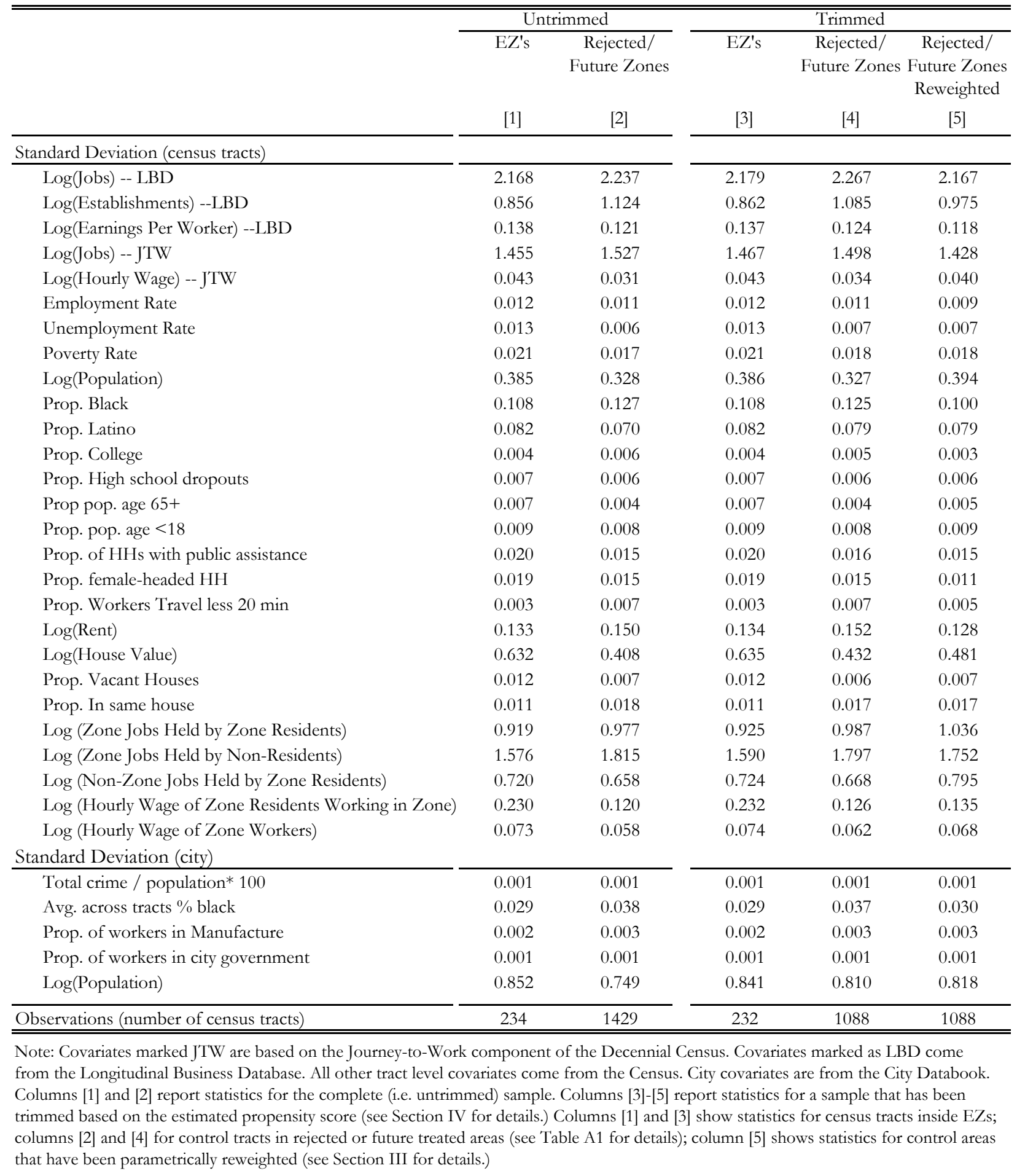


TABLE A.3.B: CHANGES 1980-1990 TREATMENT AND CONTROLS

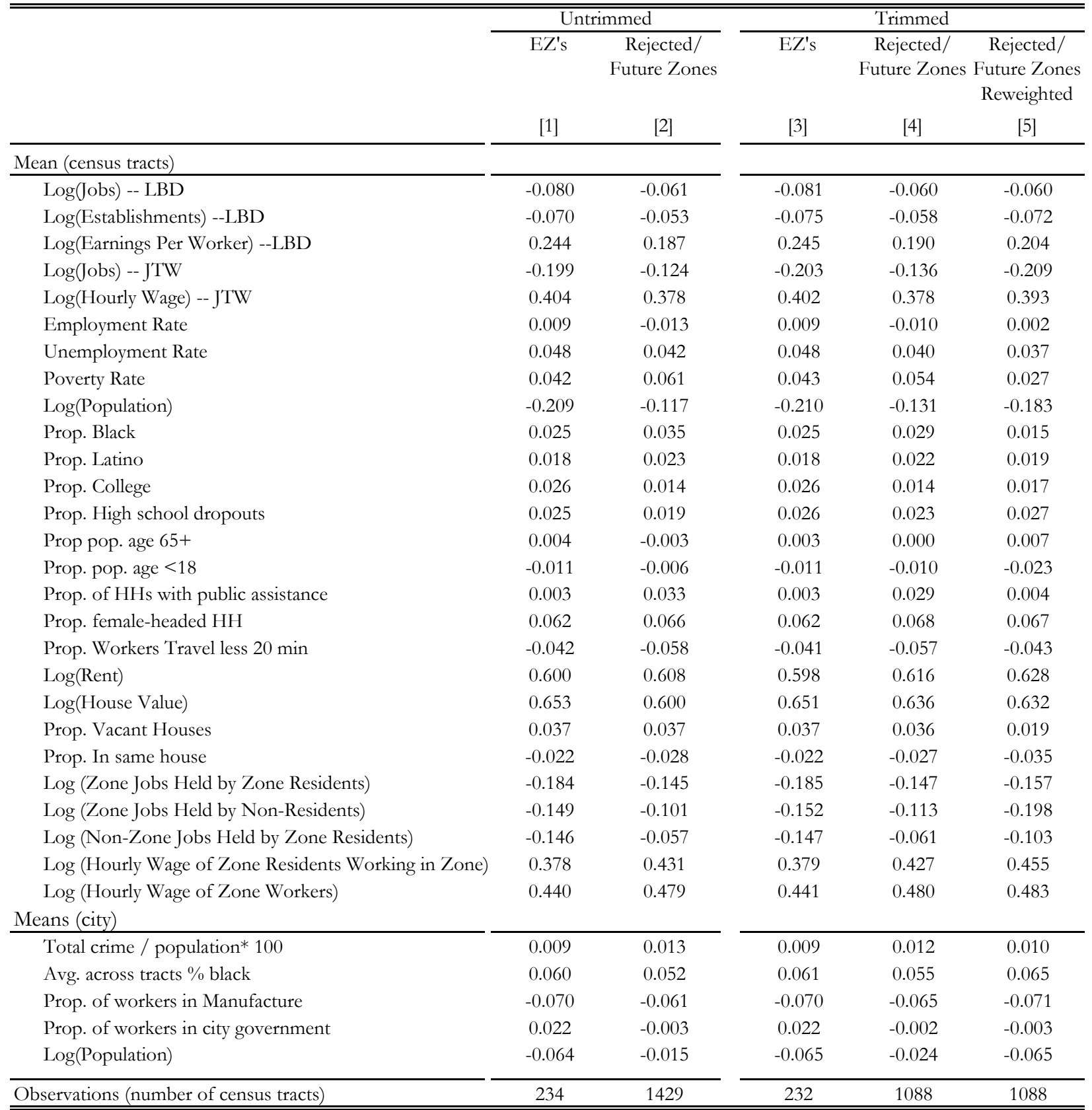

Note: Covariates marked JTW are based on the Journey-to-Work component of the Decennial Census. Covariates marked as LBD come from the Longitudinal Business Database and are analyzed over the period 1987-1992, all other tract level covariates come from the Census and analyzed over the period 1980-1990. City covariates are from the City Databook. Columns [1] and [2] report statistics for the complete (i.e. untrimmed) sample. Columns [3]-[5] report statistics for a sample that has been trimmed based on the estimated propensity score (see Section IV for details.) Columns [1] and [3] show statistics for census tracts inside EZs; columns [2] and [4] for control tracts in rejected or future treated areas (see Table A1 for details); column [5] shows statistics for control areas that have been parametrically reweighted (see Section III for details.) 
FIGURE 1: CHICAGO EMPOWERMENT ZONE

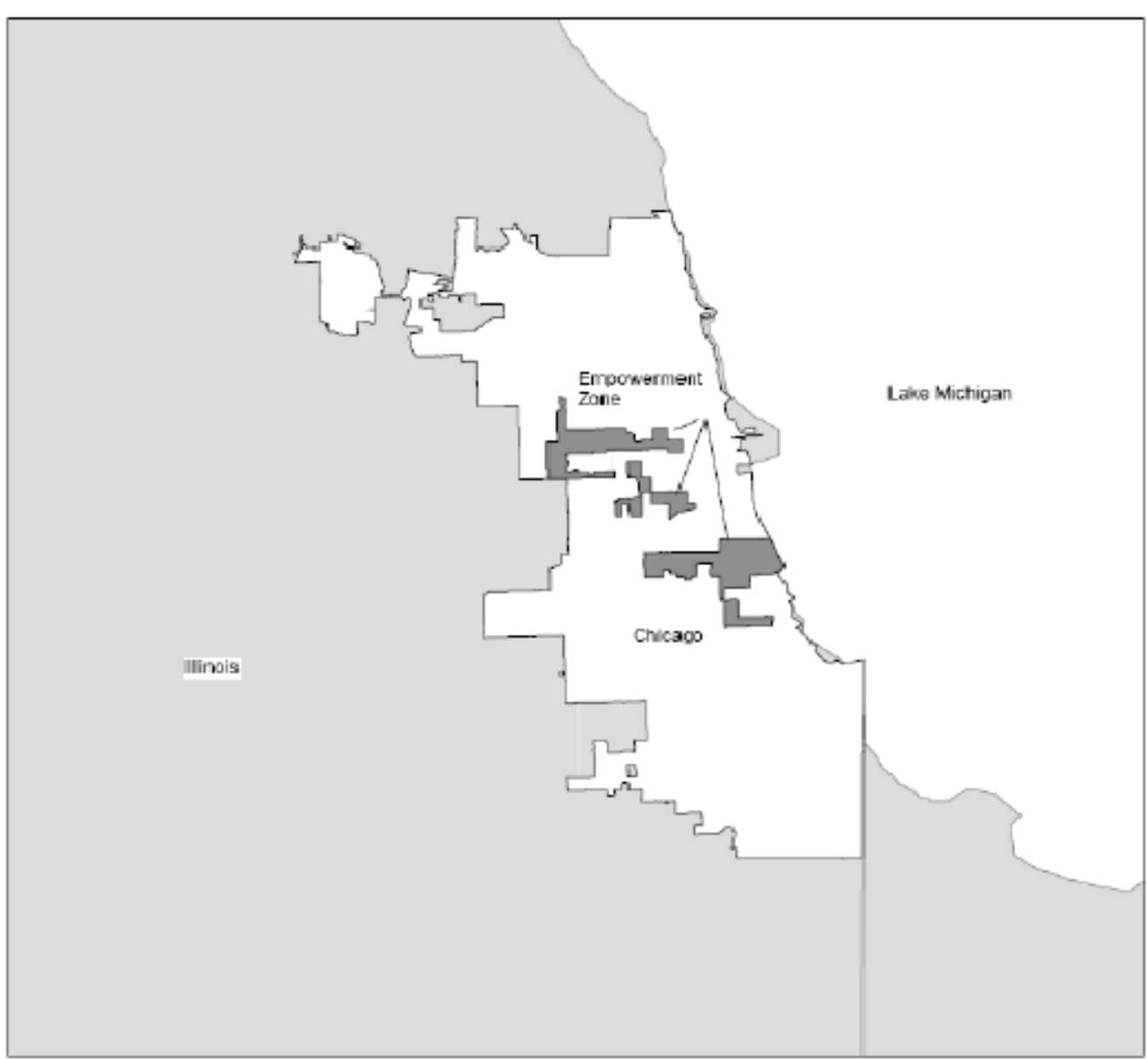


FIGURE 2: OVERLAP

Conditional Densities of the Propensity Score Before Trimming
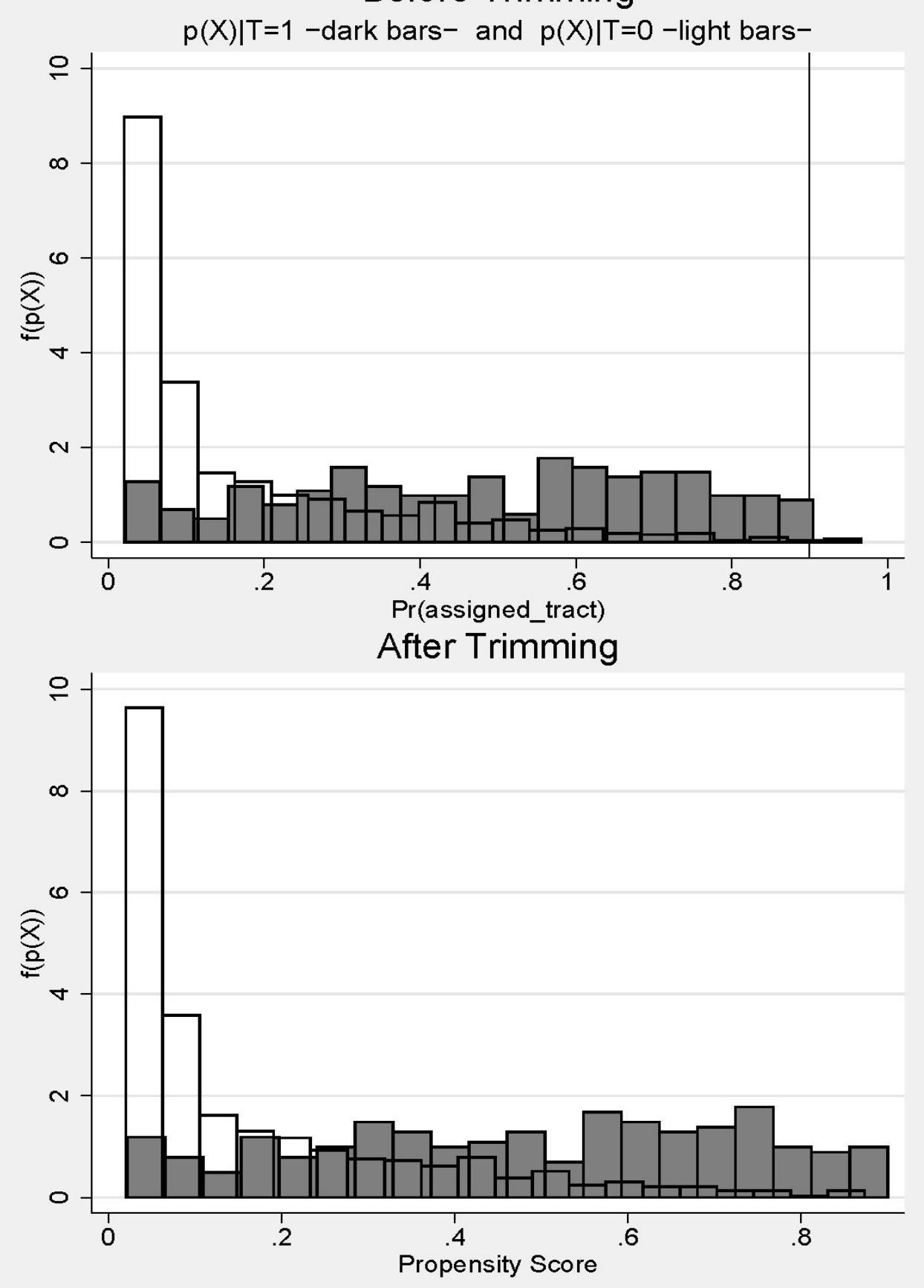


\section{FIGURE 3A: TIME SERIES CHARACTERISTICS}

\section{Balance of Levels and Trends}
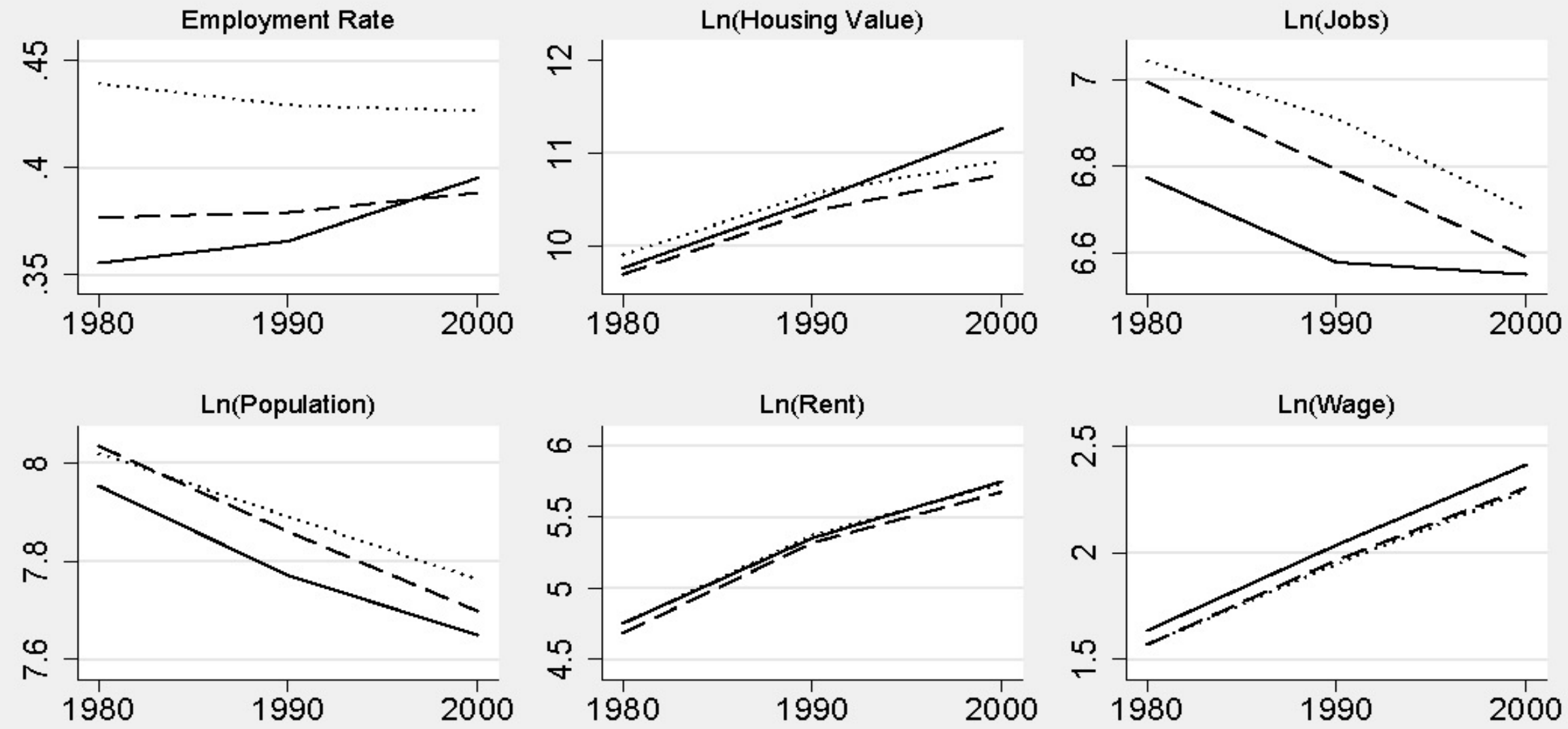

Year 


\section{FIGURE 3B: TIME SERIES CHARACTERISTICS}

\section{Balance of Levels and Trends}
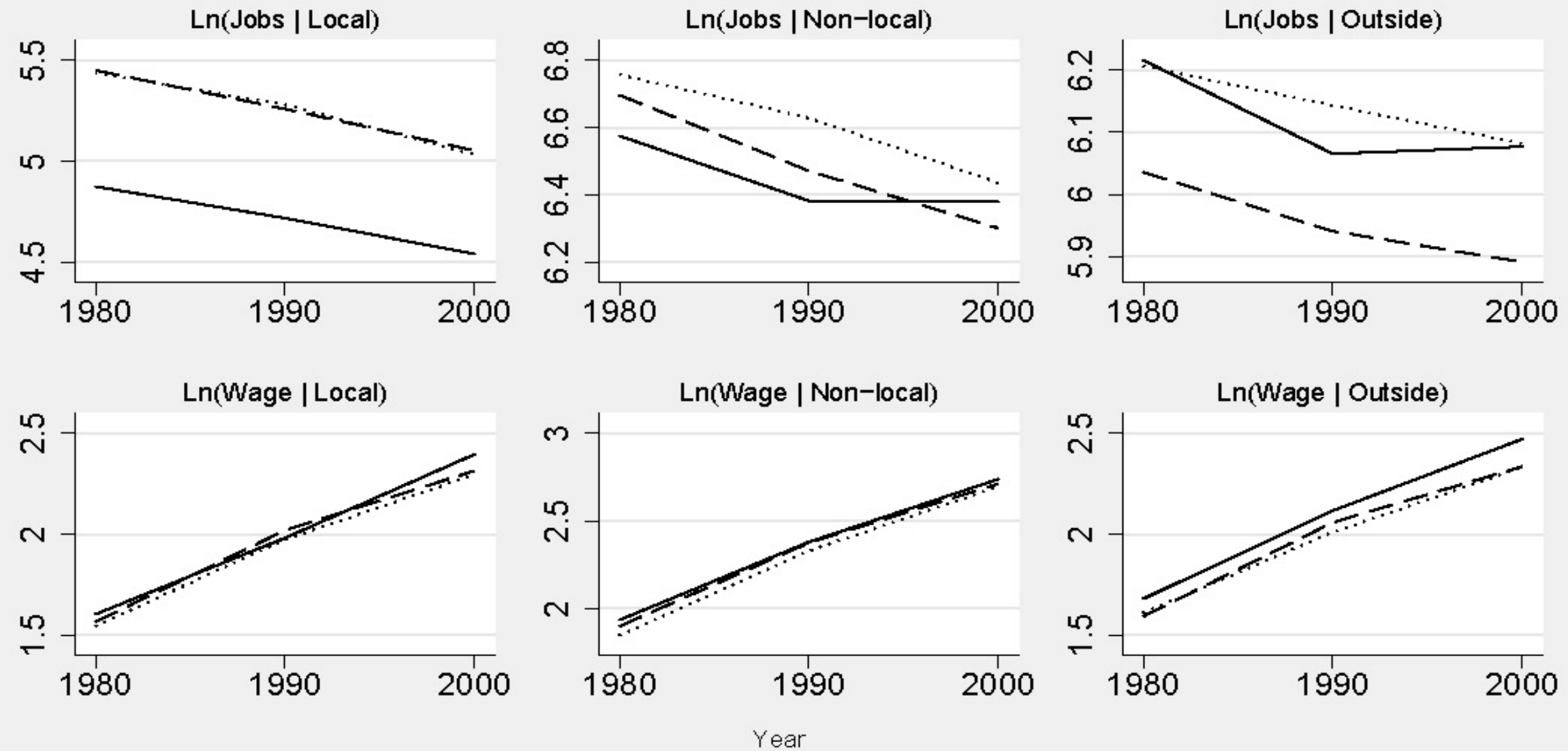

Local: Zone residents working inside the zone. Non-local: Zone non-residents working inside the zone. Outside: Zone residents working outside the zone. 


\section{Appendix I: Methods}

\section{A. Computation of PW Estimator}

We run a pooled tract-level regression of the form

$$
\Delta Y_{t z c}=\mu^{1} T_{z}+\left(1-T_{z}\right) \times X_{n(t)}^{\prime} \alpha^{x}+\left(1-T_{z}\right) \times P_{c}^{\prime} \alpha^{p}+e_{t z c}
$$

where $X_{n(t)}$ is assumed to include a constant. Note that because this regression is fully interacted, $\widehat{\mu}^{1}$ will evaluate to the mean of $\Delta Y_{t z c}$ among the EZ tracts. Let $Z_{t}=\left[X_{n(t)}, P_{c}\right]$ and $\widehat{\alpha}=\left[\widehat{\alpha}^{x}, \widehat{\alpha}^{p}\right]^{\prime}$. The counterfactual mean estimate for treated observations may be computed as

$$
\begin{aligned}
\widehat{\mu}^{0} & =\frac{1}{N_{1}} \sum_{t} T_{t} Z_{t}^{\prime} \widehat{\alpha} \\
& =\frac{1}{N_{1}} \sum_{t} T_{t} Z_{t}^{\prime}\left[\left(\sum_{l}\left(1-T_{l}\right) Z_{l} Z_{l}^{\prime}\right)^{-1} \sum_{m}\left(1-T_{m}\right) Z_{m} \Delta Y_{m z c}\right] \\
& =\sum_{m}\left(1-T_{m}\right) \omega_{m} \Delta Y_{m z c}
\end{aligned}
$$

where the $\omega_{m}=\frac{1}{N_{1}} \sum_{t} T_{t} Z_{t}^{\prime}\left(\sum_{l}\left(1-T_{l}\right) Z_{l} Z_{l}^{\prime}\right)^{-1} Z_{m}$ are weights obeying $\sum_{m}\left(1-T_{m}\right) \omega_{m}=1$. It is straightforward to verify that for any covariate $Q_{t} \in Z_{t}, \sum_{t}\left(1-T_{t}\right) \omega_{t} Q_{t}=\frac{1}{N_{1}} \sum_{t} T_{t} Q_{t}$. Hence the regression weights yield reweighted covariate means among the controls numerically equivalent to the corresponding covariate means in the treatment group. See Kline (2010b) for the interpretation of this procedure as a propensity score reweighting estimator. We use these weights in computing the reweighted control means reported in Figure 3 and column 5 of Table 3 . Tract level covariate means are not perfectly balanced in Table 3 because we condition on distance weighted averages of covariates rather than tract level variables themselves.

The treatment effect estimator in 15 may be written $\widehat{\theta}=\widehat{\mu}^{1}-\widehat{\mu}^{0}$, which is the quantity reported in our PW impact estimates. An analytical variance estimate may be computed as

$$
\widehat{\operatorname{Var}}(\widehat{\theta})=\widehat{V}_{1}+\left(\frac{1}{N_{1}} \sum_{t} T_{t} Z_{t}^{\prime}\right) \widehat{\boldsymbol{V}}_{0}\left(\frac{1}{N_{1}} \sum_{t} T_{t} Z_{t}^{\prime}\right)^{\prime}
$$

where $\widehat{\boldsymbol{V}}_{0}$ is the standard OLS cluster robust estimator of the covariance matrix of the estimated parameters $\left(\widehat{\alpha}^{x}, \widehat{\alpha}^{p}\right)$ and $\widehat{V}_{1}$ is the corresponding variance estimate of $\widehat{\mu}^{1}$. We use this analytical variance estimate to construct an asymptotic pivot for use in our wild bootstrap procedure.

\section{B. Wild Bootstrap Inference}

As suggested by Cameron, Gelbach, and Miller (2008) we conduct inference using the cluster robust percentile-t wild bootstrap with Rademacher weights. We impose the null hypothesis that the coefficient on the EZ dummy is zero when computing our residuals. This is done both for computation of standard errors and p-values. See Kline and Santos (2010) for more on the theory and performance of cluster-robust wild bootstrap tests in small samples. 


\section{Appendix II: Data}

\section{A. Census}

We use data from the 1980, 1990, and 2000 long-form Decennial Census of population. Variables are drawn from the person, household, and geography files. Geographic variables on the 1980 and 2000 files use codes pertaining to the census geographic boundaries of their vintage. For both 1980 and 2000, we map place of residence geographic variables and place of work geographic variables to 1990 census tracts using crosswalk files from MABLE/Geocorr. Variables derived from Decennial Census data include mean log wages and earnings by place of residence and by place of work, job counts by place of residence and by place of work, housing characteristic variables, and demographic variables used in the propensity score model and to construct regression adjusted outcomes.

Individual's wages are computed by dividing labor income in the previous year by the product of weeks worked in the previous year and usual hours per week. We exclude wage observations based on allocated earnings, hours, or weeks from our analysis and winsorize nonmissing wages from below at $80 \%$ of the federal minimum wage in each year and from above at 40 times the federal minimum wage in each year.

\section{B. LBD and SSEL}

We use business data from the 1987, 1992, and 2000 Longitudinal Business Database (LBD) files. The LBD provides longitudinally linked establishment-level data for all establishments with paid employees contained in the Census Bureau's Standard Statistical Establishment List (SSEL). Data contained on these files comes primarily from the Economic Census and is supplemented with tax records from the Internal Revenue Service. We coded each establishment to a 1990 census tract using an algorithm described below based on the raw street addresses provided on the SSEL. In addition to establishments' locations, we observe each establishment's age, size (number of employees), payroll, industry, and whether the establishment belongs to a multi-establishment firm.

The outcomes in the first panel of Table 5 were computed as sums or averages over the universe of firms in each tract/year. Logs were then taken at the tract level and outcomes were differenced over time. The outcomes in the remaining panels were constructed for the subset of firms present in a given tract in 1992 obeying any stated restrictions on firm size. Sums or averages for this population were then applied at the tract/year level and logs were again taken at the tract level and then differenced over time.

\section{County/City Databook}

We extract from the County/City Databook (CCD) 1980, 1990, and 2000 values of city level variables such as crime rate, percentage of workers in the manufacturing sector and percentage of workers working in the government.

\section{HUD}

We have information on 73 of the 78 applications sent to HUD. We have repeatedly requested the 5 missing applications to no avail. Our dataset also includes all census tracts that belong to any 
urban EZ, EC, Enhanced Enterprise Community (EEC), or Renewal Community (RC) of all the first three rounds. (See Table A1 for more details).

\section{E. MABLE/Geocorr}

The MABLE/Geocorr engine generates files showing the correspondence between a wide variety of Census and cartographic geographies in the United States. We use Geocorr 1990 to map each 1980 census tract to one or more 1990 census tracts and Geocorr 2000 to map each 2000 census block to one or more 1990 census tracts. The resulting crosswalk is used to assign a 1990 census tract to each observation in: the 1980 Decennial Census (by place of residence and place of work), the 2000 Decennial Census (by place of residence and place of work), and the geocoded LBD data (by establishment location).

In some cases the geographic mappings are not unique. For cases in which an observation's geography maps to multiple 1990 census tracts, we create one duplicate of the observation being mapped for each potential 1990 target census tract and then weight each source observation in a manner that maintains representativeness. When mapping 1980 census tracts to 1990 census tracts, weight is allocated across duplicated observations in proportion to the distribution of the tract's 1980 population across 1990 tracts. When mapping 2000 census blocks to 1990 census tracts, weight is allocated equally across duplicated observations.

We also use Geocorr 2000 to match each census tract to one or more places (cities, townships, villages, etc.). Each census tract that crosses city boundaries was allocated to the city where the majority of the tract's population is located.

\section{F. Missingness/Weighting}

We exclude observations with missing and allocated values when constructing several of the tractlevel variables included in the analysis. In most of these cases, we correct for the potential introduction of non-random selection by weighting nonmissing observations by the inverse of an estimate of the probability of the observation's inclusion.

A first set of missingness weights (applied to Decennial Census data) equals the inverse of the probability of an individual having a valid (non-missing and non-allocated) place of work variable conditional on observable traits and on the individual being employed. We estimate that conditional probability with a linear probability model that includes main effects and all two-way interactions of age (under 20, 20-39, 40-64, and 65+), sex, race (black, white, and other), and education (dropout, high school grad, some college, and bachelors) and includes main effects for class of worker, wage decile (where missing wages are treated as an eleventh decile), and tract of residence. The model is estimated separately by county, year, and EZ assignment status according to tract of residence. Predicted values were winsorized to lie in the interval $[0.025,1]$. These weights are applied when computing tract aggregates of quantities defined by individuals' places of work. Those aggregates include numbers of jobs and total earnings for tract workers residing in the zone, for tract workers residing outside of the zone, and for tract residents working outside of the zone.

A second set of missingness weights (applied to Decennial Census data) equals the inverse of the probability that an individual has a valid (non-missing and non-allocated) place of work variable conditional on observable traits and on the individual being employed and having a non-allocated 
wage. We again estimate that conditional probability with a linear probability model that includes main effects and all two-way interactions of age, sex, race, and education and includes main effects for class of worker, wage decile, and tract of residence. The model is estimated separately by county, year, and residence tract EZ assignment status. Predicted values are again winsorized to lie in the interval $[0.025,1]$. These weights are applied when computing mean wages by individuals' places of work. These variables include mean log wages of tract workers residing in the zone, mean log wages of tract workers residing outside of the zone, and mean log wages of tract residents employed outside of the zone.

A third set of weights (applied to LBD data) equals the inverse of the probability that an establishment received a valid geocode during our geocoding algorithm conditional on observable establishment traits. Because the set of potential covariates was much smaller in this case the probabilities were estimated using parametric logit models. The explanatory variables in these models were dummies for establishment age (full vector of indicators for each possible age), establishment size (defined by total employment categories; 0-99, 100-249, 250-499, 500-999, and 1000+), and 1digit industry categories. Separate missingness models were estimated for single establishment firms and establishments belonging to multi-establishment firms within each county-year combination. These weights were applied in construction of all LBD based variables.

For a small fraction of tract-years, we did not observe any tract workers who reside in the zone containing the tract (local workers). To deal with this problem we replaced the change in the log of the number of local workers with the gross change divided by the average number of local workers in the two periods as suggested by Davis, Haltiwanger, and Schuh (1993). This measure varies between -2 and 2 and is well defined for tracts that have at least one local worker in either 1990 or 2000. For most tracts this measure yields values very close to the change in logs.

For tracts with no local workers we stochastically impute the mean log wage of such workers. We first regress the mean log wage of local workers on a large set of contemporaneous tract level covariates 35 in tracts for which the mean log wage of local workers is well defined. A separate regression is run for each Decennial Census year by EZ treatment status. $R^{2}$ statistics from the imputation regressions are very high, often exceeding 0.9 . We then impute a mean log wage for local workers for tracts missing that variable by assigning the sum of the linear prediction from this regression and a draw from a normal distribution with mean zero and standard deviation equal to the root mean squared error from the regression. Log wages are then re-winsorized to relative to the minimum wage.

\section{G. Covariates / Spatial Moving Averages}

We include spatial moving averages of pre-treatment variables as controls in our regression adjusted impact estimates. For each control variable, the spatial moving average assigned to a tract, $j$, is

\footnotetext{
${ }^{35}$ The covariates included in this regression are: mean log wage of tract residents, mean log wage of tract workers residing outside of the zone, mean log wage of tract residents working outside of the zone, fraction of tract residents with a commute less than 25 minutes, fraction of tract residents who are black, fraction of tract residents who are Hispanic, fraction of tract residents who are high school dropouts, fraction of tract residents with college attendance, fraction of tract residents greater than 65 years old, fraction of tract residents less than 18 years old, fraction of tract residents who are employed, fraction of tract residents below the poverty line, log of tract population, log of tract area, log of the number of households living in the tract, an indicator for whether the tract was in the central business district in 1990, the distance to the central business district, and a vector of state-city fixed effects.
} 
the kernel weighted mean value of the control variable among a set of neighboring tracts $N(j)$, defined as those tracts (other than $j$ itself) whose centroid falls within one mile of the centroid of tract $j$. The weight given to each tract in the set $N(j)$ is given by a truncated (at one mile) normal kernel with a standard deviation of 0.5 miles applied to the distance between the centroid of the neighboring tract and the centroid of tract $j$.

We used the following covariates in all specifications labeled OLS or PW:

City Level: Change in log of city population 1980-1990, Change in city employment rate 19801990, Proportion of city population black (1990), Total city crime / population* 100 (1990), Proportion of city employment in manufacturing (1990), Proportion of city employment in city government (1990).

Tract Level: Indicator for tract in central business district (1990), Poverty $>25 \%$ (1990), Poverty > 35\% (1990), Unemployment rate (1990), Ratio of number of 1990 households to 1980 population, Change in proportion of employed tract residents commuting $<25$ minutes (19801990), Change in proportion of tract workers with college degree (1980-1990), Proportion Hispanic (1990), Proportion Hispanic (1980), Proportion black (1990), Proportion black (1980), Proportion of structures vacant (1990), Proportion of structures vacant (1980), Building age index (1990), Proportion $<18$ years old (1990), Proportion < 18 years old (1980), Proportion of households female headed (1990), Proportion of households female headed (1980), Proportion $\geq 65$ years old (1990), Proportion $\geq 65$ years old (1980), Proportion of population who are high school dropouts (1990), Proportion of population who are high school dropouts (1980), Change in mean log of housing values (1980-1990), Change in mean log of rent (1980-1990), Change in log of tract population (1980-1990), Change in log of households (1980-1990), Change in mean log wage of tract residents (1980-1990), Change in mean log wage of tract workers (1980-1990), Change in log of tract employment - LBD (1987-1992), Change in log of average earnings per tract worker - LBD (1987-1992), Change in log of number of tract establishments - LBD (1987-1992)

All tract level covariates save for central business district status were averaged across tracts using the spatial kernel method.

\section{H. Geocoding Algorithm}

Our analysis of business data from the SSEL and LBD required that each establishment be coded to a 1990 census tract. While a census tract variable appears on the SSEL files for 1992 and later, the values are very often missing. Instead of using the existing tract variable, we implemented an algorithm to assign establishments to census tracts based on their raw street addresses. Our algorithm consisted of three steps. First we attempted to code each address in each cross-section of the SSEL to a 2000 Census block 36 . For this step, we used the SAS/GIS batch geocoding module

\footnotetext{
${ }^{36}$ We tested our geocoding algorithm using both 1990 TIGER/Line data and 2000 TIGER/Line data. An advantage of using the 1990 TIGER/Line files is that all coded establishments receive a 1990 Census block code, a unit within which treatment status does not vary (EZs were awarded to collections of 1990 census tracts, which nest 1990 census blocks). We found however that the rate at which we successfully assigned geocodes was higher by several percentage points using 2000 TIGER/Line files than when using 1990 TIGER/Line files. While the mapping from 2000 census blocks to 1990 census tracts is not one-to-one, less than 0.5 percent of 2000 Census blocks overlap multiple 1990 census blocks in the counties containing an EZ or control zone. We decided that the benefit of the higher successful geocoding rate outweighed the cost of slight mis-measurement of treatment assignment
} 
(invoked by the "\%GCBATCH" macro). Second, using the longitudinal links provided by the LBD, we filled in establishment-years with missing geocodes with the codes assigned to the same establishment in neighboring years. Third, we assigned each establishment a 1990 census tract based on its assigned 2000 Census block.

The SSEL provides at least one street address field for each establishment in each annual cross-section. For single establishment firms, a mailing address is nearly always provided, and a physical address is sometimes provided. SSEL documentation suggests that the physical address field should be non-missing in each case in which a single establishment firm's physical address and mailing address differ. For establishments belonging to multi-establishment firms, only a physical address is provided.

As the first step of our geocoding process, we applied the following algorithm to all SSEL physical and mailing addresses of establishments located in counties containing an EZ or a control zone. Note that for single establishment firms, we attempted to code two addresses when two addresses were provided.

1. Import 2000 TIGER/Line data into SAS/GIS spatial data sets.

2. Geocode SSEL address data using the SAS/GIS batch geocoder.

3. Set aside all observations that received a geocode in step 2. Proceed using only observations that have not yet received a geocode.

4. If all items on the following list have been reached, go to step 6. Otherwise, proceed and perform the first task on the following list that has not yet been performed.

(a) Remove all punctuation marks.

(b) Replace ordinal words with their numeric equivalents (e.g. third becomes 3rd).

(c) Remove gaps between two groups of numbers appearing at the beginning of address strings (e.g. "123 45 Elm St" becomes "12345 Elm St").

(d) Remove official U.S. Postal Service secondary address identifiers and all characters that follow them (e.g. "123 Elm St Suite 1" becomes "123 Elm St").

(e) Abbreviate all official US Postal Service primary address identifiers with their official abbreviations (e.g. "123 Elm Street" becomes "123 Elm St").

(f) Remove spaces between adjacent letters commonly used to identify cardinal directions (e.g. "123 S W Elm St" becomes "123 SW Elm St").

5. Return to step 2 .

6. Stop.

In cases in which a physical address was successfully geocoded, we assigned the establishment the geocode associated with that address. In cases in which we were unable to assigned a geocode to a physical address (usually because none was provided), we assigned the establishment the geocode associated with its mailing address.

In the second step of our geocoding process, we exploited the longitudinal links provided by the LBD to impute missing geocodes for establishments that were successfully coded in some, but 
not all, of the years in which they appeared in the SSEL. If an establishment's first observation to receive a successful geocode occurred in year $t$, we assigned the year $t$ geocode to any observations for years prior to $t$. Similarly, if an establishment's last observation to receive a successful geocode occurred in year $t$, we assigned the year $t$ geocode to any observations for years later than $t$. When an observation on the "interior" of an establishment's panel failed to receive a geocode, the observation was assigned the geocode of the nearest successfully geocoded observation. When an interior observation of this sort was equally close to two successfully geocoded observations, we chose between the geocodes of those two observations randomly, giving each a 0.5 probability of being selected.

In the final step of our geocoding process, we assigned each successfully coded establishmentyear a 1990 Census tract based on the 2000 Census block assigned in the first two steps. To do this, we constructed a many to many crosswalk file relating 2000 Census blocks to 1990 Census tracts. We began by downloading the Census provided Census Block Relationship File relating 1990 Census tabulation blocks to 2000 Census Tabulation blocks. The Census Block Relationship File has one observation for each 1990 Census tabulation block and 2000 Census tabulation block pair with a non-empty intersection. We created a 1990 Census tract variable from the provided 1990 Census block variable and dropped any duplicate observations of 1990 Census tract and 2000 Census block. We then merged this file by 2000 Census block to the list of geocoded addresses. In cases in which a 2000 Census block mapped to $N 1990$ Census tracts, we duplicated the firm's observation $N$ times, assigned one observation to each potential 1990 Census tract, and assigned weight $1 / N$ to each of those observations in any subsequent analysis.

\section{Appendix III: Regression Adjusted Outcomes}

To remove the influence of changes in demographic composition on tract level measures of behavior and prices we computed composition constant outcomes by tract for each outcome of interest using fixed effects regressions. The regression specifications used to adjust tract outcomes differ slightly for individual level outcomes aggregated by residence tract, for individual outcomes aggregated by place of work tract, and for housing characteristics.

In each case, a regression model was estimated on a pooled sample of micro-data that included all observations with non-missing values of the dependent variable from 1980, 1990, and 2000. Each regression specification included a full vector of tract-year dummy variables. For individual level outcomes aggregated by residence tract and for housing characteristics, the tract-year dummy variables indicate an individual's residence tract or the tract in which a housing structure was located. For individual level outcomes aggregated by place of work tract, tract-year dummy variables indicate the tract in which an individual worked. For individual outcomes, the regression specifications included a quartic in age, dummy variables for black non-Hispanic and other race (white non-Hispanic omitted), a dummy variable for female, and dummy variables for high school dropout, any past college attendance, and actively enrolled in school (non-enrolled high school graduate omitted). For housing stock outcomes, we included dummy variables for the number of bedrooms, the number of rooms, three building age categories, two-way interaction terms between bedrooms and rooms, and two-way interaction terms between bedrooms and building age. We computed composition constant mean outcomes by evaluating the estimated regression equation using a constant mix of included explanatory variables for each tract across the three years. 
Consider the adjustment of the mean of an outcome $Y_{i j z t}$ which (switching notation) we now take to denote the outcome of individual or housing unit $i$ in tract $j$, zone $z$, and year $t$. A zone is either an EZ, a control zone, or the non-EZ, non-control portion of a county containing an EZ or control. We estimated the following regression equations separately by zone on a pooled sample of individual respondents to the 1980, 1990, and 2000 long form Decennial Censuses.

$$
Y_{i j z t}=\eta_{j t}^{0}+X_{i j z t}^{\prime} \eta_{z}^{x}+\epsilon_{i j z t}
$$

Note that the mean OLS residual is zero for each tract-year because of the included tract-year fixed effects $\eta_{j t}^{0}$. Hence we may decompose the change in the tract level mean $\bar{Y}_{j, t}$ between 1990 and 2000 into a composition constant change and a composition effect as follows

$$
\bar{Y}_{j, 2000}-\bar{Y}_{j, 1990}=\underbrace{\left(\widehat{\eta}_{j, 2000}^{0}-\widehat{\eta}_{j, 1990}^{0}\right)}_{\text {composition constant change }}+\underbrace{\left(\bar{X}_{j, 2000}-\bar{X}_{j, 1990}\right)^{\prime} \widehat{\eta}_{z}^{x}}_{\text {composition effect }}
$$

where the $\bar{X}_{j, t}$ refer to tract by year averages of covariate values. The composition constant change is the difference between the two estimated tract-year fixed effects while the composition effect is the linear combination of the changes in mean tract characteristics.

We have also experimented with more complicated specifications that allow the $\eta_{z}^{x}$ coefficients to change over time by demographic group. These yield similar final results but sometimes erratic predictions for small demographic cells.

\section{Appendix IV: Construction of Placebo Zones}

To construct placebo zones we performed nearest neighbor matching without replacement on a propensity score estimated on all tracts in the six cities receiving Round I EZs. The propensity score was estimated on the pooled sample using a logit of assignment status on a large number of covariates. Included in this list were a number of tract outcomes measured in 1990; these include a vector of city indicators interacted with the fraction of households below the poverty line, a vector of city indicators interacted with the fraction unemployed, a vector of city indicators interacted with the population, a vector of city indicators interacted with the fraction of tract workers with a commute time less than 25 minutes, the fraction living in the same house as five years previous, the fraction with college attendance, the fraction black, the fraction Hispanic, the employment rate, the fraction who are high school dropouts, the fraction older than 65 years old, the fraction less than 18 years old, the fraction of structures that are vacant, the fraction that receive public assistance, the fraction of households headed by a female, the fraction residing in an owner occupied dwelling, the $\log$ of the number of households, the log of average wage of tract residents, the log of average home values, the log of average monthly rent, average commute time of employed residents, the distance to the central business district, the log of land area, and the fraction that work at home.

A similar list of outcomes measured in 1980 were also included; these included the fraction living in the same house as five years previous, the fraction with college attendance, the fraction black, the fraction Hispanic, the employment rate, the fraction who are high school dropouts, the fraction older than 65 years old, the fraction less than 18 years old, the fraction of structures that are vacant, the fraction that receive public assistance, the fraction of households headed by a female, the fraction residing in an owner occupied dwelling, the log of the number of households, and the share 
of dwellings that were owner occupied. Also included were interactions of the fraction households in poverty 1990 with the fraction unemployed, the log of population, the fraction black, the fraction Hispanic, the fraction who are high school dropouts, the fraction with college attendance. Dummy indicators for poverty share below 25 percent, poverty share below 35 percent, population above 2000, fraction black equalling 100 percent, fraction with college attendance equal to 0 percent, fraction Hispanic equal to 0 percent, fraction in owner occupied housing equal to 0 percent, location in the central business district in 1990 were also included.

The results in Table 8 were generated by estimating a tract level propensity score on a pooled sample of placebo tracts and controls using the same covariates as in earlier tables. We then dropped tracts with estimate propensity scores in excess of 0.9 in order to ensure overlap in the support of the two distributions. Finally we reestimated the propensity score model on the trimmed sample and computed reweighted differences-in-differences impacts. 


\section{Supplemental Appendix}

\section{A. Model Extension with Two Types of Workers}

Let a fixed proportion $\pi_{S}$ of the agents be skilled and more productive than their unskilled counterparts who constitute the remaining $\pi_{U}=1-\pi_{S}$ of the population. Write the utility of individual $i$ of skill group $g \in\{S, U\}$ living in community $j \in \mathcal{N}$ and working in community $k \in\{\emptyset, \mathcal{N}\}$ and sector $s \in\{1,2\}$ as:

$$
\begin{aligned}
u_{i j k s}^{g} & =w_{j k s}^{g}-r_{j}-\kappa_{j k}+A_{j}+\varepsilon_{i j k s}^{g} \\
& =v_{j k s}^{g}+\varepsilon_{i j k s}^{g}
\end{aligned}
$$

where $w_{j k s}^{g}$ is the wage a worker of skill group $g$ from neighborhood $j$ receives when working in sector $s$ of neighborhood $k$. Define a set of indicator variables $\left\{D_{i j k s}^{g}\right\}$ equal to one if and only if $\max _{j^{\prime} k^{\prime} s^{\prime}}\left\{u_{i j^{\prime} k^{\prime} s^{\prime}}^{g}\right\}=u_{i j k s}^{g}$ for worker $i$ and denote the measure of agents of skill group $g$ in each residential/work location by $N_{j k s}^{g}=P\left(D_{i j k s}^{g}=1 \mid\left\{v_{j^{\prime} k^{\prime} s^{\prime}}^{g}\right\}\right)$.

Suppose that skilled and unskilled workers are perfect substitutes in production so that firm output may be written $B_{k}\left(q S_{k s}+U_{k s}\right) f\left(\chi_{k s}\right)$ where the $S_{k s}$ and $U_{k s}$ refer to total skilled and unskilled labor inputs respectively, $\chi_{k s}=\frac{K_{k s}}{B_{k}\left(q S_{k s}+U_{k s}\right)}$ is the capital to effective labor ratio, and $q$ is the relative efficiency of skilled labor. Now wages will obey

$$
\begin{aligned}
B_{k}\left[f\left(\chi_{k s}\right)-\chi_{k s} f^{\prime}\left(\chi_{k s}\right)\right] & =w_{j k s}^{U}\left(1-\tau \delta_{j k s}\right) \\
w_{j k s}^{S} & =q w_{j k s}^{U} \\
f^{\prime}\left(\chi_{k s}\right) & =\rho
\end{aligned}
$$

where $w_{j k s}^{U}$ is the wage for unskilled workers and $w_{j k s}^{S}$ the wage for skilled workers. Note that

$$
\frac{d \ln w_{j k s}^{U}}{d \ln B_{k}}=\frac{d \ln w_{j k s}^{S}}{d \ln B_{k}}=1
$$

so that productivity increases may still be detected by examining impacts on the wages of commuters. However, productivity effects may also shift the skill composition of local workers and commuters which could lead us to over or understate these effects. For this reason we adjust our wage impacts in the paper for observable skill characteristics.

Our final modification is that with two skill groups, clearing in the housing market requires:

$$
H_{j}=\sum_{g} \pi_{g} \sum_{k} \sum_{s} N_{j k s}^{g}
$$

With these features in place the social welfare function may be written:

$$
W=\sum_{g} \pi_{g} V^{g}+\sum_{j}\left[r_{j} H_{j}-\int_{0}^{H_{j}} G_{j}^{-1}(x) d x\right]
$$


It is straightforward then to verify that for some community $m$ :

$$
\begin{aligned}
\left.\frac{d}{d B_{m}} W\right|_{\tau=0} & =\sum_{g} \pi_{g} \sum_{j} \sum_{k} \sum_{s} N_{j k s}^{g} \frac{d w_{j k s}^{g}}{d B_{m}} \\
& =\left[\pi_{U} N_{. m}^{U}+q \pi_{S} N_{. m}^{S}\right] R(\rho) \\
\left.\frac{d}{d A_{m}} W\right|_{\tau=0} & =N_{m} .
\end{aligned}
$$

where $N_{. m}^{g}=\sum_{j} \sum_{s} N_{j m s}^{g}$ and $N_{m .}=\sum_{g} \pi_{g} \sum_{k} \sum_{s} N_{m k s}^{g}$. Furthermore we may write the deadweight losses attributable to taxes as:

$$
\begin{aligned}
D W L_{\tau} & =\sum_{g} \pi_{g} \sum_{j \in \mathcal{N}_{1}} \sum_{k \in \mathcal{N}_{1}} N_{j k 1}^{g} w_{j k 1}^{g} \int_{0}^{d \tau} t \frac{d \ln N_{j k 1}^{g}}{d t} d t \\
& \approx \frac{1}{2} \psi d \tau^{2} \sum_{g} \pi_{g} \sum_{j \in \mathcal{N}_{1}} \sum_{k \in \mathcal{N}_{1}} N_{j k 1}^{g} w_{j k 1}^{g}
\end{aligned}
$$

where in the second line we have assumed a constant semi-elasticity of local employment $\psi=$ $\frac{d \ln N_{j k 1}^{g}}{d \tau}$. This formula is effectively the same as that in 10 , relying on the total covered wage bill and the elasticity $\psi$. Were the elasticity to vary by type we would simply need to compute the deadweight loss separately within skill group and average across groups using the marginal frequencies $\pi_{g}$. Finally, we may write the deadweight attributable to the block grants as:

$$
\begin{aligned}
D W L_{G} & \approx C\left[1-\left.\lambda_{a} \sum_{j \in \mathcal{N}_{1}} \frac{d W}{d \ln A_{j}}\right|_{\tau=0}-\left.\lambda_{b} \sum_{k \in \mathcal{N}_{1}} \frac{d W}{d \ln B_{k}}\right|_{\tau=0}\right] \\
& =C\left[1-\lambda_{a} \sum_{j \in \mathcal{N}_{1}} A_{j} N_{j}-\lambda_{b} \sum_{g} \pi_{g} \sum_{j} \sum_{k \in \mathcal{N}_{1}} \sum_{s} N_{j k s}^{g} w_{j k s}^{g}\right]
\end{aligned}
$$

As before, the deadweight loss computation relies on the parameters $\lambda_{a}$ and $\lambda_{b}$. Heterogeneity provides no essential complication to the exercise since, with knowledge of these parameters, one only needs to know the total wage bill and population inside of the zone to compute $D W L_{G}$.

\section{B. Monte Carlo Experiments}

We simulated hierarchical datasets of 64 zones with a random number of tracts $N_{z}$ within each zone. The number of tracts per zone was generated according to $N_{z}=10+\widetilde{\eta}_{z}$ where $\widetilde{\eta}_{z}$ is a Negative Binomial distributed random variable with the first two moments matching the ones observed in the data (i.e. a mean 21 and a standard deviation of 16 tracts). Hence, each simulated sample was expected to yield approximately 1,344 census tracts with no zone containing less than 10 tracts in any draw.

Outcomes were generated according to the model:

$$
Y_{t z}=\beta_{z} T_{z}+\alpha_{t}^{x} X_{t z}+\alpha_{z}^{p} P_{z}+\xi_{z}+e_{t z}
$$

where $T_{z}$ is an EZ assignment dummy, $X_{t z}$ is a tract level regressor, $P_{z}$ is a zone level regressor, $\xi_{z}$ 
a random zone effect, and $e_{t z}$ an idiosyncratic tract level error. We assume throughout that:

$$
\left[\begin{array}{c}
X_{t z} \\
P_{z} \\
e_{t z}
\end{array}\right] \sim N\left(0, I_{3}\right)
$$

To build in some correlation between the covariates and EZ designation, and to reflect the fact that treated zones tend to be larger, we model the EZ assignment mechanism as:

$$
\begin{aligned}
T_{z} & =I\left(\operatorname{rank}\left(T_{z}^{*}\right) \geq 6\right) \\
T_{z}^{*} & =\bar{X}_{z}+P_{z}+0.008 \times N_{z}+u_{z} \\
u_{z} & \sim N(0,1)
\end{aligned}
$$

where $\bar{X}_{z}=\frac{1}{N_{z}} \sum_{t \in z} X_{t z}$ and the $\operatorname{rank}($.$) function ranks the T_{z}^{*}$ in descending order. Note that this assignment process imposes that exactly six zones will be treated. Hence, each simulation sample will face the inference challenges present in our data.

The nature of the coefficients $\left(\beta_{z}, \alpha_{t}^{x}, \alpha_{z}^{p}\right)$ and the random effect $\xi_{z}$ vary across our Monte Carlo designs as described in the following table. We have two sets of results. In the first set, which we label symmetric, $\xi_{z}$ follows a normal distribution. In a second set of results, which we label asymmetric, $\xi_{z}$ follows a $\chi^{2}$ distribution.

\section{Data Generating Processes}

\begin{tabular}{lll}
\hline \hline & Symmetric & Asymmetric \\
& $\xi_{z} \sim N(0,1)$ & $\xi_{z} \sim \chi^{2}(4)$ \\
\hline 1. Baseline & $\beta_{z}=0, \alpha_{t}^{x}=\alpha_{z}^{p}=1$ & $\beta_{z}=0, \alpha_{t}^{x}=\alpha_{z}^{p}=1$ \\
2. Random Coefficient on $X_{t z}$ & Same as 1) but, $\alpha_{t}^{x} \sim N(1,1)$ & Same as 1) but, $\left(\alpha_{t}^{x}+3\right) \sim \chi^{2}(4)$ \\
3. Random Coefficient on $P_{z}$ & Same as 1) but, $\alpha_{z}^{p} \sim N(1,1)$ & Same as 1) but, $\left(\alpha_{z}^{p}+3\right) \sim \chi^{2}(4)$ \\
4. Random Coefficient on $T_{z}$ & Same as 1) but, $\beta_{z} \sim N(0,1)$ & Same as 1) but, $\left(\beta_{z}+4\right) \sim \chi^{2}(4)$ \\
5. All deviations from baseline & $(2)+(3)+(4)$ & $(2)+(3)+(4)$ \\
\hline \hline
\end{tabular}

Note that the null of zero average treatment effect among the treated is satisfied in each simulation design. Specification 1) corresponds to the relatively benign case where our regression model is properly specified and the errors are homoscedastic. Specification 2) allows for heteroscedasticity with respect to the tract level regressor, while specification 3) allows some heteroscedasticity in the zone level regressor. Specification 4) allows heteroscedasticity with respect to the treatment, or alternatively, a heterogeneous but mean zero treatment effect. Specification 5) combines all of these complications so that heteroscedasticity exists with respect to all of the regressors.

For each Monte Carlo design we compute three sets of tests of the true null that EZ designation had no average effect on treated tracts. The first (analytical) uses our analytical cluster-robust standard error to construct a test statistic $\widehat{t}=\left|\frac{\widehat{\beta}}{\widehat{\sigma}}\right|$ where and rejects when $\widehat{t}>1.96$. The second (wild bootstrap-se) uses a clustered wild bootstrap procedure to construct a bootstrap standard error $\sigma^{*}$ and rejects when $\left|\frac{\widehat{\beta}}{\sigma^{*}}\right|>1.96$. The third approach (wild bootstrap-t) estimates the wild bootstrap distribution $F_{t}^{*}($.$) of the test statistic \widehat{t}=\left|\frac{\widehat{\beta}}{\widehat{\sigma}}\right|$ and rejects when $\widehat{t}>F_{t}^{*-1}(0.95)$ - where $F_{t}^{*-1}(0.95)$ denotes the 95 th percentile of the bootstrap distribution of $t$ statistics. Both the bootstrap-se and bootstrap-t procedures simulate the bootstrap distribution imposing the null that 
$\beta=0$ as recommended by Cameron, Gelbach, and Miller (2008). The false rejection rates for these three tests in each of the five simulation designs are given in the table below.

False Rejection Rates in Monte Carlo Simulations

Tract-level models

\begin{tabular}{lcccccc}
\hline \hline & $\begin{array}{c}\text { Analytical } \\
\text { s.e. } \\
\text { OLS }\end{array}$ & $\begin{array}{c}\text { Analytical } \\
\text { s.e. } \\
\text { PW }\end{array}$ & $\begin{array}{c}\text { Wild } \\
\text { BS-s.e. } \\
\text { OLS }\end{array}$ & $\begin{array}{c}\text { Wild } \\
\text { BS-s.e. } \\
\text { PW }\end{array}$ & $\begin{array}{c}\text { Wild } \\
\text { BS-t }\end{array}$ & $\begin{array}{c}\text { Wild } \\
\text { BS-t }\end{array}$ \\
& & & & & & PW \\
\hline Symmetric & 0.126 & 0.074 & 0.039 & 0.111 & 0.054 & 0.053 \\
Baseline & 0.125 & 0.075 & 0.036 & 0.113 & 0.056 & 0.051 \\
Random Coefficient on $X_{t z}$ & 0.124 & 0.077 & 0.041 & 0.110 & 0.055 & 0.048 \\
Random Coefficient on $P_{z}$ & 0.123 & 0.073 & 0.041 & 0.110 & 0.055 & 0.053 \\
Random Coefficient on $T_{z}$ & 0.124 & 0.080 & 0.042 & 0.110 & 0.059 & 0.051 \\
All & & & & & & \\
Asymmetric & 0.123 & 0.106 & 0.037 & 0.138 & 0.055 & 0.056 \\
Baseline & 0.121 & 0.109 & 0.041 & 0.136 & 0.047 & 0.049 \\
Random Coefficient on $X_{t z}$ & 0.123 & 0.111 & 0.039 & 0.139 & 0.054 & 0.052 \\
Random Coefficient on $P_{z}$ & 0.132 & 0.111 & 0.039 & 0.142 & 0.053 & 0.056 \\
Random Coefficient on $T_{z}$ & 0.125 & 0.111 & 0.038 & 0.128 & 0.051 & 0.051 \\
All & & & & &
\end{tabular}

Standard error based methods tend to overreject in both designs save for in the case of OLS where the wild bootstrapped standard errors perform well. However the wild bootstrapped-t procedure yields extremely accurate inferences for both the OLS and PW estimators across all designs.

\section{Industry Level Analysis}

To further disentangle the role of the EZ wage subsidies from the block grants we examined whether industries more intensive in zone labor expanded in response to EZ designation. This required aggregation to the industry/zone level. We used the following 11 industry categories: Agriculture, Forestry, Fisheries, and Mining; Construction; Non-durable goods manufacturing; Durable goods manufacturing; Transportation, communications, and other utilities; Wholesale trade; Retail trade; Finance, insurance, real estate; Business and repair services, personal services, entertainment, and recreation services; Professional and related services; and Public administration.

Define $R_{i z}$ as the fraction of workers in industry $i$ of proposed zone $z$ who live in the zone as measured in the 1990 Census and $\Delta Y_{i z}$ as the change in total employment of industry $i$ of zone $z$ between 1990 and 2000. We estimated regressions of the form:

$$
\Delta Y_{i z}=d_{0}+d_{1} R_{i z}+d_{2} T_{z}+d_{3} T_{z} R_{i z}+\varsigma_{i z}
$$

where $\varsigma_{i z}$ is a random error. The coefficient of interest is $d_{3}$ which measures the differential effect of EZ designation on employment growth in industries intensive in local labor. We try augmenting this regression with zone effects, which are perfectly collinear with $T_{z}$ which we drop in those specifications. The zone effects absorb any idiosyncratic zone wide shocks.

These regressions likely suffer from attenuation bias since $R_{i z}$ is estimated from microdata. To deal with this we tried instrumenting for $R_{i z}$ and $T_{z} R_{i z}$ using $R_{i}$. and $T_{z} R_{i}$. (where $R_{i \text {. is the total }}$ number of jobs in industry $i$ staffed by zone residents across all sample zones divided by the total 
number of jobs in industry $i$ for all sample zones) and the 1980 values of $R_{i z}$ and $T_{z} R_{i z}$. Clustered wild bootstrap-t critical values are obtained for the IV estimates via a modification of the methods in Davidson and Mackinnon (2010). The results are given in the Table below:

\section{Industry Shift-Share Models}

Dependent variable: Change in the log employment at the industry-zone level

Coefficient: EZ dummy times lagged ratio of local employment to total employment at the industry-zone level

\begin{tabular}{lc}
\hline Model & Coeff. \\
\hline OLS Basic & 0.790 \\
& {$[0.488]$} \\
OLS Zone Effects & 1.121 \\
& {$[0.680]^{*}$} \\
IV Basic & 1.155 \\
& {$[0.985]$} \\
IV Zone Effects & 1.155 \\
\multicolumn{2}{l}{ Note: Wild bootstrap s.e. in square } \\
brackets. Stars reflect significance level \\
obtained via a clustered wild bootstrap- \\
t procedure. Legend: * significant at \\
10\% level; ** significant at $5 \%$ level; $* * *$ \\
significant at 1\% level.
\end{tabular}

As expected instrumenting raises our estimate of coefficient of interest relative to OLS. The results are centered around $d_{3} \approx 1$ which suggests a one percentage point increase in local employment share raises the impact of EZ designation on industry employment by one percent. These results reinforce our conclusion that the EZ wage credits (rather than city-wide shocks) stimulated local labor demand.

\section{Untrimmed Results}

Table Supplemental Appendix D shows impact estimates in the untrimmed sample for the Naïve, OLS and PW estimators. We find a similar pattern of results to that found in the trimmed sample. 


\section{Baseline Results Untrimmed}

\begin{tabular}{|c|c|c|c|}
\hline Model & $\begin{array}{c}\text { Naïve } \\
{[1]}\end{array}$ & $\begin{array}{c}\text { OLS } \\
{[2]}\end{array}$ & $\begin{array}{c}\text { PW } \\
{[3]}\end{array}$ \\
\hline Log (Jobs) -LBD & $\begin{array}{c}0.097 \\
{[0.065]^{*}}\end{array}$ & $\begin{array}{c}0.150 \\
{[0.062]^{* *}}\end{array}$ & $\begin{array}{c}0.166 \\
{[0.052]^{* *}}\end{array}$ \\
\hline Log (Jobs) -JTW & $\begin{array}{r}0.187 \\
{[0.102]}\end{array}$ & $\begin{array}{c}0.201 \\
{[0.077]^{* *}}\end{array}$ & $\begin{array}{c}0.185 \\
{[0.074]^{* *}}\end{array}$ \\
\hline Log (Zone Jobs Held by Zone Residents) & $\begin{array}{r}0.166 \\
{[0.113]}\end{array}$ & $\begin{array}{c}0.163 \\
{[0.080]^{*}}\end{array}$ & $\begin{array}{r}0.161 \\
{[0.075]}\end{array}$ \\
\hline Log (Zone Jobs Held by Non-Residents) & $\begin{array}{r}0.161 \\
{[0.084]}\end{array}$ & $\begin{array}{c}0.158 \\
{[0.064]^{* *}}\end{array}$ & $\begin{array}{c}0.143 \\
{[0.057]^{* *}}\end{array}$ \\
\hline Log (Non-Zone Jobs Held by Zone Residents) & $\begin{array}{r}0.033 \\
{[0.068]}\end{array}$ & $\begin{array}{r}0.076 \\
{[0.070]}\end{array}$ & $\begin{array}{r}0.072 \\
{[0.060]}\end{array}$ \\
\hline Log (Average Earnings per Worker) & $\begin{array}{r}0.026 \\
{[0.025]}\end{array}$ & $\begin{array}{r}0.040 \\
{[0.031]}\end{array}$ & $\begin{array}{r}0.026 \\
{[0.015]}\end{array}$ \\
\hline Log (Hourly Wage of Zone Workers) & $\begin{array}{r}-0.006 \\
{[0.020]}\end{array}$ & $\begin{array}{r}0.015 \\
{[0.022]}\end{array}$ & $\begin{array}{r}0.012 \\
{[0.015]}\end{array}$ \\
\hline Log (Hourly Wage of Zone Residents) -unadjusted & $\begin{array}{r}0.029 \\
{[0.035]}\end{array}$ & $\begin{array}{c}0.050 \\
{[0.023]^{*}}\end{array}$ & $\begin{array}{r}0.044 \\
{[0.019]}\end{array}$ \\
\hline Log (Hourly Wage of Zone Residents) -adjusted & $\begin{array}{r}0.025 \\
{[0.031]}\end{array}$ & $\begin{array}{c}0.051 \\
{[0.025]^{*}}\end{array}$ & $\begin{array}{r}0.046 \\
{[0.019]}\end{array}$ \\
\hline Log (Hourly Wage of Zone Residents) -comp. & $\begin{array}{r}0.004 \\
{[0.006]}\end{array}$ & $\begin{array}{c}-0.001 \\
{[0.005]}\end{array}$ & $\begin{array}{c}-0.002 \\
{[0.004]}\end{array}$ \\
\hline Log (Hourly Wage of Zone Residents Working in Zone) & $\begin{array}{c}0.079 \\
{[0.050]^{*}}\end{array}$ & $\begin{array}{c}0.140 \\
{[0.064]^{* * *}}\end{array}$ & $\begin{array}{c}0.124 \\
{[0.050]^{* *}}\end{array}$ \\
\hline Log (Hourly Wage of Non-Residents Working in Zone) & $\begin{array}{r}-0.010 \\
{[0.020]}\end{array}$ & $\begin{array}{c}-0.003 \\
{[0.023]}\end{array}$ & $\begin{array}{c}-0.003 \\
{[0.015]}\end{array}$ \\
\hline Log (Hourly Wage of Zone Residents Working Outside Zone) & $\begin{array}{r}0.027 \\
{[0.028]}\end{array}$ & $\begin{array}{c}0.060 \\
{[0.029]^{* *}}\end{array}$ & $\begin{array}{c}0.063 \\
{[0.018]^{*}}\end{array}$ \\
\hline Log (Establishments) & $\begin{array}{r}0.015 \\
{[0.028]}\end{array}$ & $\begin{array}{c}0.040 \\
{[0.023]^{*}}\end{array}$ & $\begin{array}{r}0.038 \\
{[0.021]}\end{array}$ \\
\hline Log (Rent) -unadjusted & $\begin{array}{r}0.023 \\
{[0.034]}\end{array}$ & $\begin{array}{r}0.026 \\
{[0.027]}\end{array}$ & $\begin{array}{r}0.028 \\
{[0.023]}\end{array}$ \\
\hline Log (Rent) -adjusted & $\begin{array}{r}0.015 \\
{[0.029]}\end{array}$ & $\begin{array}{r}0.016 \\
{[0.023]}\end{array}$ & $\begin{array}{r}0.020 \\
{[0.021]}\end{array}$ \\
\hline Log (Rent) -comp. & $\begin{array}{r}0.008 \\
{[0.012]}\end{array}$ & $\begin{array}{r}0.010 \\
{[0.010]}\end{array}$ & $\begin{array}{r}0.008 \\
{[0.007]}\end{array}$ \\
\hline Log (House Value) -unadjusted & $\begin{array}{c}0.370 \\
{[0.223]^{*}}\end{array}$ & $\begin{array}{c}0.354 \\
{[0.164]^{* *}}\end{array}$ & $\begin{array}{r}0.354 \\
{[0.155]}\end{array}$ \\
\hline Log (House Value) -adjusted & $\begin{array}{c}0.364 \\
{[0.218]^{*}}\end{array}$ & $\begin{array}{c}0.349 \\
{[0.157]^{* *}}\end{array}$ & $\begin{array}{c}0.348 \\
{[0.148]^{*}}\end{array}$ \\
\hline Log (House Value) -comp. & $\begin{array}{r}0.006 \\
{[0.008]}\end{array}$ & $\begin{array}{r}0.005 \\
{[0.007]}\end{array}$ & $\begin{array}{r}0.006 \\
{[0.004]}\end{array}$ \\
\hline Log (Households) & $\begin{array}{l}-0.007 \\
{[0.073]}\end{array}$ & $\begin{array}{l}-0.013 \\
{[0.037]}\end{array}$ & $\begin{array}{c}0.000 \\
{[0.033]}\end{array}$ \\
\hline Log (Population) & $\begin{array}{l}-0.014 \\
{[0.055]}\end{array}$ & $\begin{array}{c}0.031 \\
{[0.030]}\end{array}$ & $\begin{array}{c}0.043 \\
{[0.029]}\end{array}$ \\
\hline$\%$ Same House as Five Yrs Ago & $\begin{array}{l}-0.004 \\
{[0.009]}\end{array}$ & $\begin{array}{c}0.004 \\
{[0.009]}\end{array}$ & $\begin{array}{c}0.006 \\
{[0.005]}\end{array}$ \\
\hline$\%$ Vacant Houses & $\begin{array}{r}0.016 \\
{[0.013]} \\
\end{array}$ & $\begin{array}{c}-0.008 \\
{[0.009]}\end{array}$ & $\begin{array}{c}-0.006 \\
{[0.007]} \\
\end{array}$ \\
\hline
\end{tabular}

Note: Outcomes marked JTW are based on the Journey-to-Work component of the Decennial Census. Outcomes marked as LBD come from the Longitudinal Business Database and are analyzed over the period 1992-2000, all other outcomes come from the Census and are analyzed over the period 1990-2000. All figures computed on the untrimmed estimation sample (see Section IV.) Columns [1]-[3] give differences-in-differences (DD) estimates on a sample of untreated placebo tracts chosen by nearest neighbor matching. Columns [4]-[6] give DD impacts on percentile ranks of outcomes (see Section VI) in trimmed sample. Columns labeled "Naive" report a DD estimate without controls. Columns labeled "OLS" report the OLS DD estimate controlling for lagged city and tract level characteristics. Columns labeled "PW" report parametric reweighting DD estimates. See Appendix II.G for list of covariates. Standard errors are shown in square brackets and are clustered by city ( 69 clusters). Stars reflect significance level obtained by a clustered wild bootstrap-t procedure described in the appendix. Legend: * significant at $10 \%$ level; ** significant at 5\% level; *** significant at 1\% level. See the Appendix and Section III for details. 